\title{
Microvesicles/exosomes as potential novel biomarkers of metabolic diseases
}

This article was published in the following Dove Press journal:

Diabetes, Metabolic Syndrome and Obesity:Targets and Therapy

6 August 2012

Number of times this article has been viewed

\section{Günter Müller}

Department of Biology I, Genetics, Ludwig-Maximilians University Munich, Biocenter, Munich, Germany

Correspondence: Günter Müller Sanofi Deutschland GmbH Research and Development, Diabetes Division, Industrial Park Höchst, Bldg H82I, 65926 Frankfurt am Main, Germany Tel +4969305 427।

Fax +4969305 81901

Email guenter.mueller@sanofi.com
Abstract: Biomarkers are of tremendous importance for the prediction, diagnosis, and observation of the therapeutic success of common complex multifactorial metabolic diseases, such as type II diabetes and obesity. However, the predictive power of the traditional biomarkers used (eg, plasma metabolites and cytokines, body parameters) is apparently not sufficient for reliable monitoring of stage-dependent pathogenesis starting with the healthy state via its initiation and development to the established disease and further progression to late clinical outcomes. Moreover, the elucidation of putative considerable differences in the underlying pathogenetic pathways (eg, related to cellular/tissue origin, epigenetic and environmental effects) within the patient population and, consequently, the differentiation between individual options for disease prevention and therapy - hallmarks of personalized medicine - plays only a minor role in the traditional biomarker concept of metabolic diseases. In contrast, multidimensional and interdependent patterns of genetic, epigenetic, and phenotypic markers presumably will add a novel quality to predictive values, provided they can be followed routinely along the complete individual disease pathway with sufficient precision. These requirements may be fulfilled by small membrane vesicles, which are so-called exosomes and microvesicles (EMVs) that are released via two distinct molecular mechanisms from a wide variety of tissue and blood cells into the circulation in response to normal and stress/pathogenic conditions and are equipped with a multitude of transmembrane, soluble and glycosylphosphatidylinositol-anchored proteins, mRNAs, and microRNAs. Based on the currently available data, EMVs seem to reflect the diverse functional and dysfunctional states of the releasing cells and tissues along the complete individual pathogenetic pathways underlying metabolic diseases. A critical step in further validation of EMVs as biomarkers will rely on the identification of unequivocal correlations between critical disease states and specific EMV signatures, which in future may be determined in rapid and convenient fashion using nanoparticle-driven biosensors.

Keywords: adipose tissue, epigenetics, glycosylphosphatidylinositol, microparticles, microRNA, type II diabetes

\section{Biomarkers Definitions}

Under the direction of the National Institute for Health (NIH), the Biomarkers and Surrogate Endpoint Working Group has agreed on key definitions as well as a classification system for biomarkers as follows: (1) a biomarker represents "a characteristic that is objectively measured and evaluated as an indicator of normal biological processes, pathogenic processes or pharmacological responses to a therapeutic intervention"; (2) a clinical endpoint represents "a characteristic 
or variable that reflects how a patient feels, functions, or survives"; and (3) a surrogate endpoint represents "a biomarker intended to substitute for a clinical endpoint with the potential for predicting the clinical benefit or harm (or lack of benefit or lack of harm) on the basis of epidemiological, therapeutic, pathophysiological, or other scientific evidence." 1,2 Thus, the very aims of the use of biomarkers, clinical endpoints, and surrogate endpoints are: (1) the improvement of the prediction, diagnosis and prognosis, particularly of common complex multifactorial diseases; and (2) the facilitation of the drug discovery and development processes. ${ }^{3,4}$

According to the European Medicine Agency (EMA), clinical endpoints are distinct measurements or analyses of disease characteristics observed in a study or clinical trial that reflect the effect of the therapeutic intervention. ${ }^{5}$ Consequently, clinical endpoints are regarded as the most reliable indicators for disease or therapeutic responses. The definition of the US Food and Drug Administration (FDA) is much more practical and focused, stating that surrogate endpoints or biomarkers are "used in clinical trials as a substitute for a clinically meaningful endpoint, represents a direct measure of how a patient feels, functions or survives, and is expected to predict the effect of the therapy." 6

In other words, a biomarker is an indicator of change and therefore fluctuates as a function of time and biological influence. Importantly, this strict definition of a biomarker excludes single nucleotide polymorphisms. Lastly, from the perspective of the pharmaceutical industry, a pragmatic definition of the term biomarker describes it as: "A measurable property that reflects the mechanism of action of the molecule based on its pharmacology [and] the pathophysiology of the disease, and [may] be useful for internal decisionmaking within a pharmaceutical company."7

Moreover, a general classification system has been introduced for biomarkers that discriminates type 0 biomarkers, which measure the natural history of a disease and correlate over time with established clinical indicators; type I biomarkers, which indicate the intervention effect of a drug; and type II biomarkers, which are considered as surrogate endpoint biomarkers (Figure 1). Both type I and type II biomarkers are ultimately aimed at monitoring the so-called wellness index, which ranges from 0 (death) to 100 (perfect homeostatic control under healthy conditions). As a function of age, environment, and genes, individuals strive to maintain a biological equilibrium of homeostatic control. Various biomarkers can be used to determine the personalized progression from homeostasis via disease initiation, disease development, and further disease progression to final disease outcome (Figure 1). ${ }^{8}$

\section{Applications}

Importantly, in most cases, the biomarkers for a given indication are used primarily in the pattern recognition mode on the basis of a set of unidentified markers that may be genomic, transcriptomic, proteomic, lipidomic, metabolomic, or a combination of datasets. ${ }^{9,10}$ A priori application of these type I-like biomarkers does not necessitate the determination

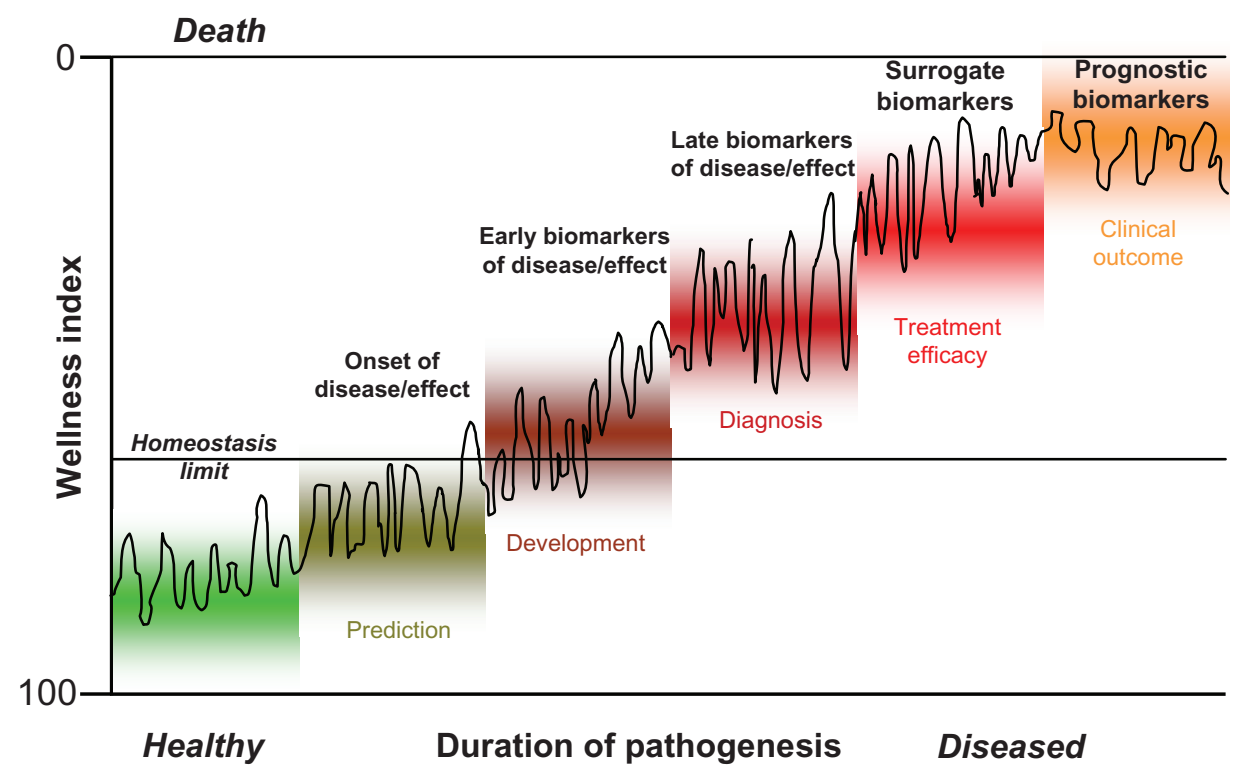

Figure I The role of biomarkers in following the pathogenesis of individuals on basis of the wellness index (see text for details). 
of the biomarker constituent identities since the pattern or signature alone denotes the specific biological activity. ${ }^{11}$ In this regard, EMVs (see "EMVs as biomarkers: General considerations") belong to type I biomarkers. In addition, the use of type II-like biomarkers (transcripts, proteins, metabolites) for deciphering or screening the pathogenetic mechanism, prediction, diagnosis, and monitoring of common complex diseases is of critical importance and requires their structural identification and validation (for at least one of them). This approach may be supported or even substituted by the discovery of complex biomarker panels of type 0 to monitor specific disease states along the complete pathogenetic pathway for prediction, initiation, development, diagnosis, progression, regression, and treatment efficacy of the disease (Figure 1). ${ }^{111-15}$ The expectation of a good biomarker ranges from a molecular signature of structurally unidentified markers to a complete panel of identified biomarkers specific to the pathogenesis being studied. Importantly, the work required to establish the reliability and validity of a new biomarker should not be underestimated; it needs detailed planning for each combination of a clinical indication and a mechanism of action. ${ }^{16}$ For example, type 0 biomarkers can be validated longitudinally in a well-defined patient population against a gold standard clinical assessor. In contrast, type I biomarkers should be validated in parallel with the drug candidate, and type II biomarkers must be relevant both to the mechanism of action of the drug and to the pathophysiology of the disease.

Critical questions for the discovery and development of modern drugs and the adequate use of biomarkers are how to adequately transform data into information and thence into knowledge and how to apply that to both processes. The general hope is that biomarker data will provide more predictive information and knowledge about the alterations in the biological processes induced after administration of the drug, ${ }^{17}$ which should allow better predictive capability and decision-making on the part of scientists and managers involved in the drug-finding procedure. ${ }^{18}$

\section{Biomarkers for metabolic diseases Pathogenesis}

The pathogenetic mechanisms underlying metabolic diseases have previously been assumed to rely on abnormal triacylglycerol storage, which is driven by excess of energy intake and insufficient energy expenditure in the case of development of metabolic syndrome, insulin resistance, and obesity, and accompanied or followed by considerable reduction in the number and function of pancreatic $\beta$-cells in the case of development of type II diabetes. ${ }^{19-21}$ Chronic low-grade inflammation ${ }^{22,23}$ and oxidative stress $^{24,25}$ are regarded as causally involved in both the induction and the progression of metabolic diseases. Importantly, the levels of a subset of proinflammatory adipokines, such as interleukin-2/6 (IL-2/6), tumor necrosis factor- $\alpha$ (TNF $\alpha)$, adiponectin, ferritin, and $\mathrm{C}$-reactive protein (CRP) have been demonstrated by epidemiological studies to be positively correlated to the degree of insulin resistance, impaired glucose tolerance and homeostasis, and excess of adipose tissue mass. ${ }^{26,27}$ They have thus been regarded as the most predictive biomarkers for metabolic diseases. ${ }^{28-30}$ The same is true for oxidized low-density lipoprotein (LDL), which induces the monocytes in plasma for their movement into and residence in the adipose tissue upon binding to the walls of the constituting vascular endothelial cells. The elevated infiltration of the adipose tissue with immune cells seems to function as the driver for the emergence of defects in insulin signaling, ie, insulin resistance; increase in adipocyte number and size, ie, obesity; and plaque destabilization and rupture, ie, atherogenesis. ${ }^{31-33}$ Moreover, elevated oxidative stress as well as the redox state in the adipose tissue has also been associated with the early phases in the pathogenesis of metabolic diseases. ${ }^{34}$ Interestingly, both inflammation and oxidative stress have consequences for insulin signaling, adipocyte proliferation and differentiation, and adipocyte apoptosis and angiogenesis, ultimately resulting in type II diabetes. Obesity and atherosclerosis have been linked to specific expression patterns of miRNAs (see "EMVs as biomarkers: Obesity"). ${ }^{35-37}$

\section{Currently used biomarkers}

Currently, the prediction within a limited period during the development of a metabolic disease prior to its diagnosis (typically 5-10 years for type II diabetes), as well as its definite diagnosis and prognosis of the future disease outcome, are based on the measurement of the levels of typical and easily accessible serum parameters, such as carbohydrate and lipid metabolites (eg, glucose, triacylglycerol, cholesterol, lipoproteins), small molecule intermediates (eg, 2-hydroxybutyrate) and metabolites (eg, creatinine) as well as surrogate entities (eg, glycated hemoglobin $\left.\mathrm{HbA}_{1 \mathrm{c}}\right) \cdot{ }^{38-42}$ In routine clinical practice, these so-called traditional biomarkers in combination enable the prediction of type II diabetes with a probability of about 0.65 to 0.75 (with 0.5 representing chance in throwing a dice) (Figure 2). The supplementation with information about physical body parameters (BMI, waist-to-hip ratio, sex) 
as well as the health state and lifestyle of the probands (eg, blood pressure, smoking, fitness, food consumption as evaluated in the Deutsche Risikoabschätzung ${ }^{43}$ ) leads to a further increase in the probability of prediction to about 0.85 or $0.90 .{ }^{43}$ In future, functional assays, currently applied on a routine basis only for the confirmatory diagnosis of a metabolic disease, such as glucose and insulin tolerance tests, as well as euglycemic clamp studies for type II diabetes and noninvasive imaging procedures ${ }^{44}$ currently in the stage of clinical testing and approval, such as magnetic resonance imaging (MRI) of the $\beta$-cell mass for type II diabetes and positron emission tomography (PET) of the brown adipose tissue mass for obesity, will supplement the portfolio of traditional biomarkers and further improve their predictive power (Figure 2). However, in any case, the prerequisite and, therefore, the critical disadvantage of the traditional, functional, and imaging biomarkers is that the earlier the time points are envisaged for the prediction, potential prevention, and therapy, the less informative they are. On the other hand, they are of particular value for prediction along further disease development and advanced stages of the pathogenesis. In sum, therefore, these phenotypic biomarkers do support prediction independent of the individual life stage and style in contrast to the prediction of disease susceptibility by genotypic biomarkers (Figure 2).

In research clinical studies, the determination of so-called novel biomarkers, predominantly peptides and proteins, such as hormones, cytokines (eg, TNF- $\alpha$ ), adipokines (leptin, adiponectin), incretins (GLP-1), and others (eg, ferritin, cross-reactive protein), in combination but not alone, led to prediction values approaching, but hardly exceeding, those achieved with well-designed combinations of traditional biomarkers. ${ }^{45}$ The highest prediction probabilities have been reported for combinations of traditional and novel biomarkers, ${ }^{46}$ as for example those evaluated by the "EASD Risk Score". ${ }^{46}$ However, because of the partial overlap of the pathogenic mechanisms and pathways covered by the two classes of biomarkers, the predictive values of the combinations did not increase to a degree as calculated from the individual contributions of each of the two classes.

In contrast to phenotypic biomarkers, genotypic biomarkers, ie, determination of the complete genetic profile encompassing all relevant polymorphisms in all metabolic disease susceptibility genes, would fulfill the typical demand for life stage/style-independent prediction. However, the research clinical studies so far reported were rather disappointing: predictive values for type II diabetes ranging from 0.54 for genetic polymorphisms in three independent susceptibility genes in combination ${ }^{28}$ to 0.60 for single nucleotide polymorphisms in 18 distinct susceptibility genes (Figure 2). ${ }^{29,43,45}$ Apparently, common complex multifactorial metabolic diseases cannot be predicted with sufficient probability or precision on the basis of genotypic biomarkers

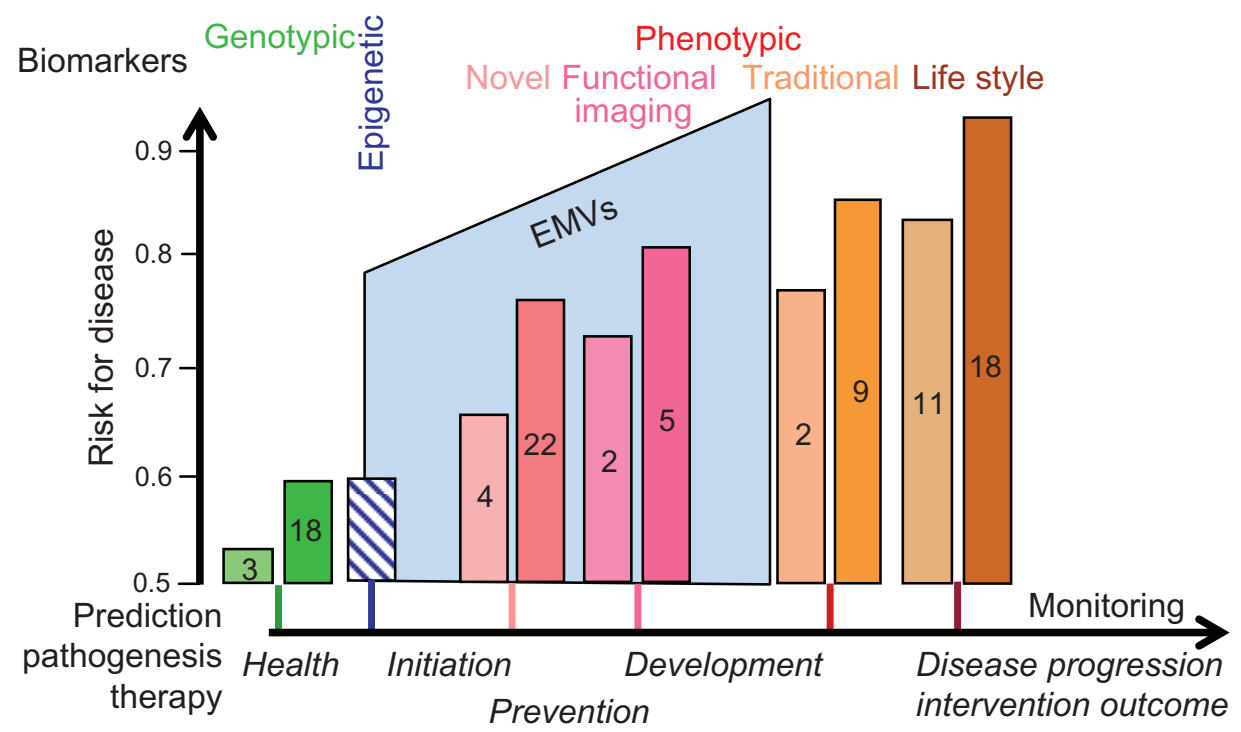

Figure 2 Correlation between the prediction of the risk for disease and the earliest time point feasible for its prediction.

Notes: The risks for disease are given for the different stages during the pathogenesis based on genetic biomarkers (in green), epigenetic biomarkers (in hatched blue), novel/functional biomarkers (in pink), and traditional/life style biomarkers (in brown) in comparison (hypothetical) to EMV signatures as biomarkers (in blue). For each type of biomarker, the number of biomarker members measured and combined for prediction is indicated within the bars.

Abbreviation: EMVs, exosomes and microvesicles. 
that have been derived from the identification of disease genes as well as susceptibility genes altered in their amount and/ or function by mutations, single nucleotide polymorphisms, copy number variants, monoallelic expression, and complex combinations. Even more discouraging was the repeated observation that combining the polymorphisms identified in known metabolic disease susceptibility genes with traditional and novel biomarkers only marginally increased the total predictive value compared to the values of the traditional and/ or novel biomarkers in the absence of genotypic markers. ${ }^{27-29}$ It may be argued that in future the further increase in the number of susceptibility genes identified for metabolic disorders will lead to considerable improvement of the predictive power of genotypic biomarkers in polymorphism and gene combinations of increasing complexity, affecting multiple target tissues and pathogenic pathways. However, the path from the genotype to the phenotype with underlying gene-gene interactions, gene-environment interactions, genome plasticity (somatic and mitochondrial mutations), and epigenetic modifications is long and complex. For these principal considerations, which are beyond the scope of this review article, it remains questionable whether the complete genetic profiling per se, ie, the determination of all relevant (single nucleotide) polymorphisms of each susceptibility gene in all relevant combinations encompassing each complete disease mechanism (eg, insulin release and insulin signaling) in all relevant tissues contributing to metabolic diseases (eg, $\beta$-cells and liver, muscle, adipose tissues) will truly enable predictions of metabolic diseases with the required high probabilities of $\geq 0.90$.

Thus, there is a critical gap between the genotypic biomarkers with their capability for very early and life stageindependent prediction of rather limited probability and the traditional as well as functional/imaging biomarkers with their capability for rather late and pathogenesis-dependent prediction of higher probability (Figure 2). Apparently, this gap has not yet been filled by novel biomarkers with their intermediary predictive values and intermediary positioning between the initiation of the pathogenesis and the full development of a complex common metabolic disease (Figure 2). With regard to drug discovery and development, the efficacy of new antidiabetic drugs has been evaluated traditionally in clinical trials using morbidity and mortality as the endpoints (Figure 3). However, such trials may require 10,000-15,000 subjects and at least 5 years of follow-up to demonstrate significant benefits. Smaller and shorter studies based on biomarkers and surrogate endpoint effects for monitoring the various stages from drug discovery via drug development to drug approval have the potential to revolutionize the drug finding and approval process (Figure 3).

\section{Requirements for future biomarkers}

In future, biomarkers should enable monitoring of the upregulation of the number and size of adipocytes, the downregulation of the number and/or functionality of pancreatic $\beta$-cells, the impairment in insulin sensitivity of peripheral tissues, such as muscle, fat, and liver, the development of impaired glucose tolerance and homeostasis, and finally the manifestation of obesity and type II diabetes and further progression to late complications of diabetes, such as retinopathy, nephropathy, neuropathy, and micro/macroangiopathy. These biomarkers should preferably circulate in the plasma and allow monitoring (1) of the overall pathogenesis or critical pathogenic steps; (2) of drug efficacy in a target-independent fashion; and (3) with limited expenditure in preclinical and clinical studies. Furthermore, they should fill the above-mentioned gap left by genotypic, traditional, and novel biomarkers (Figure 2).

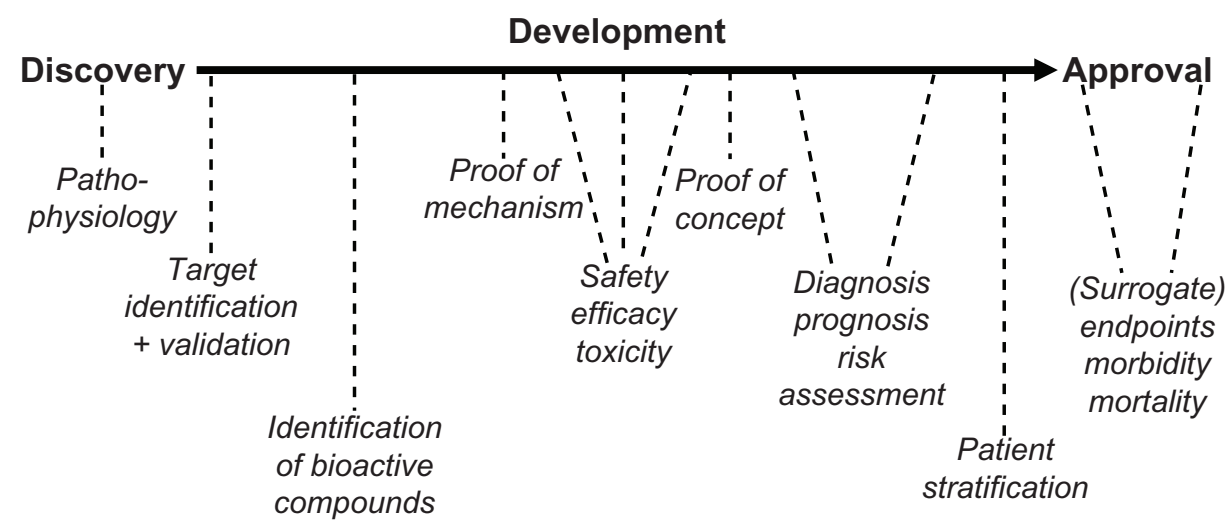

Figure 3 Paradigm for the use of biomarkers in drug discovery, development and approval. 
Although it seems reasonable to determine biomarkers in disease-relevant and affected organs, tissues and cells where they typically occur at higher concentrations, it is of huge practical advantage to measure them in the plasma. However, the huge dynamic range in the amounts of the individual protein components in plasma ( $>10$ orders of magnitude in difference) hampers the discovery as well as routine determination of novel biomarkers, since typical plasma proteomics is biased towards the detection of primarily highabundance proteins. This necessitates complex and tedious fractionation procedures that may facilitate the access to low-abundance proteins. However, these are not typically compatible with high-throughput analysis, which is, however, a prerequisite for the monitoring of large clinical trials that are appropriate and required for metabolic diseases.

\section{Exosomes and microvesicles (EMVs)}

In contrast, plasma proteomics based on EMVs have the distinct advantage that the information obtained may encompass a considerable reservoir of novel biomarker candidates being transferred from organs, tissues, and cells to that compartment and protected from degradation. Moreover, the plasma EMV sub-proteome is characterized by a smaller dynamic range and a higher portion of undegraded soluble and membrane proteins at considerably high concentrations, and their amount and composition is determined by specific stimuli (eg, drugs) or microenvironmental and pathogenic factors (eg, cellular stress, high glucose). EMVs are expected to fulfill and connect the above criteria of very early prediction, high prediction probability, and feasibility of measurement. This expectation is based on (1) the structure and composition of EMVs with constituent mRNAs encoding genotypic biomarkers as well as constituent cytokine biomarkers, signaling proteins, receptors, transporters, and enzymes; (2) the function of EMVs in intercellular information transfer in various pathogenic processes; (3) the sensitivity of EMVs toward environmental stimuli with regard to their release from the donor cells of almost each tissue and organ into the circulation; and (4) the accessibility and ease of detection and technological determination of EMVs in the plasma. For routine applications in the mid-term, it will be tremendously important to identify significant and physiologically relevant correlations between EMVs and metabolic diseases along subsequent stages of each of the different disease mechanisms covering (1) the healthy state; (2) the initiation of the disease process; (3) its subsequent development to the established disease; (4) the benefits and failures of therapeutic intervention; and (5) the further progression to complications linked to diabetes and obesity (Figure 2).

\section{Structure and composition}

It has long been known that small membrane vesicles are released from most animal cell types, ${ }^{47,48}$ such as mast cells ${ }^{49}$ dendritic cells, B lymphocyte cell lines, ${ }^{49}$ astrocytes, platelets, neurons, endothelial cells, and epithelial cells..$^{50,51}$ They have been regarded as "extracellular organelles" and a family member of the "bioactive vesicles" (Figure 4). They have the same topology regarding outer and inner phospholipid bilayer leaflets as the donor cell, and are of variable diameters, which are used to discriminate the larger so-called microvesicles $(200-1000 \mathrm{~nm})$ and the smaller so-called exosomes (50-200 nm) (Figure 4). It is critically important to distinguish EMVs from the other large membrane vesicles $(0.5-3 \mu \mathrm{m})$, the so-called apoptotic bodies, which are released from almost each cell type when they are challenged by apoptotic and death signals or mechanical stress (Figure 5).$^{52}$ Despite a variety of morphological and structural similarities, apoptotic bodies and EMVs appear to differ considerably with regard to the cellular origin and molecular composition as well as the releasing signals and mechanisms. Interestingly, EMVs were identified more than three decades ago as being released from reticulocytes during their maturation into erythrocytes, whereby the transferrin receptor as a constituent component of those EMVs becomes downregulated in the mature erythrocytes. ${ }^{53}$

EMVs have been detected in the circulatory system (plasma) and various body fluids, such as urine, bronchoalveolar lavage, mucus, saliva, bile, ascites, cerebrospinal fluid, and breast milk. ${ }^{54-56}$ On the basis of the identification of tumor-derived EMVs in the plasma of patients with glioblastoma, multiform malignant glioma, ovarian carcinoma, and lung adenocarcinoma, ${ }^{55,57}$ it may be concluded that EMVs are transferred across the blood-brain barrier and are released from both the apical and basolateral plasma membranes of polarized epithelial and endothelial cells, respectively. EMVs harbor a wide variety of (glyco)phospholipids, mRNAs, and microRNAs (miRNAs), but not ribosomal RNAs, ${ }^{58}$ in concert with soluble, peripheral, transmembrane, and glycosylphosphatidylinositol- (GPI-)anchored proteins (Figures 4 and 5) with overlapping yet distinct patterns between different cell types (Tables 1-4). It seems plausible that their composition depends on the cell type from which they originate and is therefore heterogeneous, which is revealed by proteomic analysis of EMV components in the large scale derived from various cell types ${ }^{59}$ (detailed summarized information in http://dir.nhlbi.nih.gov/papers/lkem/exosome) and from the urine.$^{60}$ The latter study described the presence of 1132 polypeptides and, in addition, of phosphoproteins in EMVs. 


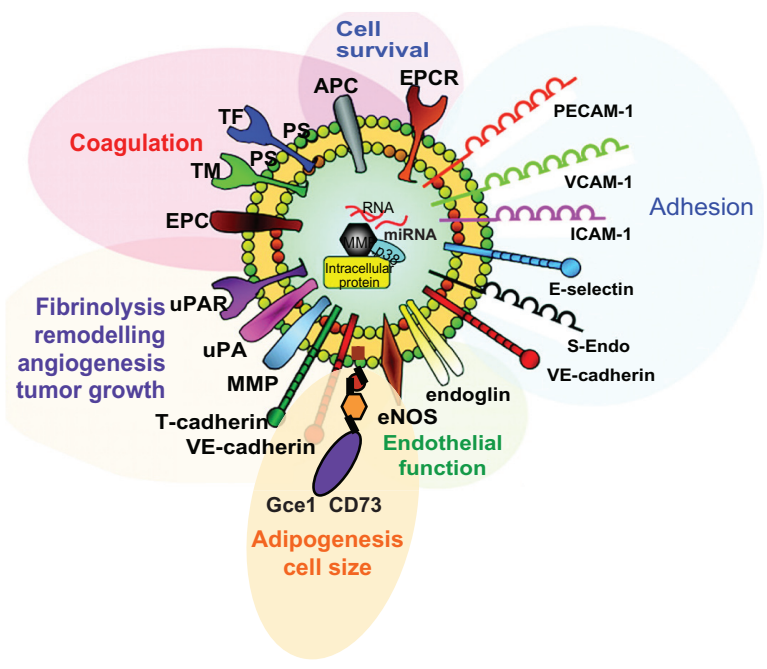

Figure 4 Structure of "model" EMVs with functions of some of their components (see text for details).

Note: $\odot 20 I$ I Wolters Kluwer Health. Adapted with permission from Dignat-George F, Boulanger CM. The many faces of endothelial microparticles. Arterioscler Thromb VasC Biol. 20I I;3I (I):27-33. ${ }^{376}$

Abbreviations: EPCR, endothelial protein Creceptor; PECAM-I, platelet endothelial cell adhesion molecule-I; VCAM-I, vascular cell adhesion molecule-I; ICAM-I, intercellular cell adhesion molecule-I; E-selectin, endothelial selectin; S-Endo, CDI46/melanoma cell adhesion molecule; VE-cadherin, vascular endothelial cadherin; eNOS, endothelial nitride oxide synthase; MMP, matrix metalloproteases; uPA, urokinase plasminogen activator; uPAR, uPA receptor; EPC, endothelial protein C; TM, thrombomodulin.

Moreover, the current version (3.1) of ExoCarta ${ }^{61}$ compiles 11,261 protein entries, $2375 \mathrm{mRNA}$ entries, and 764 miRNA entries derived from 134 studies that deal with EMVs. ${ }^{61}$ All these EMV components originate from the cytoplasm, nucleus, cytoskeleton, proteasome, plasma membranes, and intracellular membranes (eg, mitochondria, endoplasmic reticulum) of the donor cell (Figure 5). Thus, the differential composition of EMVs from various body fluids is a prerequisite for their potential use as biomarkers for metabolic diseases.

\section{Biogenesis}

At present, the detailed mechanisms underlying the biogenesis of EMVs remain unclear. According to current models, microvesicles develop as buds directly at the plasma membrane and are subsequently released by shedding under control of the intracellular calcium concentration and reorganization of the cytoskeleton, with annexin playing a key regulatory role (Figure 6A). Alternatively, the membrane of intracellular endosomes buds into the luminal space. After shedding, they form multivesicular bodies (MVB), which in the course of trafficking to and fusion with the plasma membrane result in exosomes released into the extracellular space (Figure 6B). ${ }^{47,62}$ The energy-dependent formation of soluble $\mathrm{NSF}$ attachment protein receptor (SNARE) complexes ${ }^{63}$ is thought to mediate the attachment of the exosomal membranes (via v-SNAREs) with the target plasma membranes (via t-SNAREs). ${ }^{64}$ Upon initiation of complex assembly at the amino-terminal regions of the SNAREs and further movement toward the membrane-anchoring carboxy-terminal

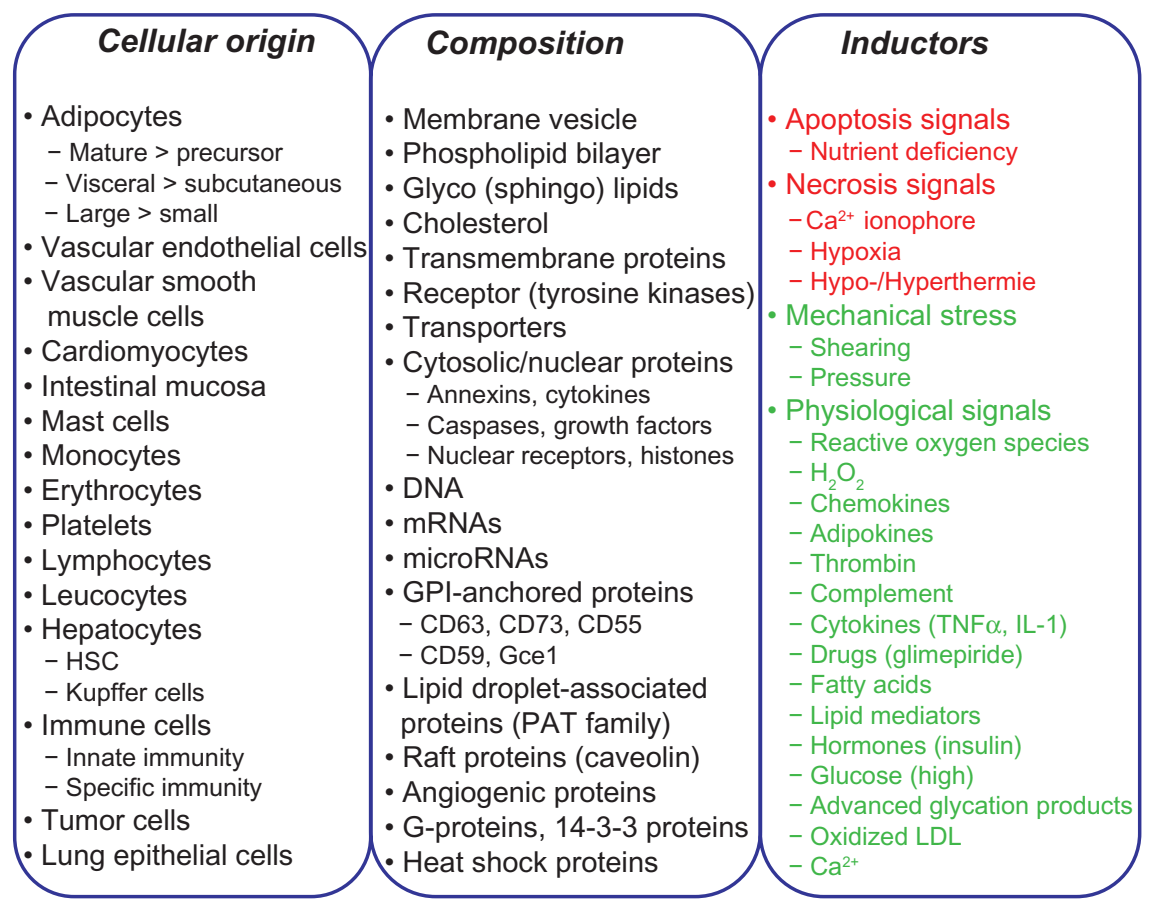

Figure 5 Cellular origin and composition of EMVs and apoptotic vesicles released from donor cells in response to inductors, such as physiological and stress signals (in green) or apoptotis and necrosis signals (in red). 


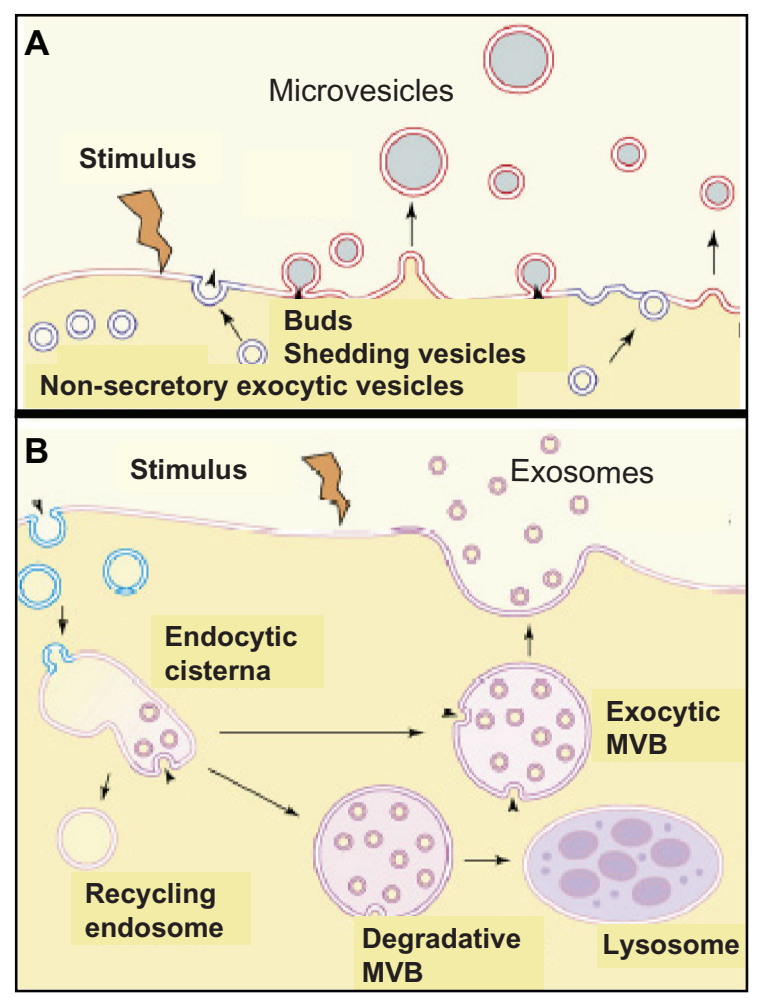

Figure 6 Molecular mechanisms for the release of exosomes. (A) involves the budding and subsequent shedding of specialized areas of the plasma membrane, which are identical to lipid rafts (in red), from the donor cells. (B) involves exocytosis, ie, fusion with the plasma membrane, of exocytic multivesicular bodies (MVB) which originated from endocytic cisternae and escaped degradation by degradative MVB and lysosomes as well as recycling by endosomes, and of microvesicles.

Note: These vesicles are structurally and functionally distinct from nonsecretory exocytic vesicles. (C) 2008, Elsevier. Adapted with permission from Cocucci E, Racchetti G, Meldolesi J. Shedding microvesicles: artefacts no more. Trends Cell Biol. 2008;19:43-51. ${ }^{47}$

regions, ${ }^{65}$ an intermediary complex constituted by SNAP-25 and syntaxin-1 is formed that interacts with synaptobrevin-2. The SNARE-dependent docking of the MVB at the plasma membrane is apparently regulated by Rab27a, Rab27b, and Rab35 $5^{66,67}$ since downregulation of their expression and/or activity led to size increases/accumulation and redistribution to the perinuclear region of the MVB/endosomes.

A recent study described a novel and interesting mechanism for the regulation of exosome biogenesis and release, which involves members of the tetraspanin protein family. The tetraspanin transmembrane proteins possess four membane-spanning domains and are engaged in a very wide range of specific molecular interactions that result in the formation in the plane of the membrane of tetraspanin-enriched microdomains, which are identical or similar to lipid rafts. ${ }^{68-71}$ Tetraspanins have been implicated in a multitude of biological processes, such as cell adhesion, migration, fusion, and signal transduction through their associated partner molecules. ${ }^{72,73}$ Microarray analysis showed that CD9 expression in tumor cells correlated with the down-regulation of several Wnt family genes and their targets, suggesting that CD9 may act as an upstream negative regulator and tumor suppressor in the Wnt signaling pathway. ${ }^{74}$ Previous immunoelectron microscopic studies showed that several members of the tetraspanin family, including CD63 and CD82, are rich in exosomes. ${ }^{75}$ At steady state, tetraspanins CD9 and CD82 are organized in a signaling complex with the membrane adaptor and $\beta$-catenin-binding protein, E-adherin, at the plasma membrane. ${ }^{76}$ This signaling complex, including CD9, CD82, E-cadherin, and the transcription factor, $\beta$-catenin, becomes internalized and delivered to early endosomes where the exosome biogenesis is initiated with inward vesicle budding. After maturation of the exosomecontaining endosomes into late MVB, they fuse with the plasma membrane and thereby release the $\beta$-cateninharboring exosomes. Thus, in general, the tetraspanins CD9/ CD82 seem to drive and control the release of exosomes. In the case of $\beta$-catenin-containing exosomes they apparently trigger the reduction in the cytoplasmic/nuclear pool of $\beta$-catenin with the accompanying downregulation of $\mathrm{Wnt} / \beta$-catenin signaling and tumorigenesis. ${ }^{76}$

According to their biogenesis, a principal differentiation between microvesicles and exosomes seems feasible (Figure 6; Table 5); however, their classification according to composition and cellular origin is problematic (Figure 5). This is predominantly due to the lack of unambiguous physical properties or unique molecular markers of EMVs (Tables 1-4) and, consequently, the difficulties in knowing their cellular origin and biogenetic pathway. Moreover, a number of experimental observations are difficult to reconcile with a strict separation between microvesicle and exosome biogenesis (Table 5). For instance, (glyco)sphingolipids and GPI-anchored proteins - eg, the prion protein ${ }^{77}$ - already embedded in the outer leaflet of the plasma membrane can also be efficiently released via exosomes. ${ }^{78}$ This process can be quite extensive, as demonstrated in reticulocytes, which release approximately $50 \%$ of GPI-anchored acetylcholinesterase from the plasma membrane via exosomes during their differentiation into erythrocytes. ${ }^{79}$ Thus, exosomal proteins and phospholipids are able to bud directly from the plasma membranes of the donor cells. ${ }^{80}$ In addition, exosomes are also detectable as deep invaginations of plasma membranes and thus possibly share the site of biogenesis with that of microvesicles. ${ }^{81}$ Consequently, it has been speculated that exosomes and microvesicles use similar or overlapping pathways in their biogenesis. Surprisingly, recent findings 
Table I Some protein components identified in EMVs from rodent adipocytes ${ }^{300,302,307,322}$

\begin{tabular}{|c|c|c|c|}
\hline Protein class & Name & Accession number & Size (kDa) \\
\hline \multirow{6}{*}{ Metabolic enzymes } & Phosphoglycerate kinase I & P094II & 44.5 \\
\hline & NADP-dependent malic enzyme & XP923436 & 61.5 \\
\hline & Citrate synthase & AAHI 3554 & 51.7 \\
\hline & Malate dehydrogenase & CAA30274 & 35.6 \\
\hline & Fatty acid binding protein-3 & BAE24952 & 14.8 \\
\hline & Fatty acid binding protein- 4 & CAAJI8597 & 14.6 \\
\hline \multirow[t]{14}{*}{ Secretory/membrane proteins } & MFG-E8 & BAE42274 & 51.2 \\
\hline & Adiponectin & BAC30866 & 26.7 \\
\hline & Fasting-induced adipose factor & AAF86342 & 45.5 \\
\hline & CD9 & AAh70474 & 25.2 \\
\hline & CD63 & XP_919469 & 25.7 \\
\hline & Integral membrane protein TAPA-I & $\mathrm{AAB} \mid 9417$ & 25.8 \\
\hline & Clathrin heavy chain & BAE25402 & II4.I \\
\hline & MMP-2 & AAH70430 & 74.0 \\
\hline & MMP-9 & XP_925466 & 98.5 \\
\hline & Coagulation factor II & AAHI 3662 & 70.2 \\
\hline & Coagulation factor $V$ & BAE23393 & 115.7 \\
\hline & Fibulin 2 & AAD34456 & 131.9 \\
\hline & Annexin II & NP_067449 & 49.4 \\
\hline & Complement $\mathrm{C} 3$ & P0I027 & 186.4 \\
\hline \multirow[t]{8}{*}{ Heat shock proteins } & Hspl & AAI06II3 & 59.4 \\
\hline & HSP60 & XP_925296 & 21.2 \\
\hline & HSP70 & XP_930845 & 70.9 \\
\hline & HSP75 & BAË39316 & 80.1 \\
\hline & HSP84 & PII499 & 83.3 \\
\hline & TCP-I chaperone family $\beta$-subunit & BAA95054 & 52.4 \\
\hline & TCP-I chaperone family $\gamma$-subunit & BAE42283 & 31.5 \\
\hline & TCP-I chaperone family $\varepsilon$-subunit & BAC97866 & 59.7 \\
\hline \multirow[t]{2}{*}{ GPI-anchored proteins } & Gcel & & 54.2 \\
\hline & CD73 & & 73.5 \\
\hline
\end{tabular}

Abbreviation: EMVs, exosomes and microvesicles.

suggested that exosome biogenesis does not depend on the formation of MVB since the latter but not the former process requires functional endosomal sorting complexes required for transport (ESCRT) machinery. ${ }^{80,82}$ This argues for identical MVB-independent biogenetic pathways for both microvesicles and exosomes. Given these uncertainties, it has recently been suggested to use the collective acronym, EMVs, for exosomes plus microvesicles ${ }^{83}$ for any released nonapoptotic small membrane vesicle (Figures 5 and 6 ) that is also used in this review article.

\section{Releasing signals}

Multiple signaling mechanisms are presumably involved in the cell- or agonist-specific release of both types of EMVs (Figure 5). It is important to point out that EMV release is not a random process, such as the degradation of plasma membranes of dying necrotic cells, but a highly controlled process triggered by a multitude of structurally diverse stimuli (Figure 5). For instance, in platelets, EMV release is induced by the following stimuli with increasing potency: epinephrine, adenosine diphosphate, thrombin, collagen, thrombin plus collagen, and $\mathrm{Ca}^{2+}$ ionophore A23187. ${ }^{84}$ Furthermore, the complement membrane attack complex C5b-9 or antiplatelet antibodies represent other stimuli that cause EMV release in platelets. In addition to biological and chemical stimuli, mechanical factors, such as shear stress, induce EMV release in platelets and many other cell types. Significantly, many stimuli can trigger the release in additive or even synergistic fashion to other stimuli.

\section{miRNA components}

miRNAs are small, noncoding RNA sequences of about

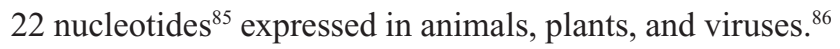
All precursor miRNAs have stem loop structures that are cleaved by the Drosha and Dicer protein complexes to form mature functional miRNA. Through the formation of RNA-induced silencing complexes, miRNAs can either cleave mature mRNA molecules or inhibit their translation, thus representing an additional posttranscriptional layer of gene regulation. Interestingly, miRNAs were found 
Table 2 Some protein components identified in EMVs from rodent adipocytes ${ }^{300,302,307,322}$

\begin{tabular}{|c|c|c|c|}
\hline Protein class & Name & Accession number & Size $(k D a)$ \\
\hline \multirow[t]{5}{*}{ Ubiquitin/proteasome-related proteins } & $26 \mathrm{~S}$ proteasome subunit $\alpha \mathrm{I}$ & BAE40I84 & 20.2 \\
\hline & $26 \mathrm{~S}$ proteasome subunit $\beta 3$ & XP_920004 & 18.8 \\
\hline & $26 \mathrm{~S}$ proteasome subunit $\beta 5$ & O55234 & 22.9 \\
\hline & $26 \mathrm{~S}$ proteasome subunit $\mathrm{Rpn} 13$ & BAE42495 & 38.2 \\
\hline & Ubiquitin-activating enzyme EI & BAE25369 & 117.8 \\
\hline \multirow[t]{10}{*}{ Nuclear proteins } & Histone HI.I & NP_034507 & 21.6 \\
\hline & Histone HI.5 & BAB3200I & 22.3 \\
\hline & Histone HI.3 & BAE33250 & 22.1 \\
\hline & Histone $\mathrm{H} 2 \mathrm{~A}$ & AAHI0564 & 14.9 \\
\hline & Histone H2B & XP_2I4483 & 16.6 \\
\hline & Histone $\mathrm{H} 4$ & XP_9II558 & 18.6 \\
\hline & $40 S$ ribosomal protein SA & XP_909595 & 9.0 \\
\hline & $40 S$ ribosomal protein $\mathrm{S} 8$ & XP_890310 & 37.6 \\
\hline & $60 S$ ribosomal protein $\mathrm{L} 7$ & CAA41028 & 17.7 \\
\hline & $60 S$ ribosomal protein $\mathrm{LI} 8 \mathrm{a}$ & BAE40206 & 20.6 \\
\hline \multirow[t]{5}{*}{ Cytoskeleton } & Actr Ib protein & $\mathrm{AAH} 2486 \mathrm{I}$ & 19.6 \\
\hline & $\beta$-Actin & BAB403I7 & 15.0 \\
\hline & Tubulin $\alpha 2$ & $X P \_89880$ & 28.1 \\
\hline & Tubulin $\beta 2$ & XP_917827 & 49.8 \\
\hline & Tubulin $\beta 5$ & BAE30573 & 42.1 \\
\hline \multirow[t]{2}{*}{ Membrane transport/fusion } & Annexin II & XP_622573 & 32.6 \\
\hline & Annexin V & BAĒㄱ| 952 & 35.7 \\
\hline \multirow[t]{9}{*}{ Miscellaneous } & Galectin I & AAH02063 & 14.9 \\
\hline & Galectin 3 & BAE31013 & 64.5 \\
\hline & Translation elongation factor-I & XP_921527 & 19.6 \\
\hline & Translation elongation factor-2 & BAC28I20 & 95.2 \\
\hline & Translation initiation factor $4 \mathrm{~A}$ & XP_929093 & 37.4 \\
\hline & Major vault protein & AAL02325 & 95.9 \\
\hline & $14-3-3 \beta$ & $\mathrm{AACI} 4343$ & 28.1 \\
\hline & Dynein heavy chain & NP_0845I4 & 531.7 \\
\hline & Albumin & BAC34I45 & 68.7 \\
\hline
\end{tabular}

Abbreviation: EMVs, exosomes and microvesicles.

incorporated into EMVs released from primary or cultured cells in vitro or circulating in the plasma. For instance, a large number of miRNA species has been detected associated with EMVs in the plasma of normal subjects, which are predicted to control homeostasis and metabolism of hematopoietic cells. ${ }^{87}$ Importantly, the miRNA species (as revealed by advanced array technologies) of those EMVs did not reflect the total miRNA profiles of the donor cells, ${ }^{57,58,87-89}$ which is an argument for rather selective miRNA packaging into EMVs. Nevertheless, EMVs released from T-cells, B-cells, and dendritic cells have been demonstrated to harbor miRNA species unique to the expression pattern in their donor cells. ${ }^{90}$ The molecular mechanisms underlying the selective packaging of miRNAs into EMVs remain unknown so far.

Importantly, miRNAs have been demonstrated to be more stable than their cellular counterparts ${ }^{91}$ and to resist degradation during prolonged storage and repeated freezing/ thawing cycles. ${ }^{92}$ This apparent stability of EMV contents underscores the attractiveness of EMVs as biomarkers. Moreover, during the development of many diseases and in a multitude of pathological states, EMVs prepared from patients were found to harbor specific miRNAs that were detected at lower levels or not at all in EMVs from normal healthy subjects. ${ }^{57,88,93,94}$ For instance, levels of miR-133a, which regulates the NFATc4 protein known to accompany or even induce the development of cardiac hypertrophy, have been found increased in circulating EMVs isolated from injured myocardium of patients with cardiometabolic diseases. ${ }^{95}$ In agreement, the administration of miR-133a antagomirs that specifically inhibit miR-133a function was reported to decrease the extent of cardiac hypertrophy. ${ }^{95}$

The administration and targeted cellular delivery of specific miRNAs via EMV-like vehicles prepared from natural sources and subsequently chemically modified or reconstituted in vitro is under intense investigation and 
Table 3 Some protein components identified in EMVs from various cell types ${ }^{303,322,361,363,372-375}$

\begin{tabular}{lll}
\hline Protein class & Name & Cell type \\
\hline Antigen & MHC class I and II & B-cells \\
presentation & & Dendritic cells \\
& & Enterocytes \\
& & Tumor cells \\
& & T-cells \\
Integrins & alpha4 $\beta$ I & Mastocytes \\
& alphaM $\beta 2$ & Reticulocytes \\
& 32 & Dendritic cells \\
Immunoglobulin- & ICAMI/CD54 & T-cells \\
family members & & Mastocytes \\
& & B-cells \\
& P-selectin & Dendritic cells \\
Cell surface & A33 antigen & Mastocytes \\
peptidases & Dipeptidylpeptidase-IV/CD26 & Mastocytes \\
Tetraspanins & Aminopeptidase N/CDI3 & Enterocytes \\
& CD63 & Mastocytes \\
& & B-cells \\
Heat shock & HSC70 & Dendritic cells \\
proteins & & Enterocytes \\
& & Platelets \\
& & T-cells \\
& & Mastocytes \\
& & B-cells \\
& & Dendritic cells \\
& & Reticulocytes \\
& & Dendritic cells \\
& & Tumor cells \\
& & Dendritic cells \\
& & Enterocytes \\
\hline
\end{tabular}

Abbreviation: EMVs, exosomes and microvesicles.

discussion. ${ }^{96}$ Antagomirs represent a new class of chemicals, which have been successfully used to downregulate the endogenous expression of miRNAs. ${ }^{97}$ They represent chemically modified small synthetic RNA oligonucleotides perfectly complementary to the selected miRNA target but mispairing at the cleavage site of argonaute 2 or harboring some modified bases to interfere with argonaute 2 cleavage. Furthermore, antagomirs must be protected from rapid degradation, which is usually accomplished by the introduction of 2' methoxy groups or phosphothioates. The molecular mechanism by which antagomirs block the miRNA function remains to be elucidated, but it may involve irreversible binding to the targeted miRNA..$^{97,98}$ Alternatively, miRNAs can be inactivated, even in vivo, upon administration of so-called "locked" nucleic acids. ${ }^{99-101}$ On the contrary, the endogenous function of a selected miRNA can be recapitulated upon introduction into the target cells of synthetic miRNA mimics consisting of a "guide
Table 4 Some protein components identified in EMVs from various cell types ${ }^{303,322,361,363,372-375}$

\begin{tabular}{lll}
\hline Protein class & Name & Cell type \\
\hline $\begin{array}{l}\text { Cytoskeletal } \\
\text { proteins }\end{array}$ & Actin & $\begin{array}{l}\text { Dendritic cells } \\
\text { Enterocytes } \\
\end{array}$ \\
& $\begin{array}{l}\text { Actin-binding proteins (cofilin) } \\
\text { Tubulin }\end{array}$ & $\begin{array}{l}\text { Dendritic cells } \\
\text { Dendritic cells }\end{array}$ \\
& Annexin I, II, IV, V, VI & Enterocytes \\
Membrane & Annexin VI & Dendritic cells \\
transport/fusion & RAB7, RAPIB, RAB-GDI & Mendrites \\
& Gi2alpha, I4-3-3 & Dells \\
Signal & CBL, LCK & Dendritic cells \\
transduction & Enolase-I & Enterocytes \\
Metabolic & Thioredoxine peroxidase & Dendritic cells \\
enzymes &
\end{tabular}

Abbreviation: EMVs, exosomes and microvesicles.

strand," which is identical to that of the selected miRNA and a "passenger strand," which is chemically linked to a "carrier" molecule, such as cholesterol, for facilitating cellular uptake. Both strands have to be chemically modified to increase their stability to a considerable extent.

In summary, there is increasing evidence for the potential use of EMVs-associated miRNA signatures in body fluids, particularly peripheral blood, as biomarkers for the prediction of metabolic diseases. ${ }^{102} \mathrm{In}$ addition, the technologies for the up- and downregulation of miRNA activity introduced for eluciduation of its (patho)physiology will open new avenues for the miRNA/EMV-based therapy of metabolic diseases.

\section{GPI-anchored protein components}

GPI-anchored proteins are widely distributed among all eukaryotic organisms. ${ }^{103-106}$ They harbor lipidic tail structures that tether them to the outer phospholipid leaflet of plasma membranes and EMVs, respectively, as well as relatively large hydrophilic proteinaceous domains that protrude into extracellular/vesicular spaces (Figure 4). The evolutionary purpose of membrane anchorage via GPI linkage for surface protein expression remains unclear so far. GPI-anchored enzymes, receptors, binding proteins, and structural proteins are known to be involved in a number of different physiological processes and functions, such as catalysis, signal transduction, cell adhesion, and complement regulation (Table 6). ${ }^{107-123} \mathrm{GPI}$-anchored proteins also have a great role in embryogenesis, since abrogation in their biosynthesis results in embryonic lethality. Recently, it was shown that interaction of GPI-anchored EphrinA with its receptor is crucial for closure of the neural tube. ${ }^{122}$ 
Table 5 Comparison of composition and biogenesis between microvesicles and exosomes ${ }^{376-381}$

\begin{tabular}{lll}
\hline & Exosomes & Microvesicles \\
\hline Typical membrane proteins & CD63, TNFRI, GPI-anchored proteins & Integrins, Gcel, CD73, metalloproteinases \\
Typical luminal proteins & Cytokines, annexins & Caspases, annexins, cytokines, growth factors \\
Typical lipids & Cholesterol, ceramides, lysobisphosphatidic acid & Cholesterol \\
miRNA & Growth, metabolism & Metabolism \\
mRNA & Growth factors & Growth factors \\
SNAREs, Rabs, budding proteins & Preliminary evidence & Unknown \\
Site of generation & Multivesicular bodies (MVB) & Plasma membrane \\
Mechanism of generation & Membrane budding and fusion & Membrane budding and fusion \\
Mode of release & Constitutive, regulated & Regulated \\
Mechanism of release & Exocytosis of MVB & Plasma membrane budding \\
Mechanism of sorting & Ceramide-dependent & Unknown \\
Intracellular storage & Yes & No
\end{tabular}

First indications that proteins might be attached to plasma membranes by lipidic anchors were reported in 1963 with the finding that bacterial phospholipase can release alkaline phosphatase from cells. ${ }^{124}$ The existence of inositolcontaining phospholipid protein anchors was suggested in $1976^{125}$ and was finally accepted in 1985, when detailed compositional data about Torpedo electric organ and human acetylcholinesterase, ${ }^{126,127}$ rat brain and thymocyte Thy- $1,{ }^{128}$ and Trypanosoma brucei variant surface glycoprotein ${ }^{129,130}$ became available. Today, hundreds of GPI-anchored proteins are known, and it is estimated that approximately $0.5 \%$ of all proteins in lower and higher eukaryotes are modified in this manner. ${ }^{131}$

All GPI anchors share a common glycolipidic core structure. ${ }^{105,106}$ Phosphatidylinositol is glycosidically linked through carbon- 6 of the myoinositol ring to the reducing end of a nonacetylated glucosamine moiety. Three mannosyl residues, linked to $\alpha 1-4, \alpha 1-6$, and $\alpha 1-2$, respectively, are attached to this glucosamine. The terminal $\alpha 1-2$ linked mannose is linked to phosphoethanolamine via a phosphodiester linkage. The GPI anchor becomes attached to the carboxyl terminus of the protein by an amide linkage to the amino group of phosphoethanolamine. This common core structure can be further modified in a way that depends on both the organism and the cell type in which it is synthesized. ${ }^{104}$

The whole process of GPI biosynthesis is carried out in the endoplasmic reticulum, ${ }^{106}$ and nearly 20 enzymes are involved in this pathway. Corresponding genes have been cloned from mammals, yeast, and protozoa. ${ }^{132,133}$ The initial step, the attachment of $\mathrm{N}$-acetylglucosamine to phosphatidylinositol, depends on the product of the $\mathrm{X}$-chromosomal gene, phosphatidylinositolglycan class A (PIG-A) in humans. ${ }^{134} \mathrm{~A}$ deficiency in PIG-A results in a rare human disease called paroxysmal nocturnal hemoglobinuria (PNH). ${ }^{134-137}$ Patients with PNH have abnormal cells of various hematopoietic lineages that are defective in the biosynthesis of GPI-anchored proteins. These include the complement-regulatory proteins, CD55 and CD59, whose absence results in enhanced complementmediated lysis. ${ }^{138,139}$ Since deficiency of GPI biosynthesis is embryonically lethal, ${ }^{119-121}$ all PNH patients reported to date

Table 6 Some representatives for GPI-anchored proteins ${ }^{382-387}$

\begin{tabular}{lll}
\hline Enzymes & Receptors & Others \\
\hline Alkaline phosphatase & Folate-binding protein & Thy-I \\
Acetylcholinesterase & CDI4 & CD24 \\
$5^{\prime}$-nucleotidase (CD73) & CDI6 & CD55 (DAF) \\
Alkaline phosphodiesterase I & CD48 & CD58 \\
cAMP-specific phosphodiesterase (Gcel) & Plasmodium transferrin receptor & Tamm-Horsfall glycoprotein \\
Renal dipeptidase (MDP) & Urokinase receptor & Carcinoembryonic anigen \\
Aminopeptidase P & CNTF receptor & Prions (PrPC, PrPSc) \\
NAD+ glycohydrolase & Nogo-66 receptor & NCAM-I20fs \\
Carboxypeptidase M & & Ly6 family (CD59, Ly6A) \\
Carbonic anhydrase IV & & \\
ADP-ribosyltransferase & &
\end{tabular}

Abbreviations: GPI, glycosylphosphatidylinositol. 
apparently have acquired a somatic mutation in PIG-A. ${ }^{140}$ The exact mechanism how one or a few of the large number of pluripotent hematopoietic stem cells that bear a mutation in PIG-A achieve dominance in the bone marrow and the peripheral blood is not known so far. ${ }^{141}$ Possibly, PIG-A deficient cells have lower susceptibility to TNF- $\alpha$ and IFN- $\gamma$, and this resistance might contribute to their clonal dominance.

Once the biosynthesis of the GPI anchor is completed, it is transferred to a specific site upstream of the carboxyterminal end of the protein in the endoplasmic reticulum lumen by the action of a transamidase complex, which simultaneously cleaves off the remaining carboxy-terminal peptide. ${ }^{132,133}$ A specific signal for GPI anchor attachment has been identified at the carboxy terminus of the protein moiety. ${ }^{103,106}$ After attachment of the prefabricated GPI anchor, the GPI-modified proteins are then transferred from the endoplasmic reticulum to the Golgi complex where they are subjected to further modifications at their GPI moiety. Finally, they are transferred to the plasma membrane via the trans-Golgi network and secretory vesicles as mature GPI-anchored proteins. In mammalian polarized cells, the GPI-anchored proteins seem to be targeted predominantly to the basolateral plasma membrane domain. ${ }^{142}$

Although the polypeptide moieties attached to the GPI anchors do not apparently share common features, the presence of the GPI anchor itself appears to confer some important characteristics on them. In particular, localization to plasma membrane microdomains or lipid rafts - which are highly enriched in (glyco)sphingolipids, cholesterol, saturated fatty acids, and certain proteins, serving as platforms for a variety of cellular functions, such as vesicular trafficking ${ }^{143,144}$ and signal transduction (Table 7)-appears to play critical roles in the transduction of signals across the plasma membrane, the translocation of GPI-anchored proteins from plasma membrane lipid rafts onto cytoplasmic lipid droplets (LDs), ${ }^{145-147}$ and the release of GPI-anchored proteins into EMVs. ${ }^{148,149}$ The clustering of GPI-anchored proteins in lipid rafts ${ }^{150-161}$ may be required for the initial budding, subsequent shedding, and final release of EMVs enriched in GPI-anchored proteins.

\section{Release and transfer of EMV-associated GPI-anchored proteins}

In addition to liberation by enzymatic, ie, lipolytic or proteolytic cleavage, GPI-anchored proteins can be released
Table 7 Some selected signaling pathways mediated by lipid rafts and major components involved ${ }^{388-394}$

\begin{tabular}{ll}
\hline Signaling pathway & Major component \\
\hline Humoral immune response & B-cell receptor \\
Growth, differentiation & EGF receptor \\
Nitric oxide & Endothelial NOS \\
Immune response & FceRI receptor \\
Insulin, glucose metabolism & Insulin receptor \\
Antidiabetic therapy & Glimepiride-induced \\
& phospholipase C \\
Insulin-mimetic signaling & Phosphoinositolglycans \\
Cell adhesion & Integrins \\
Cellular immune response & T-cell receptor \\
\hline
\end{tabular}

from the outer leaflet of the plasma membrane with their GPI anchors remaining intact. This release can occur via embedding the GPI-anchored proteins into small aggregates together with some membrane phospholipids. ${ }^{162}$ Alternatively and more frequently, the release is provoked through EMVs. Little is known about the signals that target proteins, such as GPI- and other lipid-anchored, eg, acylated proteins to the site(s) of EMV release. Candidate signals represent amino-terminal acylation or myristoylation tags, internal phosphatidylinositol-(3,)4,5-bisphosphate-binding domains, carboxy-terminal prenylation, and palmitoylation tags as well as type-I integral plasma membrane outer leaflet targeting domains. ${ }^{80,83,163,164}$ With regard to GPI-anchored proteins, their segregation into the site(s) of EMV release may rely on the intrinsic capability of GPI anchors to spontaneously insert, accumulate, and aggregate in lipid rafts of the outer plasma membrane leaflet. ${ }^{165}$

The phenomenon of the release of polypeptides from donor cells and subsequent intercellular transfer to and uptake by acceptor cells of a GPI-anchored protein were reported even before the actual discoveries of GPI anchors and the presence of GPI-anchored proteins in EMVs. While investigating phospholipid exchange between cells and artificial vesicles and liposomes, ACE and some other erythrocyte proteins were observed to be transferred from the erythrocytes to the vesicles and liposomes in reversible fashion. ${ }^{166}$ The rate, direction, and extent of those apparent intermembrane transfers were found to depend on the relative phospholipid composition and fluidity of both the donor and the acceptor membranes. ${ }^{167}$ In addition, the spontaneous insertion of exogenously added purified human decay accelerating factor (DAF) into the surface of sheep erythrocytes was reported, ${ }^{168}$ which resulted in freely mobile and fully active DAF, as demonstrated by its inhibition of convertase complexes and mediation of resistance to complement-mediated lysis. ${ }^{169}$ 
Since then, a number of other GPI-anchored proteins were successfully incorporated into a variety of different cell types in vitro under retention of the same characteristics and functions as their endogenously expressed counterparts. ${ }^{162,167-180}$ For instance, CD59 was transferred from seminal plasma to erythrocytes and other cells, ${ }^{179,181,182}$ as well as from erythrocytes to endothelial cells in mice made transgenic for this GPI-anchored protein. ${ }^{169,183}$ Storage of erythrocytes resulted in the loss of both CD55 and CD59 from the erythrocyte membrane ${ }^{183}$ and generation of erythrocyte EMVs that are enriched in GPI-anchored proteins, including CD55 and CD59. ${ }^{184}$ Interestingly, CD59 incorporated into U937 monocytic cells and allowed to equilibrate for 2 hours at $37^{\circ} \mathrm{C}$ showed redistribution into lipid rafts and signaling via intracellular $\mathrm{Ca}^{2+}$ fluxes. ${ }^{185}$ Therefore, exogenously added GPI-anchored proteins appear to become functional within the target cell membrane once they have acquired a distribution similar to that of their endogenous counterparts during a slow process that can take even more than 24 hours. ${ }^{186,187}$ Incubation of rat Thy-1 antigen with murine lymphocytes showed that the rat protein was transferred to murine cells and incorporated into their plasma membranes, where the exogenous protein migrated with the same lateral mobility as endogenous murine Thy- 1 protein. ${ }^{188}$ Similarly, incorporation of T. brucei variant surface glycoprotein (VSG) into baby hamster kidney cells showed that the inserted VSG exhibited lateral mobility equivalent to that of endogenous VSG in T. brucei. ${ }^{189}$

When erythrocytes from PNH patients who were deficient in GPI-anchored proteins were incubated with high-density lipoprotein (HDL) preparations or erythrocyte EMVs from normal blood donors, significant transfer of CD55 and CD59 to the cell surface occurred. Pretreatment of the EMVs and HDL with bacterial phosphatidylinositolspecific phospholipase $\mathrm{C}$ abrogated protein transfer to CD55/59-deficient cells, indicating that the elevated cellassociated CD55/59 levels were related to the insertion of an intact GPI anchor into the outer leaflet of the plasma membrane by the GPI fatty acyl chains rather than to simple adhesion. ${ }^{184}$ An elegant experiment successfully demonstrated the ability of GPI-anchored proteins to transfer between cells in vivo. ${ }^{172} \mathrm{PNH}$ patients of blood group A1 were given transfusions of compatible washed group 0 blood. Patients' group A1 cells were distinguished from the transfused group 0 cells by staining with a Dolichos biflorus lectin that specifically binds to group A1 erythrocytes. Significant transfer of GPI-anchored proteins from donor cells to patients' erythrocytes could be demonstrated as early as one day following transfusion and persisted for several days. ${ }^{190,191}$

Transfer between membranes can occur without actual membrane fusion. ${ }^{162}$ The GPI-anchored proteins are apparently transferred through EMVs released from the donor cells. ${ }^{192}$ Moreover, GPI-anchored proteins were reported not to transfer spontaneously from erythrocytes to liposomes or between plasma membranes in vivo. ${ }^{192}$ The involvement of a catalyst was supported by the observation that CD4 engineered to become biosynthetically coupled to a GPI anchor is efficiently transferred between plasma membranes in one type of cell, ${ }^{193}$ while another cell line expressing CD4-GPI fusion protein failed to release it in any form. ${ }^{194}$ With regard to CD59, HDL may act as its carrier and manage to transfer CD59 to erythrocytes. ${ }^{195}$ The exact mechanism(s) underlying the EMV-mediated transfer of GPI-anchored proteins, which may involve receptor-receptor interactions, direct fusion or endocytosis of the EMVs by the acceptor cell, subsequent fusion with endosomes (Figure 7), and identification of the hypothetical catalyst are currently under intense investigation, ${ }^{169,173,185-188,196}$ but in any case, they rely on the intactness of both GPI lipid and protein moieties. ${ }^{168,186}$ This conclusion was drawn from the observation that transgenic mice expressing the GPI anchorless (released instead of cell surface-expressed) version of the prion protein $(\mathrm{PrP})$ were infected with the pathogenic scrapie form of PrP, but they never developed manifest prion disease ${ }^{197}$ Experiments with cells expressing anchorless PrP were also resistant to scrapie infection. ${ }^{198}$ Apparently, lack of the GPI anchor on PrP would prevent its transfer and could explain why cells expressing GPI anchor-less PrP were unable to sustain a scrapie infection over time.

\section{(Patho)physiological roles of EMV- associated $\mathrm{GPI}$-anchored proteins}

The transport of GPI-anchored proteins and miRNAs across the plasma membrane and their intracellular translocation onto cytoplasmic LDs (GPI-anchored proteins, only) or release into the circulation through EMVs (GPI-anchored proteins and miRNAs) as well as the subsequent transfer from the EMVs of the donor cell to the plasma membrane of an acceptor cell were independently discovered and rediscovered in several distinct research areas during the past decades and termed shedding, release, incorporation, painting, uptake, jumping, transfer, and translocation. ${ }^{62,159,162,192,199-201}$ In these studies, the differential release and transfer of EMVs originating from a multitude of cell types were implicated with the pathogenesis of a broad variety of diseases. 


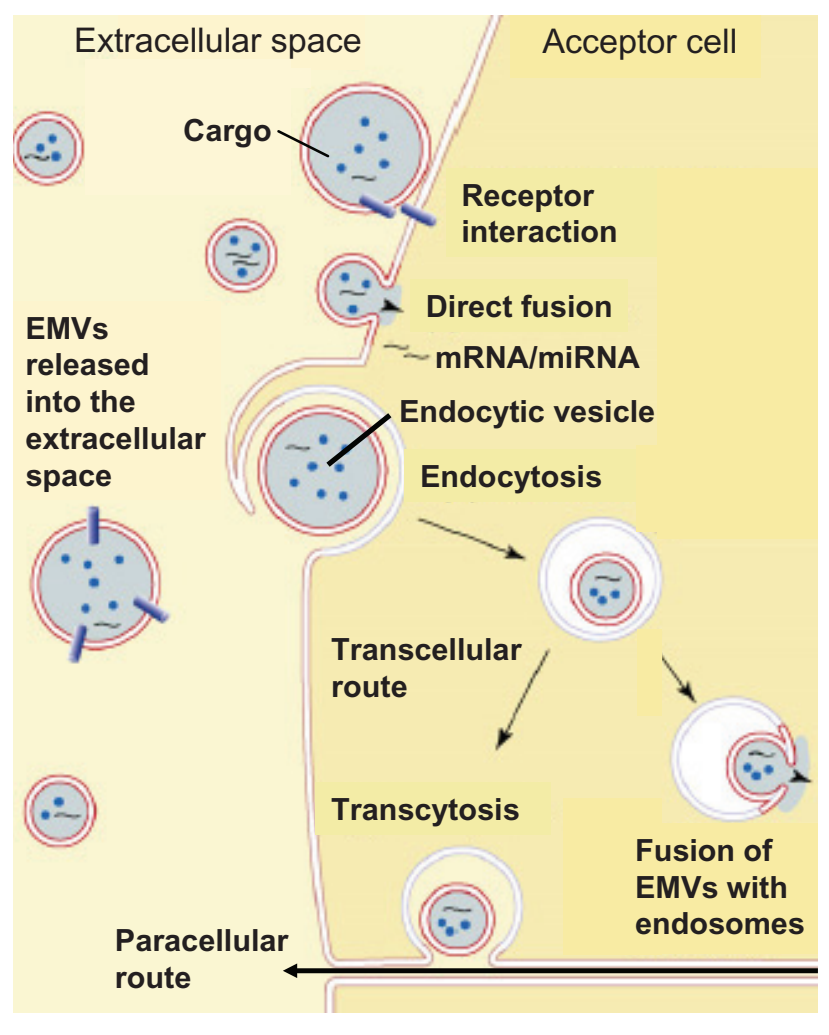

Figure 7 Current working hypotheses for the different modes of interaction of EMVs released from donor cells into the extracellular space with target acceptor cells. Notes: May involve receptor interaction, direct fusion or endocytosis. Upon fusion of the endocytic vesicle membrane with the EMV membrane, the EMV contents become delivered to the cytoplasm of the acceptor cell. Alternatively, in polarized epithelial or endothelial cells the endocytic vesicle upon budding from the apical plasma membrane may undergo transcytosis and fuse with the basolateral plasma membrane. This transcellular pathway, as well as the paracellular route across cellconnecting tight junctions, mediate the transport of EMVs released from tissue cells into body fluids. (C) 2008, Elsevier. Adapted with permission from Cocucci E, Racchetti G, Meldolesi J. Shedding microvesicles: artefacts no more. Trends Cell Biol. 2008; 19:43-51. ${ }^{47}$

Abbreviation: EMVs, exosomes and microvesicles.

One prominent source of EMVs is tumor cells that use the release and transfer of certain EMV components to evade destruction by immune cells. ${ }^{52,201}$ Retroviruses exploit transfer via EMVs for spreading to other cells. ${ }^{200-203}$ However, these extensively studied mechanisms are actually examples of a misuse of EMVs and some of their components. The real reason that this process developed in the course of evolution has yet to be elucidated. One reported physiological function is the transfer of GPI-anchored proteins and gangliosides by prostasomes from prostate epithelium to spermatozoa. ${ }^{162}$ Since spermatozoa do not synthesize proteins, the transfer may represent an important target cell-oriented mechanism by which spermatozoa can obtain new proteins and alter their antigenicity or acquire resistance to immune attack and other surface properties. Another rather probable function of the transfer is the modulation of the composition of lipid rafts and their function, eg, in signal transduction. Together with the GPI-anchored proteins, gangliosides are located in lipid rafts. Even though they arise from different biochemical pathways, they both have lipid anchors that tether them to the outer leaflet of plasma membranes and enable their release from the donor cell and transfer to the acceptor cell in a regulated fashion. ${ }^{58}$ Since GPI-anchored proteins and gangliosides are both localized in lipid rafts, they could affect each other. Exogenous administration of gangliosides affected the distribution of GPI-anchored proteins within lipid rafts. ${ }^{203-206}$ It is tempting to speculate that modification of lipid rafts by removal or addition of specific gangliosides might create favorable conditions for the release of GPIanchored proteins.

In rodent adipose tissues, the release of (GPI-anchored) proteins and mi/mRNAs from donor adipocytes and subsequent transfer to acceptor adipocytes via EMVs is known to exert multiple (patho)physiological consequences. ${ }^{207-211}$ Recently, the fusion of EMVs derived from large white rat adipocytes and harboring the GPI-anchored proteins, Gce1 and CD73, the mRNAs coding for the fat-specific (LD-associated) protein, FSP27, and the lipid-synthesizing enzyme, glycerol-3-phosphate acyltransferase (GPAT3), as well as the microRNAs, miR-16 and miR-222, with distinct small adipocytes was demonstrated to stimulate lipid synthesis and storage, in parallel with inhibition of lipid degradation through lipolysis. ${ }^{207-211}$ Importantly, the release of those EMVs from human and rat donor adipocytes was upregulated by physiological signals, such as palmitate and $\mathrm{H}_{2} \mathrm{O}_{2}$, as well as pharmacological signals, such as the antidiabetic sulfonylurea drug, glimepiride. ${ }^{207-212}$ Furthermore, there is experimental evidence that this induced release is epigenetically controlled via demethylation of histone $\mathrm{H} 3$ at lysine 4 and dual methylation of histone H3 at lysine 9 within the promoter of the tetraspanin protein, CD9 (Müller G et al, unpublished data). Ectopic expression of CD9 and silencing of endogenous CD9 expression in human adipocytes triggered significant upregulation and downregulation, respectively, of the release of EMVs harboring CD73 and CD9 proteins, FSP27/CideC mRNA and miR-222. This was accompanied by downregulation and upregulation of lipid degradation and oxidation, respectively. In agreement, lipid synthesis and the expression of the LD-associated proteins FSP27/CideC and perilipin A were decreased and increased upon up- and downregulation of CD9 expression, respectively. Lipolysis, LD-associated Gce1 protein and its cAMP-specific phosphodiesterase activity, the oxygen consumption rate, the extracellular acidification rate, and the expression of the mitochondrial proteins, uncoupling 
protein 1 (UCP1) and $\mathrm{F}_{1}$-ATPase, became elevated and diminished in response to up- and downregulated CD9 expression, respectively (Müller $\mathrm{G}$ et al, unpublished data). Together these findings suggest that upregulation of the release of EMVs harboring specific GPI-anchored proteins, mRNAs and miRNAs, is under the control of differential histone methylation of the CD9 promoter, which leads to fostered CD9 expression and ultimately triggers lipolysis and oxidation of the fatty acid products in (newly generated and partially uncoupled) mitochondria. This raises the possibility that upregulation of EMV release and transfer within human adipose tissue depots may represent a novel target for the therapy of obesity. ${ }^{213,214}$

Unfortunately, the phenomenon of transfer of GPIanchored proteins via EMVs is difficult to discover and track for the following reasons: (1) different GPI-anchored proteins undergo different mechanisms of release and its regulation; (2) transfer efficacy is often rather limited, at least if total GPI-anchored proteins are analyzed; (3) transfer is directed to only a limited number of GPI-anchored proteins and/or specific cell types; (4) from a technological point of view, it is difficult to detect the transfer of GPI-anchored proteins in whole organisms. In conclusion, the physiological significance and function of release and transfer of EMVs are not well understood at present. It will be interesting to learn whether and, if so, how they support the integration of individual cells within and between tissues.

\section{(Patho)physiological roles of EMV- associated $\mathrm{mi} / \mathrm{mRNAs}$}

Considering the importance of miRNAs as an inevitable cornerstone of the human genetic system, the engagement of EMVs for the transfer of genetic material could be an efficient method within the human body to exchange biological information. EMVs containing miRNAs would enable intercellular and inter-organ communication in the body. ${ }^{215}$ Consequently, EMVs could shuttle mRNAs and miRNAs directly from donor to acceptor cells, thereby considerably increasing the probability that the transferred genetic information would affect the function of the acceptor cells upon their successful expression and silencing functions, respectively. The release of mi/mRNA-harboring EMVs may enable the cell-to-cell communication irrespective of the distance between the cells within an organ or tissue or between cells of different, more or less remote organs and tissues. The identification of EMVs in blood and various body fluids hints at the possibility that this exchange of genetic information between organs or tissues may involve EMVs. ${ }^{215}$
Moreover, the membrane of EMVs harbors donor cellspecific factors (eg, GPI-anchored proteins) that enable the EMVs to target specific acceptor cells for transfer of their mi/ mRNA contents with exquisite specificity and efficacy. Those EMV-associated mi/mRNAs may reflect disease-specific causal mechanisms. Experimental evidence is emerging that the prediction, diagnosis and prognosis of certain diseases may be facilitated by measurement of the levels of specific $\mathrm{mi} / \mathrm{mRNAs}$ in EMVs isolated from certain body fluids.

Initial credit for this attractive possibility was gained during cancer research. ${ }^{216-226}$ Certain tumors were recently demonstrated to shed EMVs, which are rich in signaling molecules and genetic material that together constitute a specific and readily identifiable signature. ${ }^{47}$ Moreover, miRNAs entrapped in EMVs were detected in the serum of cancer patients by quantitative real-time polymerase chain reaction in tumor-specific fashion. ${ }^{58,221}$ The miRNA profiles from circulating tumor EMVs were found unique and distinct compared to those from normal controls. ${ }^{88}$ Similarly, specific miRNA profiles have been reported for EMVs isolated from patients with lung cancer, glioblastoma, and heptocellular carcinoma. ${ }^{57}$ In lung adenocarcinoma, the total tissue miRNA signatures differ considerably between cancer patients and normal probands, and the profiles of the EMV-associated miRNAs resemble very closely those isolated from the tumors. ${ }^{57}$ Tumor-derived EMVs are known to transfer mRNAs to monocytes within the tumor microenvironment to stimulate these cells for the production of cytokines, resulting in enhanced tumor growth and dampening of the immune response. ${ }^{220}$ EMV-associated miRNAs released from hepatocellular carcinoma cells were shown to induce the downregulation of the transforming growth factor- $\beta$ activated kinase-1 (TAK1) signaling pathway in hepatocarcinogenesis, and thereby may cause the local spreading, intrahepatic metastases, and multifocal growth in hepatocellular carcinoma. ${ }^{218}$ Tumor-released EMVs were found to be a prerequisite for the promotion of tumor metastasis in the course of proinflammatory cytokine-driven proliferation of myeloid-derived suppressor cells via the MyD88 pathway. ${ }^{223}$ EMVs released from Epstein-Barr virus-infected B95-8 LCL cells and isolated from monocyte-derived dendritic cells were found to induce gene silencing in the acceptor cells. ${ }^{222}$ Macrophages have been reported to increase the invasiveness of breast cancer cells by EMV-mediating transfer of oncogenic miRNAs from the macrophages to potential cancer cells. ${ }^{225}$ mRNAs from endothelial-derived EMVs have been found to exert proangiogenic effects. ${ }^{226}$ 
An additional link between EMVs and miRNAs has recently become apparent in immunology and virology research. EMVs released from human and murine mast cell lines were found to harbor over $1200 \mathrm{mRNA}$ and about 121 miRNA species. ${ }^{215}$ EMVs released from donor dendritic cells were reported to dock to and fuse with target dendritic cells and to transfer their contents into the target cells under accompanying specific silencing of the miRNA-targeted genes. ${ }^{227}$ miRNA-harboring EMVs released from stromal cells have been shown to support quiescence of B-cells. The apparent transfer of miRNAs from bone marrow stroma to B-cells could be involved in the dormancy of bone marrow metastases. ${ }^{224}$ The presence of viral miRNAs in EMVs is evidence that they may function as vesicular carriers for spreading of the disease or initiation of the infection process. ${ }^{228,229}$ Thus, there is increasing evidence that EMV-associated miRNAs function in the acceptor cells following their transfer. Based on the unique and specific signatures of the transferred EMV-associated miRNAs, their use as biomarkers in screening tests for the prediction and prognosis of cancer and other diseases has been proposed.

\section{EMVs as biomarkers \\ General considerations}

The following characteristics argue for the potential of EMVs as a promising source for new biomarkers: (1) EMVs are identifiable and isolatable on the basis of typical intrinsic and well-defined properties, such as phosphatidylserine content, size, sedimentation behavior; (2) EMVs are specific with regard to the expression of cell-lineage markers as well as the overall molecular composition and patterns of their luminal and surface contents; (3) EMV signatures critically depend on the stimulation and micro-environment of the donor cells; (4) EMVs are initial and rapid "responders" since they are released early during stimulatory or micro-environmental changes and in the pathogenic cascade of a disease; (5) EMVs are noninvasive since they are detectable in many body fluids; (6) EMVs are "translatable" since their release is not limited to one cell type or one species; and (7) EMVs act as vectors since they transport and protect biological messages, ie, mRNAs, microRNAs, proteins, and phospholipids, which are normally confined to cells/tissues.

It is well established that for each type of biomarker, its predictive value increases with the number of members of this biomarker type combined as well as with the relative proximity of the time points of biomarker measurement, ie, disease prediction and onset of the disease, ie, diagnosis
(Figure 2). On the basis of the specific structural and functional features of EMVs (see "EMVs as biomarkers: Type II diabetes" and "Obesity"), it seems reasonable (albeit still speculative) to assume that EMVs enable prediction with higher probability (compared to genotypic biomarkers) and at earlier time points (compared to phenotypic biomarkers) along the complete pathogenetic pathway, including the initiation, further development, diagnosis, further progression, and outcome of the disease.

\section{Origins and sources}

During the past two decades, the existence of EMVs has been demonstrated in blood and a range of other body fluids, such as urine, saliva, mucus, and breast milk. Consequently, there is an increasing interest in their potential use as tissueborne and easily accessible diagnostic biomarkers for many diseases, including cancer, cardiovascular diseases, and metabolic diseases. ${ }^{116,117,230-242}$ As a prerequisite for the use of EMVs as multi-component biomarkers reflecting different dysfunctional or disease stages of those relevant cells/tissues from which they originate, it is important to understand the critical parameters and molecular mechanisms involved in their passage from the donor cells into the corresponding body fluid (Figure 7).

Current estimates of the concentration of EMVs in peripheral blood of healthy probands are $5-50 \mu \mathrm{g} / \mathrm{mL}$. Although the term "microparticles" is neither specific nor fully descriptive, it has been used for the past 30 years and unfortunately remains standard in the current literature on EMVs of the blood. ${ }^{84,242-248}$ Using flow cytometry, it was found that the majority of the peripheral blood EMVs from normal individuals are actually derived from blood cells, particularly platelets (Figures 8 and 9). ${ }^{249,250}$ For instance, about $80 \%$ of the EMVs analyzed in human plasma samples obtained during a clinical study were determined to be of platelet origin, ${ }^{251}$ and the number of nonplatelet-derived (eg, tissue-derived) EMVs were well correlated to the clinical data and disease history of the patients. Initially, plateletderived EMVs were considered to have pathophysiological importance since they expose a multitude of procoagulant anionic phospholipids, such as phosphatidylserine, in a similar fashion as activated platelets and consequently have been the most extensively studied..$^{84,244,247,252}$ In the 1940 s, it was demonstrated that clotting of platelet-deprived plasma was delayed after high-speed centrifugation. ${ }^{253}$ This observation suggested that procoagulant subcellular structures are present in plasma and are removed by sedimentation. Surprisingly, the release of membrane fragments from activated platelets, 


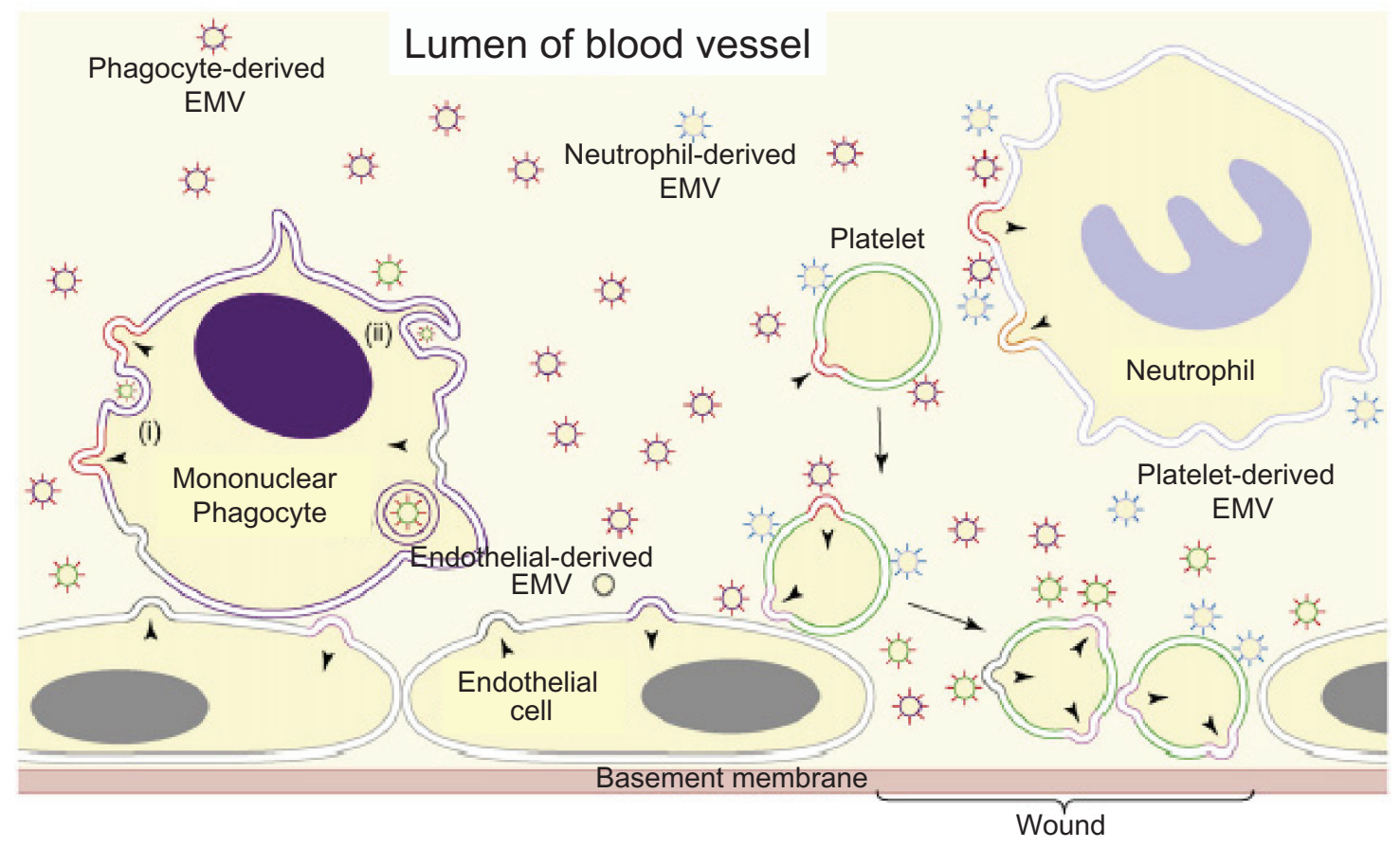

Figure 8 Schematic depiction of the origin of EMVs in the blood. @ 2008, Elsevier. Adapted with permission from Cocucci E, Racchetti G, Meldolesi J. Shedding microvesicles: artefacts no more. Trends Cell Biol. 2008;19:43-51. ${ }^{47}$

Abbreviation: EMVs, exosomes and microvesicles.

thereafter called "platelet dust," was not demonstrated until 1967.254

The second-largest population of blood EMVs is derived from the mononuclear phagocyte cell lineage (Figures 8 and 9). In contrast, only a small percentage of the peripheral blood EMVs originates from T-cells and

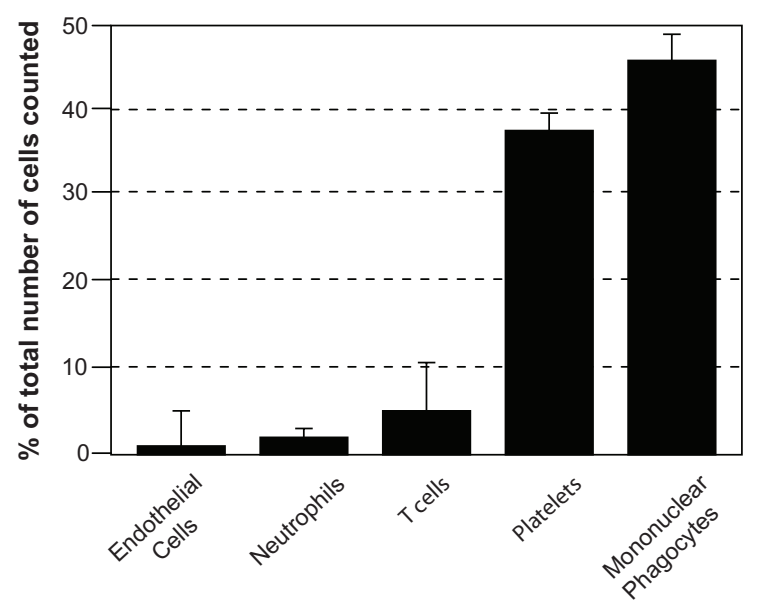

Figure 9 Analysis of the origin of peripheral blood EMVs.

Notes: EMVs from the peripheral blood of healthy donors were analyzed by flow cytometry on the basis of staining for CD3, CD202b, CD66b, CD79a and CD4Ia to delineate their release from T-cells, endothelial cells, neutrophils, B-cells and platelets, respectively, or for CDI4, CD206, CCR3, CCR2/5 to reveal their release from mononuclear phagocytes. ${ }^{406-412}$

Abbreviation: EMVs, exosomes and microvesicles. neutrophils. A small subpopulation of blood EMVs seems to be released from endothelial cells according to the expression of corresponding cell surface antigens, ${ }^{251}$ in contrast to the massive EMV production observed with human endothelial cells in vitro. ${ }^{255-257} \mathrm{~B}$-cells do not seem to contribute to EMVs to any significant degree.

In addition to blood, urine is one of the most useful sources for EMVs, which are assumed to be released by tubular epithelial cells. It is of tremendous advantage that their collection is simple and noninvasive by nature. Urinary EMVs, the majority of which are thought to represent exosomes, have recently been the subject of intense proteomic analyses. ${ }^{258-260}$ Interestingly, aquaporin-2 has recently been identified in urinary EMVs, but not in EMVs from other sources. ${ }^{261}$ Thus, aquaporin-2 positive EMVs may be useful as biomarkers for renal dysfunction and structural injury as they typically develop during diabetic nephropathy.

The transport pathway of platelet-, blood cell-, and endothelial cell-derived as well as tubular epithelial cellderived EMVs into the circulation and urine, respectively, appears to be straightforward. In contrast, the mechanism of how EMVs released from tissue cells reach the blood is intriguing since these EMVs have to transit vascular endothelial cells during their passage from the interstitial space into the circulation. The transport of EMVs across 
endothelial cells may occur via (1) the transcellular route involving transport vesicles, which are generated by endocytosis of the plasma membrane and subsequently fuse with the opposite plasma membrane; or (2) the paracellular route involving the transient opening of tight junctions in course of direct interaction with certain protein components (Figure 7). Recently, the operation of a third pathway has become conceivable based on the observation that small leucine-rich proteoglycans, such as biglycan and decorin, as secreted components of the extracellular matrix critically affect the communication between neighboring tissue cells in the course of their continuous formation and degradation. ${ }^{262-264}$ Hence, biglycan and decorin seem to regulate the active and passive transport of nutrient and hormones ${ }^{265,266}$ and possibly also of EMVs. Interestingly, biglycan was found to be elevated in obese artherosclerotic mice, ${ }^{267}$ in rats with metabolic syndrome, and in type II diabetes patients ${ }^{268,269}$ compared to controls. Its prominent expression in stromal vascular cells of visceral adipose tissue suggests that the expression level of biglycan and other components of the extracellular matrix may modulate the efficacy of EMV transfer from donor to acceptor cells within a tissue depot (eg, from large to small adipocytes) as well as of EMV transport from donor cells into body fluids (eg, from adipocytes into plasma). These pathways and the underlying molecular mechanisms must be delineated for a better understanding of the correlation between the levels of EMVs in body fluids and the pathogenesis of metabolic diseases.

\section{Type II diabetes}

Preclinical studies aimed at finding evidence for the potential usefulness of EMVs as type II diabetes biomarkers demonstrated that: (1) $\mathrm{db} / \mathrm{db}$ mice display significantly higher levels of circulating total and platelet-derived (but not tissue-derived) EMVs compared to $\mathrm{db} /+$ mice; (2) male $\mathrm{db} / \mathrm{db}$ mice treated for 2 weeks with antidiabetic compound and exhibiting significantly elevated body weight gain, diminished blood glucose levels, increased plasma adiponectin levels, and decreased plasma insulin levels have significantly reduced amounts of total and tissue-derived (but not platelet-derived) EMVs; (3) streptozotocin-induced mice exhibit significantly increased levels of circulating total, platelet-derived and tissue-derived EMVs prior to the onset of fully established diabetes; and (4) circulating EMVs increase in levels and change their signature between healthy volunteers and patients suffering from type II diabetes ${ }^{270-272}$ or metabolic syndrome..$^{272-278}$
The development of vasculopathies and endothelial dysfunction during type II diabetes is known to involve multifactorial processes, including the pathological activation of vascular cells. The release of EMVs by activated cells was reported predominantly for diseases associated with thrombotic risk, but few data are available for type II diabetes. Platelet-derived EMVs of both CD42 ${ }^{+}$and CD41 $\mathrm{a}^{+}$ phenotypes as well as monocyte-derived EMVs $\left(\mathrm{CD} 14^{+}\right)$ were found elevated in patients with type II diabetes. ${ }^{279}$ In particular, the latter EMVs were highly increased in patients suffering from diabetic nephropathy and may be indicators of vascular complications. ${ }^{280,281}$ Another study demonstrated sustained, elevated amounts of circulating platelet-derived procoagulant EMVs $\left(\mathrm{CD}^{4} 2^{+}\right)$after acute myocardial infarction in diabetic patients, which were higher than in nondiabetic patients with myocardial infarction. ${ }^{282}$ Tissue factor-positive EMVs associated with $\mathrm{T}_{\mathrm{H}}$ cell-derived $\left(\mathrm{CD}^{+}\right)$, granulocyte-derived $\left(\mathrm{CD}_{6} \mathrm{e}^{+}\right)$or platelet-derived $\left(\mathrm{CD} 1^{+}\right)$ antigen were significantly increased in early type II diabetes when compared with healthy control subjects. ${ }^{283}$ Importantly, EMV numbers did not correlate with in vivo coagulation markers, but correlations were found between various tissue factor-positive EMV subpopulations and several components of the metabolic syndrome, such as body mass index, fasting plasma glucose, insulin, TNF- $\alpha$, and serum HDL cholesterol. This hints at a diabetogenic role that is distinct from the procoagulant role of the detected tissue factor antigen.

In addition, significant differences have been demonstrated in the number and the procoagulant activity of circulating EMVs between type I and II diabetic patients. ${ }^{280,284,285}$ When compared with control subjects, type I diabetic patients presented significantly higher numbers of plateletderived EMVs $\left(\mathrm{CD} 41^{+}\right)$, endothelial cell-derived EMVs $\left(\mathrm{CD} 51^{+}\right)$, and total phosphatidylserine-positive EMVs as well as elevated levels of EMV-associated procoagulant activity. In contrast, in type II diabetic patients, only the number in phosphatidylserine-positive EMVs was significantly higher without concomitant increase of their procoagulant activity. ${ }^{286}$ Importantly, in type I diabetic patients, only procoagulant activity associated with phosphatidylserine-positive EMV was correlated with the level of glycated hemoglobin, suggesting that procoagulant activity is associated with impaired glucose tolerance and homeostasis. ${ }^{287}$

Previous reports have indicated that high levels of plasma dipeptidyl peptidase-IV (DPP-IV), also known as CD26, are positively correlated with type II diabetes. DPP-IV degrades the active form of the incretin, glucagon-like peptide-1, 
which is released from intestinal L-cells after meal intake and enhances insulin secretion in a glucose-dependent manner (Table 3). DPP-IV inhibition causes blood glucose decrease in animal models of diabetes and type II diabetic patients. The DPP-IV inhibitors sitagliptin and vildagliptin are currently widely used as an adjunct to diet and exercise to improve glycemic control in type II diabetic patients. ${ }^{288,289}$ DPP-IV is a membrane-associated peptidase highly expressed in the brush border and microvillar fractions of the kidney cortex. Recent findings showed that in urine, EMV-associated DPP-IV represents the major portion of urinary DPP-IV activity. ${ }^{290,291}$ The excretion of this urinary EMV-associated DPP-IV was significantly higher in type II diabetic patients compared to control probands. ${ }^{291}$ The urinary levels of EMVassociated DPP-IV were found to be positively correlated with the urinary albumin/creatinine ratio in type II diabetic patients. ${ }^{292,293}$ These results suggest that the urinary level of EMV-associated DPP-IV is associated with and may be used for the prediction of the development and outcome of diabetic nephropathy.

The potential of EMV-associated miRNAs as biomarkers for type II diabetes can be indirectly inferred from the known multiple roles of miRNAs in the regulation of lipid and glucose metabolism. These were revealed by a multitude of in vitro and in vivo (mice) studies, which used the delivery of miRNA precursors or antagomirs ${ }^{97}$ into cells to overexpress or silence the miRNAs of interest and to evaluate their application to therapy. ${ }^{294,295}$ For instance, the blockade of miR-122 expression by systemic administration of an miR-122 antagomir oligonucleotide caused considerable lowering of plasma cholesterol levels as well as hepatic fatty acid and cholesterol synthesis rates in normal mice, leading to diminished levels of triglycerides and hepatic steatosis in diet-induced obese mice. ${ }^{296}$ Consequently, the mice appeared to be in good health after 4 weeks of therapy with the antagomirs. Furthermore, the expression of miR-103/107 was found upregulated in obese insulin-resistant ob/ob mice. ${ }^{297}$ The specific and efficient silencing of miR-103/107 in liver and fat by delivery of cholesterol-conjugated anti-miR antagomir significantly improved glucose homeostasis and insulin sensitivity in ob/ob as well as diet-induced obese, but not chow-fed wild-type mice compared to scrambled or mismatched antagomirs. Interestingly, as a consequence of the downregulation of miR-103/107, the amount of caveolin-1, a positive regulator of insulin receptor signaling, becomes elevated in parallel with improved insulin signaling, reduced adipocyte size, and upregulated insulin-stimulated glucose transport. ${ }^{297}$ These findings argue for the potential use of specific miRNAs as biomarkers for the development of insulin resistance and type II diabetes, in particular, if the miRNAs are incorporated together with other typical EMV components into circulating EMVs.

In summary, the currently available experimental evidence strongly argues for the usefulness of EMVs, particularly those released into the plasma and urine, as specific biomarkers for the pathogenesis of type II diabetes. Moreover, there is an urgent need to detect those EMVs that originate from disease-relevant tissues, are released into accessible body fluids and have already increased in number in the prediabetic state. ${ }^{298-300}$ Putative candidates for relevant EMV donor cells and tissues are pancreatic islets, particularly $\beta$-cells, liver, skeletal muscle, adipose tissue, smooth muscle cells, vascular endothelial cells, and tissue and plasma macrophages. The future challenge will be to identify the EMV signatures that are specific to those cells and tissues causally involved in the pathogenesis of type II diabetes and/or reflecting the temporal and individual disease states.

\section{Obesity}

The increased prevalence of obesity in present day society and the current view of adipose tissue as one of the most critical regulators of energy homeostasis and metabolism have warranted a sustained interest in studying the mechanisms controlling its formation. In general, obesity can be regarded as the consequence of a long-lasting imbalance between energy intake and energy expenditure, finally leading to the storage of the surplus energy as triacylglycerol in the adipocytes, which thereby undergo both hypertrophy and hyperplasia. Clearly, both adipocyte hypertrophy and hyperplasia is now generally accepted to be involved in the dramatic increase in adipose tissue mass in obese as well as type II diabetic patients. ${ }^{301}$ The underlying molecular mechanisms and defects have not yet been fully elucidated. Interestingly, they may encompass the paracrine exchange of information about the lipogenic vs lipolytic state between large and small adipocytes within adipose tissue depots via adipokines and/or EMVs. ${ }^{302,303}$

Alterations in the number and size of adipocytes are typically accompanied by changes in the expression patterns for subsets of miRNAs. For instance, during adipocyte differentiation, the levels of miR-130b and miR-210 were found to be decreased in both lean and obese probands. Levels of miR-222 were decreased in lean probands but increased in obese subjects. ${ }^{304,305}$ Levels of miR-103, miR-107, miR143, and miR-185 were upregulated in the lean state but downregulated in the obese state. ${ }^{304,305}$ Interestingly, from the 
miRNAs analyzed so far, only miR-34a has been found to be positively correlated with the rate of adipocyte differentiation and development of the BMI. ${ }^{305}$ The expression of the majority of these miRNAs is known to be controlled by certain adipokines, such as TNF $\alpha$ that downregulates miR-103 and miR-143 and upregulates miR-221 and miR-222. ${ }^{304}$

It was recently found that EMVs released from dysfunctional and hypertrophic adipocytes manage to impair the function of vascular endothelial cells, which may have implications for the development of obesity-linked complications. For instance, EMVs released from primary rodent adipocytes were demonstrated to stimulate angiogenesis in vivo. ${ }^{306}$ Strikingly, as revealed by antibody arrays and gelatin zymographic analyses, these EMVs harbored a multitude of angiogenic and antiangiogenic adipokines, growth factors and enzymes, such as leptin, TNF $\alpha$, acidic fibroblast growth factor- $\gamma$ and matrix metalloproteases- $2 / 5$. Upon incubation with human umbilical vein endothelial cells, these EMV cargo proteins promoted the induction of cell migration and tube formation, but only in combination after the removal of leptin, TNF $\alpha$, or fibroblast growth factor- $\gamma$ by neutralizing antibodies, which caused abrogation of the angiogenic effect to a major degree. ${ }^{306}$ Moreover, a subset of miRNAs (let-7b, miR-103/143/146b/148/155/221) was found associated with those EMVs. ${ }^{307}$ Surprisingly, let-7b, miR-143, miR-155, and miR-221 are known to play similar roles in the control of cell proliferation, apoptosis, inflammation and angiogenesis in adipose and vascular tissues. ${ }^{308}$ Consequently, it may be proposed that these tissues communicate via EMVs that are released from donor adipocytes and targeted to vascular endothelial acceptor cells. ${ }^{308}$ This hypothesis gained further credit upon the recent finding that EMVs isolated from plasma and peripheral blood monocytes share the expression of 71 miRNAs, ${ }^{87}$ the majority of which regulate the differentiation of blood cells, immune functions, and metabolic pathways. Furthermore, a few other EMV-associated miRNAs derived from adipocytes, endothelial cells, or monocytes have been detected in the plasma and demonstrated to affect the function and phenotype of the corresponding acceptor cell type. ${ }^{215,309}$

However, in comparison with the approximately 400 studies that revealed differential miRNA expression profiles during different cardiovascular disease states and the limited number of medically attractive EMVassociated miRNAs left for the prediction and prevention of cardiovascular diseases so far, ${ }^{309-313}$ even fewer EMVassociated miRNA candidates have been reported to date as being differentially expressed in and released from adipose tissue cells in the course of obesity development. In particular, miRNAs have also been recognized as regulators of adipocyte metabolic integration, energy homeostasis, and differentiation (Table 8) ${ }^{314-315}$ For instance, the expression of 50 out of 70 miRNAs was found to significantly differ between human pre- or mature adipocytes from lean and obese individuals. ${ }^{311}$ Moreover, EMVs released from cultured 3T3-L1 adipocytes have been reported to harbor about 140 miRNAs. ${ }^{305}$ The majority of them were adipocytespecific, abundant in correlation with their expression level in the donor cells, and considerably upregulated during adipocyte differentiation in vitro. ${ }^{316,317}$ Interestingly, these apparently adipocyte-derived EMVs also seem to mediate the transport of mRNAs coding for adiponectin, resistin and PPAR $\gamma$ into cultured macrophages and to induce angiogenesis. ${ }^{318-321}$ In addition, adipocyte-specific mRNAs and miRNAs have also been detected in EMVs isolated from rat serum. ${ }^{302,322,323}$

Table 8 Functions of dysregulated miRNAs in adipose tissue

\begin{tabular}{lll}
\hline miRNA & Function & References \\
\hline let-7 & Adipogenesis, angiogenesis, inflammation & $94,395,396$ \\
miR-17 & Adipogenesis, differentiation, insulin resistance & 3 I3,397 \\
miR-2I & Adipogenesis, apoptosis, inflammation & 398 \\
miR-27b & Adipogenesis, adipocyte dysfunction & 399 \\
miR-34a & Adipogenesis & 305 \\
miR-92 & Adipogenesis & 397 \\
miR-125b & Adipogenesis, adipocyte dysfunction, inflammation & 305 \\
miR-130a & Adipogenesis & 400 \\
miR-132 & Inflammation, insulin resistance & $40 I, 402$ \\
miR-143 & Adipogenesis, adipocyte dysfunction, proliferation \\
miR-155 & Apoptosis, inflammation, oxidative stress & 300,398 \\
miR-2I0 & Adipogenesis & $40 I, 403$ \\
miR-22I & Adipogenesis, adipocyte dysfunction, angiogenesis, inflammation & 305 \\
miR-222 & Adipogenesis, adipocyte dysfunction, angiogenesis, inflammation & 305,404 \\
\hline
\end{tabular}


Moreover, EMV-associated miRNAs seem to play key roles in the proper functioning of adipocytes and vascular endothelial cells as well as adhesion, apoptosis, oxidative stress, hypoxia, and infiltration of inflammatory cells (Table 8). The similarity in the apparent effects of EMVassociated miRNAs on adipose and vascular tissues raises the possibility of the operation of parallel molecular mechanisms in adipocytes, vascular cells, and macrophages. Apparently, lipid storage and handling varies among adipocytes (triacylglycerols), macrophages, and smooth muscle foam cells (cholesterylesters). However, rather than the species of the accumulated lipids, changes in their amount per se may trigger phenotypic and functional alterations. This view was supported by the observation that the initial expansion of adipose tissue is accompanied by the emergence of M2-polarized adipose tissue macrophages, whereas in the course of further adipose tissue enlargement (as a consequence of both adipocyte hypertrophy and hyperplasia), the mere deposition of lipids of the same species in these macrophages induces their M1 polarization. ${ }^{324}$ This conversion of the macrophage phenotype associated with obesity-induced insulin resistance, inflammation, and severe oxidative stress may be further enhanced by lowered levels of adiponectin. This adipokine is known to be preferentially released from small instead of fully lipid-loaded adipocytes ${ }^{303,325}$ and to improve the metabolism of macrophages through its antidiabetic and anti-inflammatory activities. ${ }^{326}$ Hence, EMVs derived from adipocytes, vascular cells and macrophages, and harboring miRNA constituents seem to reflect the functional state of the adipose tissue and thereby may be useful for following the development of obesity.

The posttranscriptional cascade governing adipogenesis, ie, the differentiation of adipocytes from precursor cells and their subsequent maturation from small unilocular (ie, containing many small LDs) to large multilocular (ie, containing few large LDs) cells has been extensively studied for many years. ${ }^{327}$ Novel findings suggest the involvement of EMVs in the control of maturation of rodent adipocytes within adipose tissue depots in vitro. ${ }^{146-149,300,302,307,321,328}$ In particular, the release of EMVs from primary and cultured rat and mouse adipocytes has been demonstrated to undergo considerable upregulation upon challenge with physiological stimuli, such as excess of fatty acids (palmitate) and reactive oxygen species $\left(\mathrm{H}_{2} \mathrm{O}_{2}\right)$, as well as pharmacological agents, such as the antidiabetic drug, glimepiride. ${ }^{206-210}$ These adipocyte-derived EMVs are thought to regulate lipid metabolism between large and small adipocytes within the same adipose tissue depot during the transfer of some of their constituent components (Figure 10). Among them are the GPI-anchored cAMPspecific phosphodiesterase, Gce1, and 5'-nucleotidase, CD73 (Table 6), which in concerted fashion catalyze (c) AMP degradation, ${ }^{145,146,328}$ and the mRNAs coding for GPAT3 and FSP27, which drive lipid synthesis and LD biogenesis, respectively, ${ }^{329-334}$ as well as the miRNAs, miR-16, and miR-222, which have been implicated in the coordination of lipid metabolic pathways. ${ }^{292,300,322}$ The underlying mechanisms encompass (1) the release of those EMVs from preferentially large donor adipocytes; (2) the interaction, fusion or endocytosis of those EMVs (Figure 7) with or by, respectively, preferentially small acceptor adipocytes; (3) the translocation of Gce1 and CD73 from the (lipid rafts of the) EMV membranes to intracellular LDs of the acceptor adipocytes as well as the delivery of the GPAT3- and FSP27-encoding mRNAs and miR-16/222 from the EMV lumen to the cytoplasm of the acceptor adipocytes; (4) the degradation of (c)AMP at the LD surface zone by Gce1 and CD73 (Table 6); and, finally, (5) the upregulation of fatty acid esterification at the LDs and downregulation of fatty acid release from the LDs by concerted action of GPAT3 and FSP27 enzymic and structural activities, respectively, by decreasing of the cAMP levels and by miR-16/222 expression in the acceptor adipocytes. ${ }^{145-149,207-209,302}$ These findings strongly argue that EMVs transfer lipogenic and antilipolytic information from large to small adipocytes to shift the burden of lipid loading within adipose tissue depots during certain (patho)physiological states (Figure 10). ${ }^{328}$ Among them are excessive fatty acid intake, antidiabetic pharmacotherapy, and exposure to cellular oxidative stress, which are well known to accompany or foster the obese state. The measurement of these adipocyte-derived EMVs in the adipose tissue depots or, more practicably, in the plasma if they became adequately released into this compartment, could provide helpful information for the prediction of obesity long before the body mass index and the waist-tohip ratio increase considerably. In fact, EMV levels were reported to be increased in the serum of slightly overweight women compared to normal age-matched controls and suggested to account for the significantly increased risk for obesity-linked (eg, thrombotic) complications during later and advanced obesity in this population. ${ }^{335,336}$

\section{Epigenetic control}

To date obesity has been studied predominantly from a thermoenergetic point of view, taking into consideration the imbalance between energy intake and energy expenditure, 


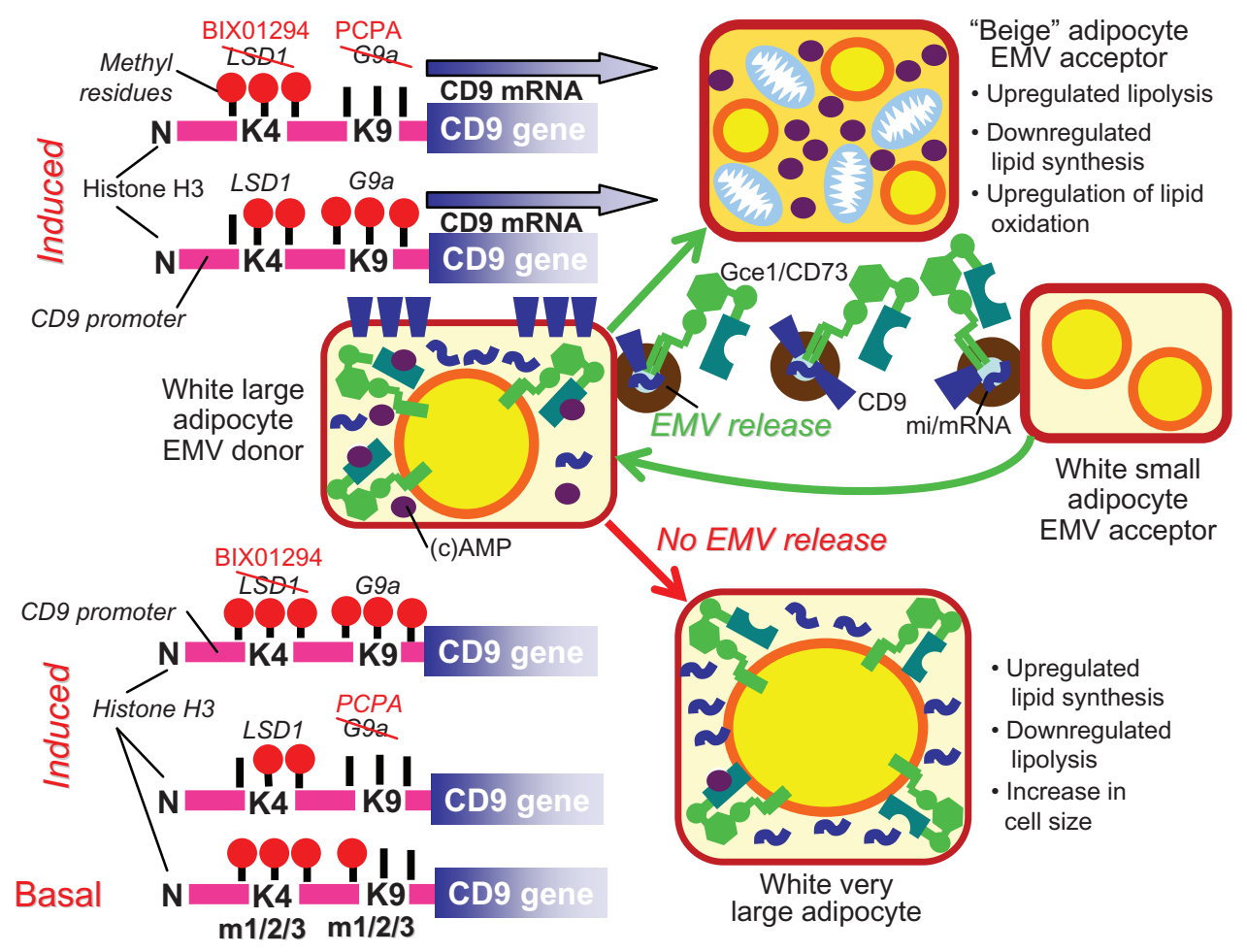

Figure 10 Hypothetical model for the regulation of lipid storage and lipid oxidation in adipose tissue depots consisting of large and small white adipocytes by the release of EMVs harboring miRNAs $s^{207-212}$ under the epigenetic control of CD9 expression and their paracrine action (see text for details).

Abbreviation: EMVs, exosomes and microvesicles.

which is determined by complex interrelationships between gene mutations/polymorphisms and lifestyle. The putative involvement of epigenetic mechanisms - ie, of inheritable alterations in gene expression that are manifest in the absence of changes in the DNA nucleotide sequence itself in the development of obesity - has only recently begun to attract attention..$^{337,338}$ The underlying molecular mechanisms include (but are not restricted to) covalent post-translational modifications of the histone amino-terminal tails, ${ }^{339-341}$ in which lysine methylation either enhances or silences the transcriptional state of a given gene, depending on the modified residue. In particular, methylation of lysine 4 of histone H3 (H3K4) usually correlates with gene activation, whereas methylation of lysine 9 of histone $\mathrm{H} 3$ (H3K9) is typically associated with transcriptional silencing. ${ }^{341-346}$

With regard to obesity, an adverse environment during in utero or lactation periods is generally assumed to affect its future development, suggesting that the mother's nutrition or perinatal lifestyle could alter the developmental programming of the fetus and pubs. ${ }^{337}$ In contrast, the role of adverse environment (eg, nutrition, physical activity, cellular stress, pharmacotherapy) during postnatal growth and adulthood for the modification of the epigenetic pattern remains a matter of debate. Thus, changes in histone methylation patterns could be the result of the interplay of various dietary and environmental factors and provide a source of interindividual differences with respect to the efficacy of adipogenesis and adipocyte differentiation ${ }^{345-349}$ and ultimately explain the differential susceptibility of genetically similar individuals to develop obesity. ${ }^{337,350}$

However, it is disappointing that despite the assignment of some miRNAs to critical functions in the epigenetic control of adipogenesis and obesity ${ }^{307,322,337,338}$ and the identification of other miRNAs in EMVs released from adipocytes and circulating in various body fluids, ${ }^{302,307,322}$ experimental evidence for the involvement of EMVs as putative carriers of epigenetic information between somatic cells in para- or endocrine fashion has not been reported so far. However, recent findings of the regulation of cell size and lipid metabolism between large and small rat adipocytes by EMVs harboring specific GPI-anchored proteins, mRNAs, and miRNAs $\mathrm{s}^{300,302}$ raised the possibility that the transfer of EMVs in response to certain environmental stimuli is under epigenetic control (Figure 10). A recent study demonstrated that in the course of long-term incubation with inhibitors of either $\mathrm{H} 3 \mathrm{~K} 9$ methylation or $\mathrm{H} 3 \mathrm{~K} 4$ demethylation, the palmitate-, glimepiride-, and $\mathrm{H}_{2} \mathrm{O}_{2}$-induced release of those EMVs from large primary rat and differentiated 
human adipocytes is significantly reduced. ${ }^{212}$ These results emphasized the putative epigenetic control of adipogenesis with emphasis on the late maturation stage of lipid storage and increased cell size.

The putative functional consequences of the apparent epigenetic regulation of the induced (by fatty acids, oxidative stress, glimepiride) EMV release for large and small adipocytes within an adipose tissue depot can be summarized in the following working model (see also Figure 10): large white donor adipocytes release EMVs harboring the GPI-anchored proteins, CD73 and Gce1, GPAT3 and FSP27 mRNAs, and miR-16 and miR-222. The loss of these EMV components from the large donor adipocytes leads to the upregulation of lipolysis (as a consequence of increased levels of cAMP at the LD surface zone) and downregulation of lipid synthesis (as a consequence of decreased levels of GPAT3 and FSP27 proteins), which trigger the degradation of LDs and eventually the induction of the brown adipose tissue-like phenotype. ${ }^{351}$ The release of these EMVs from the large donor adipocytes is blocked by modulation of their histone $\mathrm{H} 3$ methylation state (eg, in the course of G9a or LSD1 inhibition). The retention of these EMV components in the large donor adipocytes supports the downregulation of lipolysis (as a consequence of decreased levels of cAMP at the LD surface zone) and upregulation of lipid synthesis (as a consequence of increased levels of GPAT3 and FSP27), which lead to LD biogenesis and elevation of the cell size. The EMVs fuse preferentially with the plasma membranes of small white (pre)adipocytes. Thereby, the EMVs will deliver the GPAT3/FSP27 mRNAs and miR-16/222 miRNAs into the cytoplasm and translocate the GPI-anchored proteins, CD73/Gce1, onto the LD surface of the acceptor adipocytes. Consequently, GPAT3 and FSP27 protein expression becomes upregulated in parallel with degradation of (c)AMP at the LD surface zone, resulting in the direct stimulation of lipid synthesis and inhibition of lipolysis (Figure 10). The consequent promotion of $\mathrm{LD}$ biogenesis drives the increase in cell size of the (initially small) adipocytes and contributes to the stabilization of their white adipose tissue-like phenotype. ${ }^{352,353}$ Upon blockade of the release of the EMVs from large white adipocytes (as provoked experimentally by BIX01294 or tPCPA) or of their transfer to and fusion with the plasma membranes of small white adipocytes (as provoked experimentally by [c]AMP-Sepharose ${ }^{208,209}$ or di-annexin ${ }^{354}$ ), the lack of upregulation of FSP27 and GPAT3 protein expression in concert with elevated levels of cAMP at the LD surface zone fosters lipolysis and impairs lipid synthesis. These regulatory events are linked to the stimulation of mitochondrial biogenesis and blockade of LD biogenesis, respectively, which ultimately lead to the induction of the brown adipose tissue-like or "beige" phenotype (Figure 10). The validity of this working model has to be examined in vitro and in vivo using human adipocytes and rodent animal models that enable monitoring of adipocyte hypertrophy in response to supraphysiological concentrations of palmitate and reactive oxygen species or pharmacological concentrations of glimepiride.

Based on present and previous findings, it is already conceivable that the release of EMVs from large donor adipocytes or/and their fusion with small acceptor adipocytes within adipose tissue depots can be used as a biomarker tool for the prediction of the epigenetically controlled lipogenic/adipogenic state of this adipose tissue depot, and, in the case of EMV release from the depot into the circulation, of the whole organism. At present, only a limited number of effector molecules and tool compounds are known to modulate EMV release or fusion, ${ }^{207-209,355}$ among them the antidiabetic sulfonylurea drug, glimepiride. The determination of adipocyte-derived EMVs in the blood of type II diabetic patients treated with glimepiride ${ }^{356}$ could enable the prediction of their risk for developing obesity.

\section{Measurement}

\section{General considerations}

For the purpose of disease prediction, it is sufficient to find correlations between distinct disease states and subsets of EMVs of specific and unique composition, ie, EMV signatures. Importantly, there is no need for the elucidation of the overall molecular composition of the EMVs (ie, the identity of each constituent) and of their cellular/tissue origin. Of course, this information may turn out to be very valuable for a better understanding of the disease mechanism if the EMVs are causally associated. However, the currently available technologies for the analysis of EMVs rely on their (1) biochemical composition as predominantly revealed by (shotgun) transcriptomics, proteomics and lipidomics and the constituting basic methods of one- and two-dimensional electrophoretic separations, (LC-)MS/MS, nanoLC, Q-TOF, MALDI-TOF/ TOF, and state-of-the-art data mining in combination with gene expression studies performed with the candidate donor cells; (2) size, mass and morphology; (3) cellular origin; and (4) flow cytometry. ${ }^{318-321,357-363}$ These technologies manage the biased elucidation of the exact nature of selected constituents, but only in a limited number. It is of crucial 
importance to considerably increase the discriminative power of future EMV analytics by the generation of multidimensional patterns reflecting the overall constituent signatures of a given EMV species as is typical for type I biomarkers (see "Biomarkers: Definitions"). This demand may be met with the introduction of so-called "nanoparticle tracking" and "chemical noses," which are already in use for the analysis of complex macromolecules, small vesicles, cell surfaces, and microorganisms for research purposes. ${ }^{364-369}$

\section{Biosensors}

The principal mode of operation of a biosensor for the generation of EMV signatures based on "chemical noses" is as follows (Figure 11A): EMVs isolated from the body fluids of healthy control probands and patients (ie, suffering from type II diabetes) will compete with a selected reporter enzyme, such as glucose oxidase for interaction with nanoparticles. These consist of a gold core with covalently attached tentaclelike aliphatic, positively charged and aromatic substituents

A

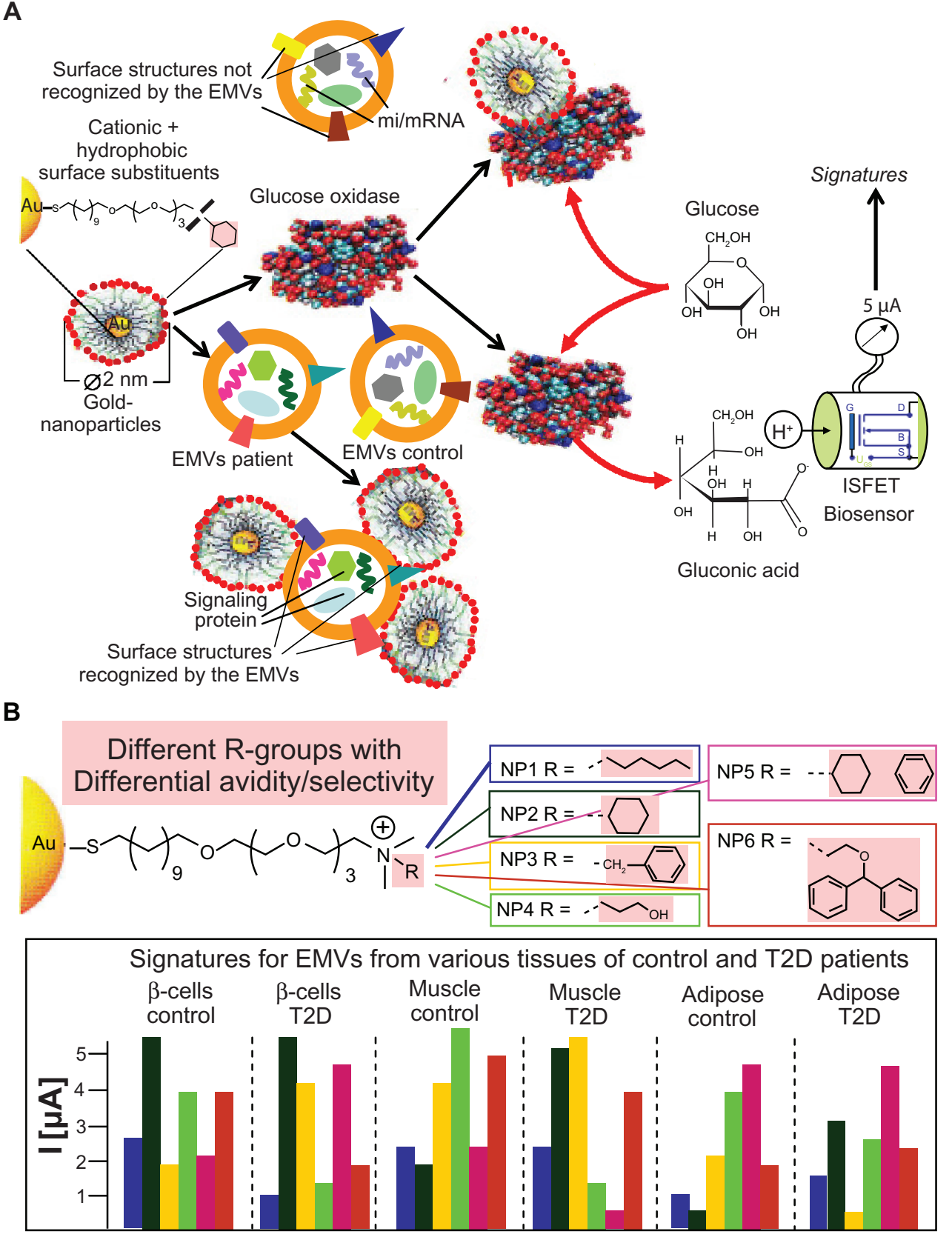

Figure II Schematic depictions of the operation of a nanoparticle-based biosensor for the identification of EMV signatures. (A) Detection principle. The sizes of the nanoparticles versus EMVs are not drawn at scale. (B) Generation of signatures specific for EMVs from different tissues from normal and type II diabetic patients (see text for details).

Abbreviations: EMVs, exosomes and microvesicles; ISFET, ion-sensitive field effect transistor; T2D, type II diabetes. 
at their surface, and are capable of interacting with the proteinaceous and lipidic surface structures of EMVs. Moreover, it seems likely that nanoparticles equipped with similar but uncharged substituents can cross the phospholipid bilayer of the EMVs and finally interact with the protein and mi/mRNAs contents in the lumen of the EMVs. The high-avidity interactions of the differentially substituted nanoparticles with the EMV constituents are apparently based on multiple hydrogen, electrostatic, hydrophobic, and van der Waals bonds.

In the case of nanoparticles interacting with glucose oxidase that has higher avidity and specificity than EMVs have, the reporter enzyme becomes inhibited, eg, through steric hindrance of substrate (ie, glucose) access to its binding cleft/catalytic site (Figure 11A). Alternatively, the nanoparticles may prefer interacting with one or the other of the EMVs contained in the sample in differential fashion rather than with each species with the same avidity. Consequently, this nanoparticle species will dissociate from glucose oxidase, relieving it from inhibition. The resulting glucose oxidase activity is quantitatively evaluated by monitoring the generated protons using a biosensor chip based on ion-sensitive, field-effect transistor technology. ${ }^{367,368}$ Upon incorporation into microfluidic cards and lab-on-thechips, EMV populations can be characterized in a highthroughput format. The measured currents will finally be transformed into EMV-specific signatures (Figure 11B).

A single nanoparticle species will usually not be sufficient for the unequivocal identification of the desired EMV species. More likely, the use of a single or a few nanoparticle species results in more or less similar or even identical signatures due to overlapping recognition patterns and similar surface structures among the various EMV species. However, the discriminative power can be drastically increased by the inclusion of a multitude of nanoparticle species that differ considerably in their surface substituents in hydrophobicity, hydrogen donors/acceptors, and charges. The combination of the different signals provided by separate cycles of biosensor read out will create signatures typical for EMVs from distinct cellular/tissue origin and reflecting the distinct stages of the various disease pathways causing type II diabetes and obesity (Figure 11B).

\section{Conclusion}

The physiological function of EMVs is probably intercell signaling through specific interactions with target cells and transferring of biological information encoded in transmembrane, soluble and GPI-anchored proteins,
mRNAs, miRNAs, and phospholipids. Therefore, EMVs may participate in pathogenic processes, such as the development of metabolic diseases. Further insights into the molecular signatures and specificities of distinct EMV species may allow the identification of their cellular origin and contribute to the elucidation of novel drug targets for metabolic diseases. For instance, the removal from plasma of harmful EMVs may be beneficial during the development of type II diabetes and obesity, in which EMVs apparently deliver thrombogenic and inflammatory signals.

In addition, an increasing body of experimental evidence indicates the possibility that EMVs may offer predictive, diagnostic, and prognostic information for metabolic diseases, such as type II diabetes and obesity. The appearance of EMVs in body fluids makes them readily accessible. Their number, cellular origin, composition, and function seem to depend on and correlate with individual disease stages. In fact, EMV levels are positively correlated with type II diabetes and obesity and, in particular, accompany or even induce the development of diabetes- and obesity-linked complications. This finding is based on the demonstration of (1) quantitative differences in circulating EMVs in various animal disease models; (2) changes in circulating EMV levels occurring prior to the onset of atherosclerotic or diabetic symptoms; and (3) differential modulation of the EMV signature in course of pharmacological interference. Analyses of plasma (and, if feasible, tissue) samples from various cohorts of patients at very early to late stages in disease development and recruited for a multitude of clinical studies should be initiated for (1) comparisons between the different pathophysiological states along cross-sectional studies; and (2) follow-up studies for the pathogenesis along longitudinal studies for several years after the recruitment.

On the other hand, and not addressed in this review, EMVs derived from stem cells may reprogram altered functions in target cells, suggesting that they could be exploited in regenerative medicine to repair damaged tissues. ${ }^{370}$ In addition, EMV-mediated transfer of genetic information could explain the observed plasticity and the functional effects of stem cells without the need for their transdifferentiation into tissue cells. ${ }^{371,372}$

Many issues remain to be clarified, such as (1) the stimuli and the molecular mechanisms that regulate the assembly of the EMVs and their bioactive load that they transfer from donor to acceptor cells; (2) the stimuli that trigger the release of the EMVs from donor cells; (3) the nature of the surface receptors at the acceptor cells that confer exquisite specificity; (4) the complete diagnostic potential of EMVs for the whole 
range of metabolic diseases; (5) the strategies to prevent the formation or to induce the removal from the circulation of potentially harmful EMVs; and (6) the therapeutic exploitation in regenerative medicine of the potency of EMVs to modify the phenotype and function of acceptor cells.

The introduction of detection methods that enable the identification of EMV signatures, in-depth characterization, and specific tracking of EMVs in plasma (and other body fluids) derived from cells and tissues, which are relevant for the pathogenesis of metabolic diseases, should be considerably intensified. It is hoped that recognition of the potential of EMVs will open novel perspectives in the prediction, diagnosis, prognosis, and therapy of metabolic diseases.

\section{Disclosure}

The author is an employee of Sanofi Deutschland $\mathrm{GmbH}$ and reports no conflicts of interest in this work.

\section{References}

1. Frank R, Hargreaves R. Clinical biomarkers in drug discovery and development. Nature Drug Discov. 2003;2:566-580.

2. Biomarker Definitions Working Group. Biomarkers and surrogate endpoints: Preferred definitions and conceptual framework. Clin Pharmacol Ther. 2002;69:89-95.

3. Müller G. Personalized strategies for the diagnosis and therapy of type II diabetes and obesity. Immun Endoc Metab Agents Med Chem. 2012;12: 80-109.

4. Jorgensen JT. A challenging drug development process in the era of personalized medicine. Drug Discov Today. 2011;16:891-897.

5. Manolis E, Vamvakas S, Isaac M. New pathways for qualification of novel methodologies in the European Medicines Agency. Proteomics Clin Appl. 2011;5:248-255.

6. Temple R. Are surrogate markers adequate to address cardiovascular disease drugs? JAMA. 1998;282:790-795.

7. Lathia CD. Biomarkers and surrogate endpoints: How and when they might impact drug development. Disease Markers. 2002;18: 83-90.

8. Zineh I, Huang SM. Biomarkers in drug development and regulation: a paradigm for clinical implementation of personalized medicine. Biomark Med. 2011;5:705-713.

9. Ioannidis JP. A roadmap for successful applications of clinical proteomics. Proteomics Clin Appl. 2011;5:241-247.

10. Calligaris D, Villard C, Lafitte D. Advances in top-down proteomics for disease biomarker discovery. J Proteomics. 2011;74:920-934.

11. Colburn WA. Biomarkers in drug discovery and development. From target identification through drug marketing. J Clin Pharmacol. 2003; 43:329-341.

12. Morel NM, Holland JM, van der Greef J, et al. Introduction to systems biology - A new approach to understanding disease and treatment. Mayo Clin Proc. 2004;79:651-658.

13. Naylor S. Biomarkers: current perspectives and future prospects. Expert Rev Mol Diagn. 2003;3:525-529.

14. Zolg JW, Langen H. How industry is approaching the search for new diagnostic markers and biomarkers. Mol Cell Proteomics. 2004;3: 345-354.

15. Trull AK, ed. Biomarkers of Disease. An Evidence-based Approach. 1st ed. Cambridge, UK: Cambridge University Press; 2002.

16. Nohaile M. The biomarker is not the end. Drug Discov Today. 2011;16: 878-883.
17. Lee JM, Han JJ, Altwerger G, Kohn EC. Proteomics and biomarkers in clinical trials for drug development. J Proteomics. 2011;74: 2632-2641.

18. Naylor S. Systems biology, information, disease and drug discovery. Drug Discovery World. 2005;6:23-33.

19. Samuel VT, Shulman GI. Mechanisms for insulin resistance: common threads and missing links. Cell. 2012;148:852-871.

20. Doria A, Patti ME, Kahn CR. The emerging genetic architecture of type 2 diabetes. Cell Metab. 2008;8:186-200.

21. Staiger H, Machicao F, Fritsche A, Häring HU. Pathomechanisms of type 2 diabetes genes. Endocr Rev. 2009;30:557-585.

22. Conen D, Rexrode KM, Creager MA, Ridker PM, Pradhan AD. Metabolic syndrome, inflammation, and risk of symptomatic peripheral artery disease in women: a prospective study. Circulation. 2009;120: 1041-1047.

23. Ridker PM, Buring JE, Cook NR, Rifai N. C-reactive protein, the metabolic syndrome, and risk of incident cardiovascular events: an 8-year follow-up of 14719 initially healthy American women. Circulation. 2003;107:391-397.

24. Holvoet P, Kritchevsky SB, Tracy RP, et al. The metabolic syndrome, circulating oxidized LDL, and risk of myocardial infarction in wellfunctioning elderly people in the Health, Aging, and Body Composition cohort. Diabetes. 2004;53:1068-1073.

25. Holvoet P, Lee DH, Steffens M, Gross M, Jacobs DR Jr. Association between circulating oxidized low-density lipoprotein and incidence of the metabolic syndrome. JAMA. 2008;299:2287-2293.

26. Duncan BB, Schmidt MI, Pankow JS, et al. Low-grade systemic inflammation and the development of type 2 diabetes: the atherosclerosis risk in communities study. Diabetes. 2003;52:1799-1805.

27. Pradhan AD, Manson JE, Rifai N, Buring JE, Ridker PM. C-reactive protein, interleukin 6 , and risk of developing type 2 diabetes mellitus. JAMA. 2001;286:327-334.

28. Lango H; UK Type 2 Diabetes Genetics Consortium, Palmer CN, et al. Assessing the combined impact of 18 common genetic variants of modest effect sizes on type 2 diabetes risk. Diabetes. 2008;57: 3129-3135.

29. van Hoek M, Dehghan A, Witteman JC, et al. Predicting type 2 diabetes based on polymorphisms from genome-wide association studies: a population-based study. Diabetes. 2008;57:3122-3128.

30. Buijsse B, Simmons RK, Griffin SJ, Schulze MB. Risk assessment tools for identifying individuals at risk of developing type 2 diabetes. Epidemiol Rev. 2011;33:46-62.

31. Heilbronn LK, Cambell LV. Adipose tissuemacrophages, low grade inflammation and insulin resistance in human obesity. Curr Pharm Des. 2008;14:1225-1230.

32. Reilly MP, Lehrke M, Wolfe ML, Rohatgi A, Lazar MA, Rader DJ. Resistin is an inflammatory marker of atherosclerosis in humans. Circulation. 2005;111:932-939.

33. De Luca C, Olefsky JM. Inflammation and insulin resistance. FEBS Lett. 2008;582:97-105.

34. Furukawa S, Fujita T, Shimabukuro M, et al. Increased oxidative stress in obesity and its impact on metabolic syndrome. J Clin Invest. 2004; 114:1752-1761.

35. Heneghan HM, Miller N, Kerin MJ. Role of microRNAs in obesity and the metabolic syndrome. Obes Rev. 2010;11:354-361.

36. Ling C, Groop L. Epigenetics: a molecular link between environmental factors and type 2 diabetes. Diabetes. 2009;58:2718-2725.

37. Bonauer A, Boon RA, Dimmeler S. Vascular microRNAs. Curr Drug Targets. 2010;11:943-949.

38. Lyons TJ, Basu A. Biomarkers in diabetes: hemoglobin A1c, vascular and tissue markers. Transl Res. 2012;159:303-312.

39. Colagiuri S. Optimal management of type 2 diabetes: the evidence. Diabetes Obes Metab. 2012;14(Suppl 1):3-8.

40. Lipska KJ, Kosiborod M. Hypoglycemia and adverse outcomes: marker or mediator. Rec Cardiovasc Med. 2011;12:132-135.

41. Rhee EP, Gerszten RE. Metabolomics and cardiovascular biomarker discovery. Clin Chem. 2012;58:139-147. 
42. Herder C, Karakas M, Koenig W. Biomarkers for the prediction of type 2 diabetes and cardiovascular disease. Clin Pharmacol Ther. 2011;90:52-66.

43. Schulze MB, Weikert C, Pischon T, et al. Use of multiple metabolic and genetic markers to improve the prediction of type 2 diabetes: the EPIC-Potsdam study. Diab Care. 2009;32:2116-2119.

44. Matthews PM, Rabiner I, Gunn R. Non-invasive imaging in experimental medicine for drug development. Curr Opin Pharmacol. 2011;11:501-507.

45. Kolberg JA, Jorgensen T, Gerwien RW, et al. Development of a type 2 diabetes risk model from a panel of serum biomarkers from the Inter99 cohort. Diab Care. 2009;32:1207-1212.

46. Younus S, Rodgers G. Biomarkers associated with cardiometabolic risk in obesity. Am Heart Hosp J. 2011;9:E28-E32.

47. Cocucci E, Racchetti G, Meldolesi J. Shedding microvesicles: artefacts no more. Trends Cell Biol. 2008;19:43-51.

48. Piccin A, Murphy WG, Smith OP. Circulating microparticles: pathophysiology and clinical implications. Blood Rev. 2007;21:157-171.

49. Laulagnier K, Motta C, Hamdi S, et al. Mast cell- and dendritic cellderived exosomes display a specific lipid composition and an unusual membrane organization. Biochem J. 2004;380:161-171.

50. Hogan MC, Manganelli L, Woolard JR, et al. Characterization of PKD protein-positive exosome-like vesicles. J Am Soc Nephrol. 2009;20: 278-288.

51. Zhou R, O'Hara SP, Chen XM. MicroRNA regulation of innate immune responses in epithelial cells. Cell Mol Immunol. 2011;8:371-379.

52. Aupeix K, Hugel B, Martin T, et al. The significance of shed membrane particles during programmed cell death in vitro and in vivo in HIV-1 infection. J Clin Invest. 1997;99:1546-1554.

53. Pan BT, Johnstone RM. Fate of the transferrin receptor during maturation of sheep reticulocytes in vitro: selective externalization of the receptor. Cell. 1983;33:967-978.

54. Masyuk AI, Huang BQ, Ward C, et al. Biliary exosomes influence cholangiocyte regulatory mechanisms and proliferation through interaction with primary cilia. Am J Physiol Gastrointest Liver Physiol. 2010;299:G990-G999.

55. Rupp AK, Rupp C, Keller S, et al. Loss of EpCAM expression in breast cancer derived serum exosomes: role of proteolytic cleavage. Gynecol Oncol. 2011;122:437-446.

56. Thery C. Exosomes: secreted vesicles and intercellular communications. F1000 Biol Rep. 2011;3:15.

57. Rabinowits G, Gercel-Taylor C, Day JM, Taylor DD, Kloecker GH. Exosomal microRNA: a diagnostic marker for lung cancer. Clin Lung Cancer. 2009; 10:42-46.

58. Valadi H, Ekström K, Bossios A, Sjöstrand M, Lee JJ, Lötvall JO. Exosome-mediated transfer of mRNAs and microRNAs is a novel mechanism of genetic exchange between cells. Nat Cell Biol. 2007;9: 654-659.

59. Schorey JS, Bhatnagar S. Exosome function: from tumor immunology to pathogen biology. Traffic. 2008;9:871-881.

60. Gonzales PA, Wang WY, Mao YW, et al. Large-scale proteomics and phosphoproteomics of urinary exosomes. J Am Soc Nephrol. 2009;20: 363-379.

61. Mathivanan S, Fahner CJ, Reid GE, Simpson RJ. ExoCarta 2012: database of exosomal proteins, RNA and lipids. Nucleic Acids Res. 2011;40:D1241-D1244.

62. Simons M, Raposo G. Exosomes-vesicular carriers for intercellular communication. Curr Opin Cell Biol. 2009;21:575-581.

63. Sudhof TC, Rothman JE. Membrane fusion: grappling with SNARE and SM proteins. Science. 2009;323:474-477.

64. Fukuda R, McNew JA, Weber T, et al. Functional architecture of an intracellular membrane t-SNARE. Nature. 2000;407:198-202.

65. Sutton RB, Fasshauer D, Jahn R, Brunger AT. Crystal structure of a SNARE complex involved in synaptic exocytosis at 2.4 A resolution. Nature. 1998;395:347-353.

66. Ostrowski M, Carmo NB, Krumeich S, et al. Rab27a and Rab27b control different steps of the exosome secretion pathway. Nat Cell Biol. 2010; 12:19-30.
67. Hsu C, Morohashi Y, Yoshimura S, et al. Regulation of exosome secretion by Rab35 and its GTPase-activating proteins TBC1D10A-C. J Cell Biol. 2010;189:223-232.

68. Dykstra M, Cherukuri A, Sohn HW, Tzeng SJ, Pierce SK. Location is everything: lipid rafts and immune cell signaling. Annu Rev Immunol. $2003 ; 21: 457-481$

69. Allende D. Jumping to rafts: gatekeeper role of bilayer elasticity. Trends Biochem Sci. 2004;29:325-330.

70. Pike L. Lipid rafts: heterogeneity on the high seas. Biochem J. 2004; 378:281-292.

71. Rao R, Logan B, Forrest K, Roszman TL, Goebel J. Lipid rafts in cytokine signaling. Cytokine Growth Factor Rev. 2004;15:103-110.

72. Hemler ME. Tetraspanin functions and associated microdomains. Nat Rev Mol Cell Biol. 2005;6:801-811.

73. Tonoli H, Barrett JC. CD82 metastasis suppressor gene: a potential target for new therapeutics. Trends Mol Med. 2005;11:563-570.

74. Huang CL, Liu D, Masuva D, et al. MRP-1/CD9 gene transduction downregulates Wnt signal pathways. Oncogene. 2004;23:7475-7483.

75. Escola JM, Kleijmeer MJ, Stoorvogel W, Griffith JM, Yoshie O, Geuze HJ. Selective enrichment of tetraspanin proteins on the internal vesicles of multivesicular endosomes and on exosomes secreted by human B-lymphocytes. J Biol Chem. 1998;273:20121-20127.

76. Chairoungdua A, Smith DL, Pochard P, Hull M, Caplan MJ. Exosome release of $\beta$-catenin: a novel mechanism that antagonizes Wnt signaling. J Cell Biol. 2010;190:1079-1091.

77. Fevrier B, Vilette D, Archer F, et al. Cells release prions in association with exosomes. Proc Natl Acad Sci U S A. 2004;101:9683-9688.

78. Vidal M, Mangeat $\mathrm{P}$, Hoekstra D. Aggregation reroutes molecules from a recycling to a vesicle-mediated secretion pathway during reticulocyte maturation. J Cell Sci. 1997;110:1867-1877.

79. Johnstone RM, Adam M, Hammond JR, Orr L, Turbide C. Vesicle formation during reticulocyte maturation. Association of plasma membrane activities with released vesicles (exosomes). J Biol Chem. 1987;262:9412-9420

80. Booth AM, Fang Y, Fallon JK, Yang YM, Hildreth JE, Gould SJ. Exosomes and HIV gag bud from endosome-like domains of the T cell plasma membrane. J Cell Biol. 2006;172:923-935.

81. Welsch S, Keppler OT, Habermann A, Allespach I, Krijnse-Locker J, Krausslich HG. HIV-1 buds predominantly at the plasma membrane of primary human macrophages. PLoS pathogens. 2007;3:e36.

82. Saksena S, Sun J, Chu T, Emr SD. ESCRTing proteins in the endocytic pathway. Trends Biochem Sci. 2007;32:561-573.

83. Shen B, Wu N, Yang JrM, Gould SJ. Protein targeting to exosomes/ microvesicles by plasma membrane anchors. J Biol Chem. 2011;286: 14383-14395.

84. Horstman LL, Ahn YS. Platelet microparticles: A wide-angle perspective. Crit Rev Oncol Hematol. 1999;30:111-142.

85. Lagos-Quintana M, Rauhut R, Lendeckel W, Tuschl T. Identification of novel genes coding form small expressed RNAs. Science. 2001;294: 853-858.

86. Bartel DP. MicroRNAs: genomics, biogenesis, mechanism, and function. Cell. 2004;116:281-297.

87. Hunter MP, Ismail N, Zhang X, et al. Detection of microRNA expression in human peripheral blood microvesicles. PLoS One. 2008; 3:e3694.

88. Taylor DD, Gercel-Taylor C. MicroRNA signatures of tumor-derived exosomes as diagnostic biomarkers of ovarian cancer. Gynecol Oncol. 2008;110:13-21.

89. Mittelbrunn M, Gutierrez-Vazquez C, Villarroya-Beltri C, et al. Unidirectional transfer of microRNA-loaded exosomes from $\mathrm{T}$ cells to antigen-presenting cells. Nat Commun. 2011;2:282.

90. Keller S, Ridinger J, Rupp AK, Janssen JW, Altevogt P. Body fluid derived exosomes as a novel template for clinical diagnostics. J Transl Med. 2011;9:86

91. Reid G, Kirschner MB, Van Zandwijk N. Circulating microRNAs: Association with disease and potential use as biomarkers. Crit Rev Oncol Hematol. 2011;80:193-208. 
92. Michael A, Bajracharya SD, Yuen PS, et al. Exosomes from human saliva as a source of microRNA biomarkers. Oral Dis. 2010;16: 34-38.

93. Ciesla M, Skrzypek K, Kozakowska M, Loboda A, Jozkowicz A, Dulak J. MicroRNAs as biomarkers of disease onset. Anal Bioanal Chem. 2011;401:2051-2061.

94. Li Q, Lin X, Yang X, Chang J. NFATc4 is negatively regulated in miR-133a-mediated cardiomyocyte hypertrophic repression. Am J Physiol Heart Circ Physiol. 2010;298:H1340-H1347.

95. Kuwabara Y, Ono K, Horie T, et al. Increased microRNA-1 and microRNA-133a levels in serum of patients with cardiovascular disease indicate myocardial damage. Circ Cardiovasc Genet. 2011;4: 446-454.

96. Kooijmans SAA, Vader P, van Dommelen SM, van Solinge WW, Schiffelers RM. Exosome mimetics: a novel class of drug delivery systems. Int J Nanomed. 2012;7:1525-1541.

97. Krützfeldt J, Rajewski N, Braich R, et al. Silencing of microRNAs in vivo with 'antagomirs'. Nature. 2005;438:685-689.

98. Czech MP. MicroRNAs as therapeutic targets. N Engl J Med. 2006; 354:1194-1195.

99. Ploner A, Ploner C, Lukasser M, Niederegger H, Huttenhofer A. Methodological obstacles in knocking down small noncoding RNAs. RNA. 2009;15:1797-1804.

100. Orom UA, Kauppinen S, Lund AH. LNA-modified oligonucleotides mediate specific inhibition of microRNA function. Gene. 2006;372 137-141.

101. Zampetaki A, Mayr M. MicroRNAs in vascular and metabolic disease Circ Res. 2012;110:508-522.

102. Cortez MA, Bueso-Ramos C, Ferdin J, Lopez-berestein G, Soos AK, Calin GA. MicroRNAs in body fluids - the mix of hormones and biomarkers. Nat Rev Clin Oncol. 2011;8:467-477.

103. Ikezawa H. Glycosylphosphatidylinositol (GPI)-anchored proteins Biol Pharm Bull. 2002;25:409-417.

104. Ferguson MA, Williams AF. Cell-surface anchoring of proteins via glycosyl-phosphatidylinositol structures. Annu Rev Biochem. 1988; 57:285-320.

105. Cross GA. Glycolipid anchoring of plasma membrane proteins. Annu Rev Cell Biol. 1990;6:1-39.

106. Low MG. Glycosyl-phosphatidylinositol: a versatile anchor for cell surface proteins. FASEB J. 1989;3:1600-1608.

107. Diep DB, Nelson KL, Raja SM, Pleshak EN, Buckley JT. Glycosylphosphatidylinositol anchors of membrane glycoproteins are binding determinants for the channel-forming aerolysin. J Biol Chem. 1998;273:2355-2360.

108. Gmachl M, Sagan S, Ketter S, Kreil G. The human sperm protein PH-20 has hyaluronidase activity. FEBS Lett. 1993;336: 545-548.

109. Tozeren A, Sung KL, Dustin ML, Chan PY, Springer TA, Chien S. Micromanipulation of adhesion of a Jurkat cell to a planar bilayer membrane containing lymphocyte function-associated antigen 3 molecules. J Cell Biol. 1992;116:997-1006.

110. Müller G, Bandlow W. Lipolytic membrane release of two phosphatidylinositol-anchored cAMP receptor proteins in yeast alters their ligand-binding parameters. Arch Biochem Biophys. 1994;308: 504-514.

111. Wang X, Jansen G, Fan J, et al. Variant GPI structure in relation to membrane-associated functions of a murine folate receptor. Biochemistry. 1996;35:16305-16312.

112. Kondoh G, Tojo H, Nakatani Y, et al. Angiotensin-converting enzyme is a GPI-anchored protein releasing factor crucial for fertilization. Nat Med. 2005;11:160-166.

113. Chan BL, Lisanti MP, Rodriguez-Boulan E, Saltiel AR. Insulin-stimulated release of lipoprotein lipase by metabolism of its phosphatidylinositol anchor. Science. 1988;241:1670-1672.

114. Romero G, Luttrell L, Rogol A, Zeller K, Hewlett E, Larner J. Phosphatidylinositol-glycan anchors of membrane proteins: potential precursors of insulin mediators. Science. 1988;240:509-511.
115. Musaka R, Umeda M, Endo T, Kobata A, Inoue K. Characterization of glycosylphosphatidylinositol (GPI)-anchored NCAM on mouse skeletal muscle cell line $\mathrm{C} 2 \mathrm{C} 12$ : the structure of the GPI glycan and release during myogenesis. Arch Biochem Biophys. 1995;318: 182-190.

116. Naghibalhossaini F, Ebadi P. Evidence for CEA release from human colon cancer cells by an endogenous GPI-PLD enzyme. Cancer Lett. 2006;234:158-167.

117. Bianco C, Strizzi L, Normanno N, Khan N, Salomon DS. Cripto-1: an oncofetal gene with many faces. Curr Top Dev Biol. 2005;67: 85-133.

118. Turner AJ, Hooper NM. The angiotensin-converting enzyme gene family: genomics and pharmacology. Trends Pharmacol Sci. 2002;23: 177-183.

119. Kawagoe K, Kitamura D, Okabe M, et al. Glycosylphosphatidylinositol-anchor deficient mice: implications for clonal dominance of mutant cells in paroxysmal nocturnal hemoglobinuria. Blood. 1996;87:3600-3606

120. Rosti V, Tremml G, Soares V, Pandolfi PP, Luzzatto L, Bessler M. Murine embryonic stem cells without Pig-a gene activity are competent for hematopoiesis with the $\mathrm{PNH}$ phenotype but not for clonal expansion. J Clin Invest. 1997;100:1028-1036.

121. Nozaki M, Ohishi K, Yamada N, Kinoshita T, Nagy A, Takeda J. Developmental abnormalities of glycosylphosphatidylinositol-anchor deficient embryos revealed by Cre/loxP system. Lab Invest. 1999;79: 293-299.

122. Abdul-Aziz NM, Turmaine M, Greene ND, Copp AJ. Ephrin-EphA receptor interactions in mouse spinal neurulation: implications for neural fold fusion. Int J Dev Biol. 2009;53:559-568

123. Watanabe K, Bianco C, Strizzi L, et al. Growth factor induction of Cripto-1 shedding by glycosylphosphatidylinositol-phospholase $\mathrm{D}$ and enhancement of endothelial cell migration. J Biol Chem. 2007;282(43):31643-31655.

124. Slein MW, Logan GF Jr. Partial purification and properties of two phospholipases of Bacillus cereus. J Bacteriol. 1963;85: 369-381.

125. Ikezawa H, Yamanegi M, Taguchi R, Miyashita T, Ohyabu T. Studies on phosphatidylinositol phosphodiesterase (phospholipase C type) of Bacillus cereus: I. purification, properties and phosphatase-releasing activity. Biochim Biophys Acta. 1976;450:154-164.

126. Futerman AH, Low MG, Ackermann KE, Sherman WR, Silman I. Identification of covalently bound inositol in the hydrophobic membrane-anchoring domain of Torpedo acetylcholinesterase. Biochem Biophys Res Commun. 1985;129:312-317.

127. Robert WL, Rosenberry TL. Identification of covalently attached fatty acids in the hydrophobic membrane-binding domain of human erythrocyte acetylcholinesterase. Biochem Biophys Res Commun. 1985;133:621-627

128. Tse AG, Barclay AN, Watts A, Williams AF. A glycophospholipid tail at the carboxyl terminus of the Thy-1 glycoprotein of neurons and thymocytes. Science. 1985;230:1003-1008.

129. Ferguson MA, Haldar K, Cross GA. Trypanosoma brucei variant surface glycoprotein has a sn-1,2-dimyristyl glycerol membrane anchor at its COOH terminus. J Biol Chem . 1985;260:4963-4968.

130. Ferguson MA, Low MG, Cross GA. Glycosyl-sn-1,2-dimyristylphosphatidylinositol is covalently linked to Trypanosoma brucei variant surface glycoprotein. J Biol Chem. 1985;260:14547-14555.

131. Eisenhaber B, Bork P, Eisenhaber F. Post-translational GPI lipid anchor modification of proteins in kingdoms of life: analysis of protein sequence data from complete genomes. Protein Eng. 2001;14: $17-25$.

132. Kinoshita T, Inoue N. Dissecting and manipulating the pathway for glycosylphosphatidylinositol-anchor biosynthesis. Curr Opin Struct Biol. 2000;4:632-638.

133. Eisenhaber B, Maurer-Stroh S, Novatchkova M, Schneider G, Eisenhaber F. Enzymes and auxiliary factors for GPI lipid anchor biosynthesis and post-translational transfer to proteins. Bio Essays. 2003;25:367-385. 
134. Miyata T, Takeda J, Iida Y, et al. The cloning of PIG-A, a component in the early step of GPI-anchor biosynthesis. Science. 1993;259: 1318-1320.

135. Takeda J, Miyata T, Kawagoe K, et al. Deficiency of the GPI anchor caused by a somatic mutation of the PIG-A gene in paroxysmal nocturnal hemoglobinuria. Cell. 1993;73:703-711.

136. Bessler M, Mason PJ, Hillmen P, et al. Paroxysmal nocturnal haemoglobinuria $(\mathrm{PNH})$ is caused by somatic mutations in the PIG-A gene. EMBO J. 1994;13:110-117.

137. Kinoshita T, Inoue N, Takeda J. Defective glycosyl phosphatidylinositol anchor synthesis and paroxysmal nocturnal hemoglobinuria. Adv Immunol. 1995;60:57-103.

138. Rosse WF, Ware RE. The molecular basis of paroxysmal nocturnal hemoglobinuria. Blood. 1995;86:3277-3286.

139. Mortazavi Y, Merk B, McIntosh J, Marsh JC, Schrezenmeier H, Rutherford TR. The spectrum of PIG-A gene mutations in aplastic anemia/paroxysmal nocturnal hemoglobinuria (AA/PNH): a high incidence of multiple mutations and evidence of a mutational hot spot. Blood. 2003;101:2833-2841.

140. Luzzatto L. Somatic mutations in paroxysmal nocturnal hemoglobinuria: a blessing in disguise? Cell. 1997;88:1-4.

141. Barcellini W. Increased resistance of PIG-A-bone marrow progenitors to tumor necrosis factor $\alpha$ and interferon $\gamma$ : possible implications for the in vivo dominance of paroxysmal nocturnal hemoglobinuria clones. Haematologica. 2004;89:651-656.

142. Ait-Slimane T, Galmes R, Trugnan G, Maurice M. Basolateral internalization of GPI-anchored proteins occurs via clathrin-independent flotillin-dependent pathway in polarized hepatic cells. Mol Biol Cell. 2009;20:3792-3800

143. Munro S. Lipid rafts: elusive or illusive? Cell. 2003;115:377-388.

144. Simons K, Toomre D. Lipid rafts and signal transduction. Nat Rev Mol Cell Biol. 2000;1:31-39.

145. Müller G, Over S, Wied S, Frick W. Association of (c)AMP-degrading glycosylphosphatidylinositol-anchored proteins with lipid droplets is induced by palmitate, $\mathrm{H}_{2} \mathrm{O}_{2}$ and the sulfonylurea drug, glimepiride, in rat adipocytes. Biochemistry. 2008;47:12774-12787.

146. Müller G, Wied S, Over S, Frick W. Inhibition of lipolysis by palmitate, $\mathrm{H}_{2} \mathrm{O}_{2}$ and the sulfonylurea drug, glimepiride, in rat adipocytes depends on cAMP degradation by lipid droplets. Biochemistry. 2008; 47:1259-1273.

147. Müller G, Wied S, Walz N, Jung C. Translocation of glycosylphosphatidylinositol-anchored proteins from plasma membrane microdomains to lipid droplets in rat adipocytes is induced by palmitate, $\mathrm{H}_{2} \mathrm{O}_{2}$ and the sulfonylurea drug, glimepiride. Mol Pharmacol. 2008; 73:1513-1529.

148. Müller G, Jung C, Straub J, Wied S. Induced release of membrane vesicles and exosomes from rat adipocytes containing lipid droplet, lipid raft and glycosylphosphatidylinositol-anchored proteins. Cell Signal. 2009;21:324-338.

149. Müller G, Jung C, Wied S, Biemer-Daub G. Induced translocation of glycosylphosphatidylinositol-anchored proteins from lipid droplets to adiposomes in rat adipocytes. Br J Pharmacol. 2009;158: 749-770.

150. Brügger B, Graham C, Leibrecht I, et al. The membrane domains occupied by glycosylphosphatidylinositol-anchored prion protein and Thy-1 differ in lipid composition. J Biol Chem. 2004;279:7530-7536.

151. Szpurka H, Schade AE, Jankowska AM, Maciejewski JP. Altered lipid raft composition and defective cell death signal transduction in glycosylphosphatidylinositol anchor-deficient PIG-A mutant cells. $\mathrm{Br}$ J Haematol. 2008;142:413-422.

152. Lai EC. Lipid rafts make for slippery platforms. J Cell Biol. 2003;162: 365-370.

153. Varma R, Mayor S. GPI-anchored proteins are organized in submicron domains at the cell surface. Nature. 1998;394:798-801.

154. Friedrichson T, Kurzchalia TV. Microdomains of GPI-anchored proteins in living cells revealed by crosslinking. Nature. 1998;394: 802-805.
155. Harder T, Scheiffele P, Verkade P, Simons K. Lipid domain structure of the plasma membrane revealed by patching of membrane components. J Cell Biol. 1998;141:929-942.

156. Pralle A. Sphingolipidcholesterol rafts diffuse as small entities in the plasma membrane of mammalian cells. J Cell Biol. 2000;148: 997-1008.

157. Sharma P, Varma R, Sarasij RC, et al. Nanoscale organization of multiple GPI-anchored proteins in living cell membranes. Cell. 2004; 116(4):577-589.

158. Ayuyan AG, Cohen FS. Raft composition at physiological temperature and $\mathrm{pH}$ in the absence of detergents. Biophys J. 2007;94: 2654-2666.

159. Pinaud F, Michalet X, Gopal I, Margeat E, Moore H-P, Weiss S. Dynamic partitioning of a glycosyl-phosphatidylinositol-anchored protein in glycosphingolipid-rich microdomains imaged by singlequantum dot. Tracking Traffic. 2009;10:691-712.

160. Wang TY, Leventis R, Silvius JR. Artificially lipid-anchored proteins can elicit clustering-induced intracellular signaling events in Jurkat thymphocytes independent lipid raft association. J Biol Chem. 2005; 280(24):22839-22846.

161. Douglass AD, Vale RD. Single-molecule microscopy reveals plasma membrane microdomains created by protein-protein networks that exclude or trap signaling molecules in T cells. Cell. 2005;121: 937-950.

162. Rooney IA, Heuser JE, Atkinson JP. GPI-anchored complement regulatory proteins in seminal plasma. An analysis of their physical condition and the mechanisms of their binding to exogenous cells. J Clin Invest. 1996;97(7):1675-1686.

163. Zacharias DA, Violon JD, Newton AC, Tsien RY. Partitioning of lipid-modified monomeric GFPs into membrane microdomains of live cells. Science. 2002;296:913-916.

164. Mayor S, Riezman H. Sorting of GPI-anchored proteins. Nat Rev Mol Cell Biol. 2004;5:110-120.

165. Leventhal I, Grzybek M, Simons K. Greasing their way: lipid modifications determine protein association with membrane rafts. Biochemistry. 2010;49:6305-6316.

166. Bouma SR, Drislane FW, Huestis WH. Selective extraction of membrane-bound proteins by phospholipid vesicles. J Biol Chem. 1977;252(19):6759-6763.

167. Cook SL, Bouma SR, Huestis WH. Cell to vesicle transfer of intrinsic membrane proteins: effect of membrane fluidity. Biochemistry. 1980; 19(20):4601-4607.

168. Medof ME, Nagarajan S, Tykocinski ML. Cell surface engineering with GPI-anchored proteins. FASEB J. 1996;10(5):574-586.

169. Kooyman DL, Byrne GW, McClelland S, et al. In vivo transfer of GPI-linked complement restriction factors from erythrocytes to the endothelium. Science. 1995;269(5220):89-92.

170. Rifkin MR, Landsberger FR. Trypanosome variant surface glycoprotein transfer to target membranes: a model for the pathogenesis of trypanosomiasis. Proc Natl Acad Sci U S A. 1990;87:801-805.

171. Sloand EM, Maciejewski JP, Dunn D, et al. Correction of the PNH defect by GPI-anchored protein transfer. Blood. 1998;92(11): 4439-4445.

172. Sloand EM, Mainwaring L, Keyvanfar K, et al. Transfer of glycosylphosphatidylinositol-anchored proteins to deficient cells after erythrocyte transfusion in paroxysmal nocturnal hemoglobinuria. Blood. 2004;104(12):3782-3788.

173. Babiker AA, Ronquist G, Nilsson UR, Nilsson B. Transfer of prostasomal CD59 to CD59-deficient red blood cells results in protection against complement-mediated hemolysis. Am J Reprod Immunol. 2002;47(3):183-192.

174. Harding C, Heuser J, Stahl P. Receptor-mediated endocytosis of transferrin and recycling of the transferrin receptor in rat reticulocytes. J Cell Biol. 1983;97(2):329-339.

175. van Niel G, Raposo G, Candalh C, et al. Intestinal epithelial cells secrete exosome-like vesicles. Gastroenterology. 2001;121(2): 337-349. 
176. Wolfers J, Lozier A, Raposo G, et al. Tumor-derived exosomes are a source of shared tumor rejection antigens for CTL cross-priming. Nat Med. 2001;7(3):297-303.

177. Blanchard N, Lankar D, Faure F, et al. TCR activation of human $\mathrm{T}$ cells induces the production of exosomes bearing the TCR/CD3/ zeta complex. J Immunol. 2002;168(7):3235-3241.

178. Zitvogel L, Regnault A, Lozier A, et al. Eradication of established murine tumors using a novel cell-free vaccine: dendritic cells-derived exosomes. Nat Med. 1998;4(5):594-600.

179. Brasoveanu LI, Fonsatti E, Visintin A, et al. Melanoma cells constitutively release an anchor-positive soluble form of protectin (sCD59) that retains functional activities in homologous complement-mediated cytotoxicity. J Clin Invest. 1997;100(5): 1248-1255.

180. Raposo G, Nijman HW, Stoorvogel W, et al. B lymphocytes secrete antigen-presenting vesicles. J Exp Med. 1996;183(3): 1161-1172.

181. Ronquist G, Brody I. The prostasome: its secretion and function in man. Biochim Biophys Acta. 1985;822:203-218.

182. Rooney IA, Atkinson JP, Krul ES, et al. Physiologic relevance of the membrane attack complex inhibitory protein CD59 in human seminal plasma: CD59 is present on extracellular organelles (prostasomes), binds cell membranes, and inhibits complement-mediated lysis. $J$ Exp Med. 1993;177:1409-1420.

183. Long KE, Yomtovian R, Kida M, Knez JJ, Medof ME. Time-dependent loss of surface complement regulatory activity during storage of donor blood. Transfusion. 1993;33(4):294-300.

184. Bütikofer P, Kuypers FA, Xu CM, Chiu DT, Lubin B. Enrichment of two glycosyl-phosphatidylinositol-anchored proteins, acetylcholinesterase and decay accelerating factor, in vesicles released from human red blood cells. Blood. 1989;74(5):1481-1485

185. van den Berg CW, Cinek T, Hallett MB, Horejsi V, Morgan BP. Exogenous glycosyl phosphatidylinositol-anchored CD59 associates with kinases in membrane clusters on U937 cells and becomes $\mathrm{Ca}(2+)$ signaling competent. J Cell Biol. 1995;131(3):669-677.

186. Civenni G, Test ST, Brodbeck U, Bütikofer P. In vitro incorporation of GPI-anchored proteins into human erythrocytes and their fate in the membrane. Blood. 1998;91(5):1784-1792.

187. Premkumar DR, Fukuoka Y, Sevlever D, et al. Properties of exogenously added GPI-anchored proteins following their incorporation into cells. J Cell Biochem. 2001;82(2):234-245.

188. Zhang F, Schmidt WG, Hou Y, Williams AF, Jacobson K. Spontaneous incorporation of the glycosyl-phosphatidylinositol-linked protein Thy-1 into cell membranes. Proc Natl Acad Sci U S A. 1992;89(12): 5231-5235

189. Bülow R, Overath P, Davoust J. Rapid lateral diffusion of the variant surface glycoprotein in the coat of Trypanosoma brucei. Biochemistry. 1988;27(7):2384-2388

190. Medof ME, Kinoshita T, Silber R, Nussenzweig V. Amelioration of lytic abnormalities of paroxysmal nocturnal hemoglobinuria with decay accelerating factor. Proc Natl Acad Sci U S A. 1985;82(9): 2980-2984.

191. Dunn DE, Yu J, Nagarajan S, Devetten M, et al. A knock-out model of paroxysmal nocturnal hemoglobinuria: Pig-a(-) hematopoiesis is reconstituted following intercellular transfer of GPI-anchored proteins. Proc Natl Acad Sci U S A. 1996;93(15):7938-7943.

192. De Broe ME, Wieme RJ, Logghe GN, et al. Spontaneous shedding of plasma membrane fragments by human cells in vivo and in vitro. Clin Chim Acta. 1977;81:237-245.

193. Anderson SM, Yu G, Giattina M, Miller JL. Intercellular transfer of a glycosylphosphatidylinositol (GPI)-linked protein: release and uptake of CD4-GPI from recombinant adeno-associated virustransduced HeLa cells. Proc Natl Acad Sci U S A. 1996;93(12): 5894-5898.

194. Keller GA, Siegel MW, Caras IW. Endocytosis of glycophospholipidanchored and transmembrane forms of CD4 by different endocytic pathways. EMBO J. 1992;11(3):863-874.
195. Vakeva A, Jauhiainen M, Ehnholm C, Lehto T, Meri S. High-density lipoproteins can act as carriers of glycophosphoinositol lipid-anchored CD59 in human plasma. Immunology. 1994;82(1):28-33.

196. Metzner C, Mostegl MM, Günzburg WH, Salmons B, Dangerfield JA. Association of glycosylphosphatidylinositol (GPI)-linked protein with retroviral particles. FASEB J. 2008;22(8):2734-2739.

197. Chesebro B, Trifilo M, Race R, et al. Anchorless prion protein results in infectious amyloid disease without clinical scrapie. Science. 2005; 308(5727):1435-1439

198. McNally KL, Ward AE, Priola SA. Cells expressing anchorless prion protein are resistant to scrapie infection. J Virol. 2009;83(9): 4469-4475.

199. Gould SJ, Booth AM, Hildreth JE. The Trojan exosome hypothesis. Proc Natl Acad Sci U S A. 2003;100(19):10592-10597.

200. Lauc G, Heffer-Lauc M. Shedding and uptake of gangliosides and glycosylphosphatidylinositol-anchored proteins. Biochim Biophys Acta. 2006;1760:584-602.

201. Camussi G, Deregibus MC, Bruno S, Cantaluppi V, Biancone L. Exosomes/microvesicles as a mechanism of cell-to-cell communication. Kidney Int. 2010;78:838-848.

202. Lu P, Sharom FJ. Immunosuppression by YAC-1 lymphoma: role of shed gangliosides. Cell Immunol. 1996;173:22-32.

203. Deng W, Li R, Ladisch S. Influence of cellular ganglioside depletion on tumor formation. J Natl Cancer Inst. 2000;92(11):912-917.

204. Simons M, Friedrichson T, Schulz JB, Pitto M, Masserini M, Kurzchalia TV. Exogenous administration of gangliosides displaces GPI-anchored proteins from lipid microdomains in living cells. $\mathrm{Mol}$ Biol Cell. 1999;10(10):3187-3196.

205. Crespo PM, Zurita AR, Daniotti JL. Effect of gangliosides on the distribution of a glycosylphosphatidylinositol-anchored protein in plasma membrane from Chinese hamster ovary-K1 cells. J Biol Chem. 2002;277(47):44731-44739.

206. Ladisch S, Gillard B, Wong C, Ulsh L. Shedding and immunoregulatory activity of YAC-1 lymphoma cell gangliosides. Cancer Res. 1983; 43(8):3808-3813.

207. Müller G, Wied S, Jung C, Biemer-Daub G, Frick W. Transfer of glycosylphosphatidylinositol-anchored 5'-nucleotidase CD73 from adiposomes into rat adipocytes stimulates lipid synthesis. $\mathrm{Br} J$ Pharmacol. 2010;160:878-891.

208. Müller G, Wied S, Jung C, Frick W, Biemer-Daub G. Inhibition of lipolysis by adiposomes containing glycosylphosphatidylinositolanchored Gcel protein in rat adipocytes. Arch Physiol Biochem. 2010; 116:28-41.

209. Müller G, Wied S, Dearey E-A, Biemer-Daub G. Glycosylphosphatidylinositol-anchored proteins coordinate lipolysis inhibition between large and small adipocytes. Metabolism. 2011;60:1021-1037.

210. Müller G, Schneider M, Biemer-Daub G, Wied S. Upregulation of lipid synthesis in small rat adipocytes by microvesicle-associated CD73 from large adipocytes. Obesity (Silver Spring). 2011;19:1531-1544.

211. Müller G. Let's shift lipid burden - from large to small adipocytes. Eur J Pharmacol. 2011;656:1-4

212. Müller G, Schneider M, Gassenhuber J, Wied S. Release of exosomes and microvesicles harbouring specific RNAs and glycosylphosphatidylinositol-anchored proteins from rat and human adipocytes is controlled by histone methylation. Am J Mol Biol. In press 2012.

213. Müller G. Personalised strategies for the diagnosis and therapy of type II diabetes and obesity. Immunol Endocr Metabol Agents Med Chem. 2012;12:80-109.

214. Müller G. Novel target identification technologies for the personalised therapy of type II diabetes and obesity. Immunol Endocr Metabol Agents Med Chem. 2012. In press.

215. Skog J, Würdinger T, van Rijn S, et al. Glioblastoma microvesicles transport RNA and proteins that promote tumour growth and provide diagnostic biomarkers. Nat Cell Biol. 2008;10:1470-1476.

216. Qazi KR, Torregrosa Paredes P, Dahlberg B, Grunewald J, Eklund A, Gabrielsson S. Proinflammatory exosomes in bronchoalveolar lavage fluid of patients with sarcoidosis. Thorax. 2010;65:1016-1024. 
217. Al-Nedawi K, Meehan B, Kerbel RS, Allison AC, Rak J. Endothelial expression of autocrine VEGF upon the uptake of tumor-derived microvesicles containing oncogenic EGFR. Proc Natl Acad Sci U SA. 2009;106:3794-3789.

218. Kogure T, Lin WL, Yan IK, Braconi C, Patel T. Intercellular nanovesicle-mediated microRNA transfer: A mechanism of environmental modulation of hepatocellular cancer cell growth. Hepatology. 2011;54:1237-1248.

219. Castellana D, Toti F, Freyssinet JM. Membrane microvesicles: Macromessengers in cancer disease and progression. Thrombosis Res. 2010;125:S84-S88.

220. Baj-Krzyworzeka M, Szatanek R, Weglarczyk K, Baran J, Zembala M. Tumour-derived microvesicles modulate biological activity of human monocytes. Immunol Lett. 2007;113:76-82.

221. Yuan A, Farber EL, Rapoport AL. Transfer of microRNAs by embryonic stem cell microvesicles. PLoS One. 2009;4:e4722.

222. Pegtel DM, Cosmopoulos K, Thorley-Lawson DA, et al. Functional delivery of viral miRNAs via exosomes. Proc Natl Acad Sci U S A. 2010;107:6328-6333.

223. Liu Y, Xiang X, Zhuang X, et al. Contribution of MyD88 to the tumor exosome-mediated induction of myeloid derived suppressor cells. $\mathrm{Am}$ J Pathol. 2010;176:2490-2499.

224. Lim PK, Bliss SA, Patel SA, et al. Gap junction-mediated import of microRNA from bone marrow stromal cells can elicit cell cycle quiescence in breast cancer cells. Cancer Res. 2011;71:1550-1560.

225. Yang M, Chen J, Su F, et al. Microvesicles secreted by macrophages shuttle invasion-potentiating microRNAs into breast cancer cells. Mol Cancer. 2011;10:117.

226. Deregibus MC, Cantaluppi V, Calogero R, et al. Endothelial progenitor of cell derived microvesicles activate an angiogenic program in endothelial cells by a horizontal transfer of mRNA. Blood. 2007;110: 2440-2448.

227. Montecalvo A, Larregina AT, Shufesky WJ, et al. Mechanism of transfer of functional microRNAs between mouse dendritic cells via exosomes. Blood. 2012;119:756-766.

228. Meckes DG Jr, Shair KH, Marquitz AR, Kung CP, Edwards RH, Raab-Traub N. Human tumor virus utilizes exosomes for intercellular communication. Proc Natl Acad Sci U S A. 2010;107:20370-20375.

229. Pegtel DM, Van De Garde MD, Middeldorp JM. Viral miRNAs exploiting the endosomal-exosomal pathway for intercellular cross-talk and immune evasion. Biochim Biophys Acta. 2011;1809:715-721.

230. Boulanger CM, Scoazec A, Ebrahimian T, et al. Circulating microparticles from patients with myocardial infarction cause endothelial dysfunction. Circulation. 2001;104:2649-2652.

231. Wilhelm OG, Wilhelm S, Escott GM, et al. Cellular glycosylphosphatidylinositol-specific phospholipase $\mathrm{D}$ regulates urokinase receptor shedding and cell surface expression. J Cell Physiol. 1999;180(2): 225-235.

232. Omoto S, Nomura S, Shouzu A, Nishikawa M, Fukuhara S, Iwasaka T, (2002). Detection of monocyte-derived microparticles in patients with Type II diabetes mellitus. Diabetologia. 2011;45:550-555.

233. Schorey JS, Bhatnagar S. Exosome function: from tumor immunology to pathogen biology. Traffic. 2008;9:871-881.

234. Simpson RJ, Lim JW, Moritz RL, Mathivanan S. Exosomes: proteomic insights and diagnostic potential. Expert Rev Proteomics. 2009;6(3): 267-283.

235. Timmers L, Lim SK, Arslan F, et al. Reduction of myocardial infarct size by human mesenchymal stem cell conditioned medium. Stem Cell Res. 2007;1(2):129-137.

236. Choo A, Padmanabhan J, Chin A, Fong WJ, Oh SK. Immortalized feeders for the scale-up of human embryonic stem cells in feeder and feeder-free conditions. J Biotechnol. 2006;122(1):130-141.

237. Pisitkun T, Shen RF, Knepper MA. Identification and proteomic profiling of exosomes in human urine. Proc Natl Acad Sci U S A. 2004;101(36):13368-13373.

238. Horstman LL. Cell-derived microparticles and exosomes in neuroinflammatory disorders. Int Rev Neurobiol. 2007;79:227-268.
239. Ichim TE, Zhong Z, Kaushal S, et al. Exosomes as a tumor immune escape mechanism: possible therapeutic implications. J Transl Med. 2008;6:37.

240. Mitchell PJ. Can urinary exosomes act as treatment response markers in prostate cancer? J Transl Med. 2009;7:4.

241. Rabinowits G, Gercel-Taylor C, Day JM, Taylor DD, Kloecker GH. Exosomal microRNA: a diagnostic marker for lung cancer. Clin Lung Cancer. 2009; 10:42-46.

242. Simak J, Gelderman MP. Cell membrane microparticles in blood and blood products: Potentially pathogenic agents and diagnostic markers. Transfusion Med Rev. 2006;20:1-26.

243. Freyssinet JM. Cellular microparticles: What are they bad or good for? J Thromb Haemost. 2003;1:1655-1662.

244. Horstman LL, Jy W, Jimenez JJ, Bidot C, Ahn YS. New horizons in the analysis of circulating cell-derived microparticles. Keio J Med. 2004;53(4):210-230.

245. Horstman LL, Jy W, Jimenez JJ, Ahn YS. Endothelial microparticles as markers of endothelial dysfunction. Front Biosci. 2004;9: $1118-1135$.

246. Morel O, Toti F, Hugel B, Freyssinet JM. Cellular microparticles: A disseminated storage pool of bioactive vascular effectors. Curr Opin Hematol. 2004;11:156-164.

247. Nomura S, Fukuhara S. Platelet microparticles. Methods Mol Biol. 2004;272:269-277.

248. Jimenez JJ, Jy W, Mauro LM, Soderland C, Horstmann LL, Ahn YS. Endothelial cells release phenotypically and quantitatively distinct microparticles in activation and apoptosis. Thromb Res. 2003; 109:175-180.

249. Van der PolE, Van Gemmert MJ, SturkA, Nieuwland R, Van LeeuwenTG. Single vs swarm detection of microparticles and exosomes by flow cytometry. J Thromb Haemost. 2012;10:919-930.

250. Leong HS, Podor TJ, Manocha B, Lewis JD. Validation of flow cytometric detection of platelet microparticles and liposomes by atomic force microscopy. J Thromb Haemost. 2011;9:2466-2476.

251. Blastos-Amador P, Royo F, Gonzalez E, et al. Proteomic analysis of microvesicles from plasma of healthy donors reveals high individual variability. J Proteom. 2012;75:3574-3584.

252. Nomura S. Function and clinical significance of platelet-derived microparticles. Int J Hematol. 2001;74:397-404.

253. Chargaff E, West R. The biological significance of the thromboplastic protein of blood. J Biol Chem. 1946;166:189-197.

254. Wolf $\mathrm{P}$. The nature and significance of platelet products in human plasma. Br J Haematol. 1967;13:269-288.

255. Bernal-Mizrachi L, Jy W, Jimenez JJ, et al. High levels of circulating endothelial microparticles in patients with acute coronary syndromes. Am Heart J. 2003;145:962-970.

256. Preston RA, Jy W, Jimenez JJ, et al. Effects of severe hypertension on endothelial and platelet microparticles. Hypertension. 2003;41: 211-217.

257. Brodsky SV, Zhang F, Nasjietti A, Gollgorsky MS. Endotheliumderived microparticles impair endothelial function in vitro. $\mathrm{Am} J$ Physiol Heart Circ Physiol. 2004;286:H1910-H1915.

258. Wang Z, Hill S, Luther JM, Hachey DL, Schey KL. Protemic analysis of urine exosomes by multidimensional protein identification technology (MudPIT). Proteomics. 2012;12:329-338.

259. Zhang Y, LiY, Qiu F, Qiu Z. Comprehensive analysis of low-abundance proteins in human urinary exosomes using peptide ligand library technology, peptide OFFGEL fractionation and nanoHPLC-chip-MS/ MS. Electrophoresis. 2010;31:3797-3807.

260. Merchant ML, Powell DW, Wilkey DW, et al. Microfiltration isolation of human urinary exosomes for characterization by MS. Proteomics Clin Appl. 2010;4:84-96.

261. Verkman AS. Dissecting the roles of aquaporins in renal pathophysiology using transgenic mice. Semin Nephrol. 2008;28:217-226.

262. Bolton K, Segal D, McMillan J, et al. Decorin is a secreted protein associated with obesity and type 2 diabetes. Int I Obes (London). 2008; $32: 1113-1121$ 
263. Fisher LW, Termine JD, Young MF. Deduced protein sequence of bone small proteoglycan I (biglycan) shows homology with proteoglycan II (decorin) and several nonconnective tissue proteins in a variety of species. J Biol Chem. 1989;264:4571-4576.

264. Rahmani M, Wong BW, Ang L, et al. Versican: signaling to transcriptional control pathway. Can J Physiol Pharmacol. 2006;84: 77-92.

265. Kresse H, Schonherr E. Proteoglycans of the extracellular matrix and growth control. J Cell Physiol. 2001;189:266-274

266. Iozzo RV, Murdoch AD. Proteoglycans of the extracellular environment: clues from the gene and protein side offer novel perspectives in molecular diversity and function. Faseb J. 1996;10:598-614.

267. King VL, Hatch NW, Chan HW, de Beer MC, de Beer FC, Tannock LR. A murine model of obesity with accelerated atherosclerosis. Obesity (Silver Spring). 2010;18:35-41.

268. Zhang W, Chuang YJ, Jin T, et al. Antiangiogenic antithrombin induces global changes in the gene expression profile of endothelial cells. Cancer Res. 2006;66:5047-5055.

269. Bolton K, Segal D, Walder K. The small leucine-rich proteoglycan, biglycan, is highly expressed in adipose tissue of Psammomys obesus and is associated with obesity and type 2 diabetes. Biol Targ Therap. 2012;6:67-72.

270. Esposito K, Maiorino MI, Di Palo C, et al. Effects of pioglitazone versus metformin on circulating endothelial microparticles and progenitor cells in patients with newly diagnosed type 2 diabetes - a randomized controlled trial. Diabetes Obes Metab. 2011;13:439-445.

271. Diamant M, Nieuwland R, Pablo RF, Sturk A, Smit JW, Radder JK Elevated numbers of tissue-factor exposing microparticles correlate with components of the metabolic syndrome in uncomplicated type 2 diabetes mellitus. Circulation. 2002;106:2442-2447.

272. Diamant M, Nieuwland R, Pablo RF, Sturk A, Smit JW, Radder JK. Elevated numbers of tissue-factor exposing microparticles correlate with components of the metabolic syndrome in uncomplicated type 2 diabetes mellitus. Circulation. 2002;106 2442-2447.

273. Esposito K, Ciotola M, Giugliano D. Pioglitazone reduces endothelial microparticles in the metabolic syndrome. Arterioscler Thromb Vasc Biol. 2006;26:1926.

274. Setzer F, Oberle V, Bläss M, et al. Platelet-derived microvesicles induce differential gene expression in monocytic cells: a DNA microarray study. Platelets. 2006;17:571-576.

275. Ferreira AC, Peter AA, Mendez AJ, et al. Postprandial hypertriglyceridemia increases circulating levels of endothelial cell microparticles. Circulation. 2004;110:3599-3603.

276. Freyssinet JM, Toti F. Formation of procoagulant microparticles and properties. Thromb Res. 2010;125(Suppl 1):S46-S48.

277. Agouni A, Lagrue-Lak-Hal AH, Ducluzeau PH, et al. Endothelial dysfunction caused by circulating microparticles from patients with metabolic syndrome. Am J Pathol. 2008;173: 1210-1219.

278. Helal O, Defoort C, Robert S, et al. Increased levels of microparticles originating from endothelial cells, platelets and erythrocytes in subjects with metabolic syndrome: relationship with oxidative stress. Nutr Metab Cardiovasc Dis. 2010;21:665-671.

279. Cipoletta C, Ryan KE, Hanna EV, Trimble ER. Activation of peripheral blood CD14+ monocytes occurs in diabetes. Diabetes. 2005;54: 2779-2786.

280. Sabatier F, Darmon P, Hugel B, et al. Type 1 and type 2 diabetic patients display different patterns of cellular microparticles. Diabetes. 2002;51(9):2840-2845.

281. Tan KT, Tayebjee MH, Lim HS, Lip GY. Clinically apparent atherosclerotic disease in diabetes is associated with an increase in platelet microparticle levels. Diabet Med. 2005;22:1657-1662.

282. Koga H, Sugiyama S, Kugiyama K, et al. Elevated levels of remnant lipoproteins are associated with plasma platelet microparticles in patients with type-2 diabetes mellitus without obstructive coronary artery disease. Eur Heart J. 2006;27:817-823.
283. Esposito K, Ciotola M, Schisano B, et al. Endothelial microparticles correlate with endothelial dysfunction in obese women. $J$ Clin Endocrinol Metab. 2006;91:3676-3679.

284. Tramontano AF, Lyubarova R, Tsiakos J, Palaia T, Deleon JR, Ragolia L. Circulating endothelial microparticles in diabetes mellitus. Mediators Inflamm. 2010;2010: Article ID 250476.

285. Nomura S, Suzuki M, Katsura K, et al. Platelet-derived microparticles may influence the development of atherosclerosis in diabetes mellitus. Atherosclerosis. 1995;116:235-240.

286. Omoto S, Nomura S, Shouzu A, Nishikawa M, Fukuhara S, Iwasaka T. Detection of monocyte-derived microparticles in patients with type II diabetes mellitus. Diabetologia. 2002;45:550-555.

287. Morel O, Hugel B, Jesel L, et al. Sustained elevated amounts of circulating procoagulant membrane microparticles and soluble GPV after acute myocardial infarction in diabetes mellitus. Thromb Haemost. 2004;91:345-353.

288. Subbarayan S, Kipnes M. Sitagliptin: a review. Expert Opin Pharmacother. 2011;12:1613-1622.

289. Baetta R, Corsini A. Pharmacology of dipeptidyl peptidase-4 inhibitors: similarities and differences. Drugs. 2011;71:1441-1467.

290. Pisitkun T, Johnstone R, Knepper MA. Discovery of urinary biomarkers. Mol Cell Proteomics. 2006;5:1760-1761.

291. Sun AL, Deng JT, Guan GJ, et al. Dipeptidyl peptidase-IV is a potential molecular biomarker in diabetic kidney disease. Diabetes Vasc Dis Res. 2012. In press.

292. Pisitkun T, Shen RF, Knepper MA. Identification and proteomic profiling of microvesicles in human urine. Proc Natl Acad Sci U SA. 2004; 101:13368-13373.

293. Pala L, Mannucci E, Pezzatini A, et al. Dipeptidyl peptidase-IV expression and activity in human glomerular endothelial cells. Biochem Biophys Res Commun. 2003;310:28-31.

294. Hu G, Zhou R, Liu J, et al. MixcroRNA-98 and let-7 confer cholangiocyte expression of cytokine-inducible Src homology 2-containing protein in response to microbial challenge. J Immunol. 2009;183: $1617-1624$

295. Kota J, Chivukula RR, O'Donnell KA, et al. Therapeutic microRNA delivery suppresses tumorigenesis in a murine liver cancer model. Cell. 2009;137:1005-1007.

296. Esau C, Davis S, Murray S, et al. miR-122 regulation of lipid metabolism revealed by in vivo antisense targeting. Cell Metabol. 2006;3:87-98.

297. Trajkovski M, Hausser J, Soutschek J, et al. MicroRNAs 103 and 107 regulate insulin sensitivity. Nature. 2011;474:649-654.

298. Nathan DM, Buse JB, Davidsom MB, et al. Medical management of hyperglycemia in type 2 diabetes: A consensus algorithm for the initiation and adjustment of therapy: A consensus statement of the American Diabetes Association and the European Association for the Study of Diabetes. Diabetes Care. 2009;32:193-203.

299. Leroyer AS, Tedgui A, Boulanger CM. Microparticles and type 2 diabetes. Diabetes Metab. 2008;34:S27-S31.

300. Müller G, Wied S, Dearey E-A, Wetekam E-M, Biemer-Daub G. Lipid storage in large and small rat adipocytes by vesicle-associated glycosylphosphatidylinositol-anchored proteins results and problems in cell differentiation. In: Richter W, Beisiegel U, Joost G, Meyerhof J, editors. Sensory and Metabolic Control of Energy Balance. Berlin: Springer Press. 2010;52:27-34.

301. De Ferranti S, Mozaffarian D. The perfect storm: obesity, adipocyte dysfunction, and metabolic consequences. Clin Chem. 2010;54: 945-955

302. Müller G. Control of lipid storage and cell size between adipocytes by vesicle-associated glycosylphosphatidylinositol-anchored proteins. Arch Physiol Biochem. 2010;117:23-43.

303. Cui J, Panse S, Falkner B. The role of adiponectin in metabolic and vascular disease: a review. Clin Nephrol. 2011;75:26-33.

304. Xie H, Lim B, Lodish HF. MicroNAs induced during adipogenesis that accelerates fat cell development are downregulated in obesity. Diabetes. 2009;58:1050-1057. 
305. Ortega FJ, Moreno-Navarrete JM, Pardo G, et al. MiRNA expression profile of human subcutaneous adipose and during adipocyte differentiation. PLoS One. 2010;5:e9022.

306. Aoki N, Yokoyama R, Asai N, et al. Adipocyte-derived microvesicles are associated with multiple angiogenic factors and induce angiogenesis in vivo and in vitro. Endocrinology. 2010;151:2567-2576.

307. Ogawa R, Tanaka C, Sato M, et al. Adipocyte-derived microvesicles contain RNA that is transported into macrophages and might be secreted into blood circulation. Biochem Biophys Res Commun. 2010; 398:723-729.

308. Hulsmans M, De Keyzer D, Holvoet P. MicroRNAs regulating oxidative stress and inflammation in relation to obesity and atherosclerosis. FASEB J. 2011;25:2515-2527.

309. Zhang Y, Liu D, Chen X, et al. Secreted monocytic miR-150 enhances targeted endothelial cell migration. Mol Cell. 2010;39: 133-144.

310. Fichtlscherer S, De RS, Fox H, et al. Circulating microRNAs in patients with coronary artery disease. Circ Res. 2010;107:677-684.

311. Matkovich SJ, Van Booven DJ, Youker KA, et al. Reciprocal regulation of myocardial microRNAs and messenger RNA in human cardiomyopathy and reversal of the microRNA signature by biomechanical support. Circulation. 2009;119:1263-1271.

312. Ceolotto G, Papparella I, Bortoluzzi A, et al. Interplay between miR-155, AT1R A1166C polymorphism, and AT1R expression in young untreated hypertensives. Am J Hypertens. 2010;24:241-246.

313. Wang X, Zhang X, Ren X, et al. MicroRNA-494 targeting both proapoptotic and antiapoptotic proteins protects against ischemia/ reperfusion-induced cardiac injury. Circulation. 2010;122: $1308-1318$.

314. Heneghan HM, Miller N, Kerin MJ. Role of microRNAs in obesity and the metabolic syndrome. Obesity Rev. 2009;11:354-361.

315. Lin Q, Gao Z, Alarcon RM, Ye J, Yun Z. A role of miR-27 in the regulation of adipogenesis. FEBS J. 2009;276:2348-2358.

316. Esau C, Kang X, Peralta E, et al. MicroRNA-143 regulates adipocyte differentiation. J Biol Chem. 2004;279:52361-52365.

317. Xie H, Lim B, Lodish HF. MicroRNAs induced during adipogenesis that accelerate fat cell development are downregulated in obesity. Diabetes. 2009;58:1050-1057.

318. Hugel B, Martinez MC, Kunzelmann C, Freyssinet J-M. Membrane microparticles: Two sides of the coin. Physiology. 2005;20:22-27.

319. Freyssinet JM. Cellular microparticles: what are they bad or good for? J Thromb Haemost. 2003;1:1655-1662.

320. Morel O, Toti F, Hugel B, Freyssinet JM. Cellular microparticles: a disseminated storage pool of bioactive vascular effectors. Curr Opin Hematol. 2004;11:156-164.

321. Thery C, Zitvogel L, Amigorena S. Exosomes: composition, biogenesis and function. Nat Rev Immunol. 2002;2:569-579.

322. Aoki N, Jin-no S, Nakagawa Y, et al. Identification and characterization of microvesicles secreted by 3T3-L1 adipocytes: redox- and hormone-dependent induction of milk fat globule-epidermal growth factor 8-associated microvesicles. Endocrinology. 2007;148: $3850-3862$.

323. Record M, Subra C, Silvente-Poirot, Poirot M. Exosomes as intracellular signalosomes and pharmacological effectors. Biochem Pharmacol. 2011;81:1171-1182.

324. Prieur X, Mok CY, Velagapudi VR, et al. Differential lipid partitioning between adipocytes and tissue macrophages modulates macrophage lipotoxicity and M2/M1 polarization in obese mice. Diabetes. 2011; 60:797-809.

325. Skurk T, Alberti-Huber C, Herder C, Hauner H. Relationship between adipocyte size and adipokine expression and secretion. J Clin Endocrinol Metab. 2007;92:1023-1033.

326. Luo N, Liu J, Chung BH, et al. Macrophage adiponectin expression improves insulin sensitivity and protects against inflammation and atherosclerosis. Diabetes. 2010;59:791-799.

327. Rosen ED, Spiegelman BM. Molecular regulation of adipogenesis. Annu Rev Cell Dev Biol. 2000;16:145-171.
328. Müller G, Schneider M, Biemer-Daub G, Wied S. Microvesicles released from rat adipocytes and harboring glycosylphosphatidylinositolanchored proteins transfer RNA stimulating lipid synthesis. Cell Signal. 2011;23:1207-1223.

329. Chen PY, Meister G. microRNA-guided posttranscriptional gene regulation. Biol Chem. 2005;386:36-38.

330. Müller G, Wied S, Jung C, Over S. Translocation of glycosylphosphatidylinositol-anchored proteins to lipid droplets and inhibition of lipolysis in rat adipocytes is mediated by reactive oxygen species. $\mathrm{Br}$ J Pharmacol. 2008;154:901-913.

331. Müller G, Wied S, Jung C, Straub J. Coordinated regulation of esterification and lipolysis by palmitate, $\mathrm{H}_{2} \mathrm{O}_{2}$ and the anti-diabetic sulfonylurea drug, glimepiride, in rat adipocytes. Eur J Pharmacol. 2008;597:6-18.

332. Cao J, Li JL, Li D, Tobin JF, Gimeno RE. Molecular identification of microsomal acyl-CoA:glycerol-3-phosphate acyltransferase, a key enzyme in de novo triacylglycerol synthesis. Proc Natl Acad Sci U SA. 2006;103:19695-19700.

333. Nishino N, Tamori Y, Tateya S, Kawaguchi T, Shibakusa T. FSP27 contributes to efficient energy storage in murine white adipocytes by promoting the formation of unilocular lipid droplets. $J$ Clin Invest. 2008;118:2808-2821.

334. Puri V, Ranjit S, Konda S, et al. Cidea is associated with lipid droplets and insulin sensitivity in humans. Proc Natl Acad Sci U S A. 2008; 105:7833-7838.

335. Goichot B, Grunebaum L, Desprez D, et al. Circulating procoagulant microparticles in obesity. Diabetes Metab. 2006;32:82-85.

336. Wang JG, Manly D, Kirchhofer D, Pawlinksi R, Mackman N. Levels of microparticle tissue factor activity correlate with coagulation activation in endotoxemic mice. J Thromb Haemost. 2009;7:1092-1098.

337. Heerwagen MJR, Miller MR, Barbour LA, Friedman JE. Maternal obesity and fetal metabolic programming: a fertile epigenetic soil. Am J Physiol Regul Integr Comp Physiol. 2010;299:R711-R722.

338. Stöger R. Epigenetics and obesity. Pharmacogenomics. 2008;9: 1851-1860.

339. Jenuwein T, Allis CD. Translating the histone code. Science. 2001;293: 1074-1080.

340. Schreiber SL, Bernstein BE. Signaling network model of chromatin. Cell. 2002;111:771-778.

341. Martin C, Zhang Y. The diverse functions of histone lysine modification. Nat Rev Mol Cell Biol. 2005;6:838-849.

342. Jenuwein $\mathrm{T}$. The epigenetic magic of histone lysine methylation. FEBS J. 2006;273:3121-3135.

343. Cole PA. Chemical probes for histone-modifying enzymes. Nat Chem Biol. 2008;4:590-597.

344. Spannhoff A, Hauser AT, Heinke R, Sippl W, Jung M. The emerging therapeutic potential of histone methyltransferase and demethlyase inhibitors. Chem Med Chem. 2009;4:1568-1582.

345. Cho Y-W, Hong SH, Jin Q, et al. Histone methylation regulator PTIP is required for PPAR $\gamma$ and $\mathrm{C} / \mathrm{EBP} \alpha$ expression and adipogenesis. Cell Metab. 2009;10:27-39.

346. Ge K. Epigenetic regulation of adipogenesis by histone methylation. Biochim Biophys Acta. 2012;1819(7):727-732.

347. Musri MM, Carmona MC, Hanzu FA, Kaliman P, Gomis R, Parrizas M. Histone demethylase LSD1 regulates adipogenesis. J Biol Chem. 2010;285:30034-30041

348. Campion J, Milagro FI, Martinez JA. Individuality and epigenetics in obesity. Obesity Rev. 2009;10:383-392.

349. Musri MM, Gomis R, Parrizas M. A chromatin perspective of adipogenesis. Organogenesis. 2009;6:15-23.

350. Pereira-Lancha LO, Campos-Ferraz PL, Lancha AH Jr. Obesity: considerations about etiology, metabolism, and the use of experimental models. Diab Metab Syn Obesity: Targets Ther. 2012;5:75-87.

351. Puri V, Virbasius JV, Guilherme A, Czech MP. RNAi screens reveal novel metabolic regulators: RIP140, MAP4k4 and the lipid droplet associated fat specific protein (FSP) 27. Acta Physiol. 2008;192: $103-115$. 
352. Parra P, Serra F, Palou A. Expression of adipose microRNAs is sensitive to dietary conjugated linoleic acid treatment in mice. PLoS One. 2010;5:e13005.

353. Toh SY, Gong J, Du G, et al. Up-regulation of mitochondrial activity and acquirement of brown adipose tissue-like property in the white adipose tissue of fsp27 deficient mice. PLoS One. 2010;3:e2890.

354. Kuypers FA, Larkin SK, Emeis JJ, Allison AC. Interaction of an annexin $\mathrm{V}$ homodimer (Diannexin) with phosphatidylserine on cell surfaces and consequent anti-thrombotic activity. Thromb Haemost 2007; $97: 478-486$.

355. vanWjik MJ, VanBavel E, Sturk A, Nieuwland R. Microparticles in cardiovascular diseases. Cardiovasc Res. 2003;59:277-287.

356. Müller G. The mode of action of glimepiride - beyond insulin secretion. Curr Med Chem. 2005;5:499-518.

357. van der Pol E, Hoekstra AG, Sturk A, Otto C, van Leeuwen TG, Nieuwland R. Optical and non-optical methods for detection and characterization of microparticles and exosomes. J Thromb Haemost. 2010;8:2596-2607.

358. Cheruvanky A, Zhou H, Pisitkun T, et al. Rapid isolation of urinary exosomal biomarkers using a nanomembrane ultrafiltration concentrator. Am J Physiol Renal Physiol. 2007;292(5): F1657-F1661.

359. Miranda KC, Bond DT, McKee M, et al. Nucleic acids within urinary exosomes/microvesicles are potential biomarkers for renal disease. Kidney Int. 2010;78:191-199.

360. Gonzales PA, Pisitkun T, Hoffert JD, et al. Large-scale proteomics and phosphoprotemics of urinary exosomes. J Am Soc Nephrol. 2009;20(2):363-379.

361. Conde-Vancells J, Rodriguez-Suarez E, Gonzalez E. Candidate biomarkers in exosome-like vesicles purified from rat and mouse urine samples. Proteomics Clin Appl. 2010;4:416-425.

362. Moon PG, You S, Lee JE, Hwang D, Baek MC. Urinary exosomes and proteomics. Mass Spectrom Rev. 2011;30:1185-1202.

363. Orozco AF, Lewis DE. Flow cytometric analysis of circulating microparticles in plasma. Cytometry. 2010;77:502-514.

364. De M, Rana S, Akpinar H, et al. Sensing of proteins in human serum using conjugates of nanoparticles and green fluorescent protein. Nat Chem. 2009;1:461-465.

365. Anslyn EV, Rotello VM. Chemosensory models: approaches and applications of differential sensing. Curr Opin Chem Biol. 2010;14: 683-684.

366. Miranda OR, Creran B, Rotello VM. Array-based sensing with nanoparticles: 'chemical noses' for sensing biomolecules and cell surfaces. Curr Opin Chem Biol. 2010;14:728-736

367. Müller G. Glycosylphosphatidylinositol-anchored protein chips for patient-tailored multi-parameter proteomics. J Biochip Tissue Chip. 2011;S3:001. doi:10.4172/2153-0777.S3-001.

368. Müller G. (Glycosylphosphatidylinositol-based) protein chips and biosensors for biopharmaceutical process analytics. $J$ Bioprocess Biotec. 2012;2:115. doi:10.4172/2155-9821.1000115.

369. Dragovic RA, Gardiner C, Brooks AS, et al. Sizing and phenotyping of cellular vesicles using nanoparticle tracking analysis. Nanomedicine NBM. 2011;7:780-788.

370. Hu G, Drescher KM, Chen X-M. Exosomal miRNAs: biological properties and therapeutic potential. Front Gene. 2012;3:56.

371. Martinez MC, Andriantsitohaina R. Microparticles in angiogenesis: therapeutic potential. Circ Res. 2011;109:110-119.

372. György B, Szabo TG, Pasztoi M, et al. Membrane vesicles, current state-of-the-art: emerging role of extracellular vesicles. Cell Mol Life Sci. 2011;68:2667-2688.

373. Lee TH, D’Asti E, Magnus N, Al-Nedawi K, Meehan B, Rak J. Microvesicles as mediators of intracellular communication in cancerthe emerging science of cellular 'debris'. Semin Immunopathol. 2011;33:455-467.

374. Dowling P, Clynes M. Conditioned media from cell lines: a complementary model to clinical specimens for the discovery of diseasespecific biomarkers. Proteomics. 2011;11:794-804.
375. Siljander PR. Platelet-derived microparticles - an updated perspective. Thromb Res. 2011;127(S2):S30-S33.

376. Dignat-George F, Boulanger CM. The many faces of endothelial microparticles. Arterioscler Thromb Vasc Biol. 2011;31(1):27-33.

377. Keller S, Sanderson MP, Stoek A, Altevogt P. Immunol Lett. 2006;107: 102-108.

378. Meckes DG Jr, Raab-Traub N. Microvesicles and viral infection. J Virol. 2011;85:12844-12854.

379. Pelchen-Matthews A, Raposo G, Marsh M. Endosomes, exosomes and Trojan viruses. Trends Microbiol. 2004;12:310-316.

380. Stoorvogel W, Kleijmeer MJ, Geuze HJ, Raposo G. The biogenesis and functions of exosomes. Traffic. 2002;3:321-330.

381. Muralidharan-Chari V, Clancy JW, Sedgwick A, D’Souza-Schorey C. Microvesicles: mediators of extracellular communication during cancer progression. J Cell Sci. 2010;123:1603-1611.

382. Martinez MC, Kunzelmann C, Freyssinet JM. Plasma membrane remodelling and cell stimulation. Med Sci. 2004;20:189-195.

383. Nosjean O, Briolay A, Roux B. Mammalian GPI proteins: sorting, membrane residence and functions. Biochim Biophys Acta. 1997;1331: $153-186$.

384. Lakhan SE, Sabharanjak S, De A. Endocytosis of glycosylphosphatidylanchored proteins. J Biomed Sci. 2009;16:93-109.

385. Ferguson MA. The structure, biosynthesis and functions of glycosylphosphatidylinositol anchors, and the contributions of trypanosoma research. J Cell Sci. 1999;112:2799-2809.

386. Kinoshita T, Fujita M, Maeda Y. Biosynthesis, remodelling and functions of mammalian GPI-anchored proteins: recent progress. J Biochem. 2008;144:287-294.

387. Paulick MG, Bertozzi CR. The glycosylphosphatidylinositol anchor: a complex membrane-anchoring structure for proteins. Biochemistry. 2008;47:6991-7000

388. Müller G, Jung C, Wied S, Welte S, Jordan H, Frick W. Redistribution of glycolipid raft domain components induces insulin-mimetic signaling in rat adipocytes. Mol Cell Biol. 2001;21:4553-4567.

389. Müller G. Dynamics of plasma membrane microdomains and crosstalk to the insulin signalling cascade. FEBS Lett. 2002;531:81-87.

390. Simons K, Sampaio JL. Membrane organisation and lipid rafts. Cold Spring Harb Perspect Biol. 2011;3:a004697.

391. Lajoie P, Nabi IR. Lipid rafts, caveolae, and their endocytosis. Int Rev Mol Biol. 2010;282:135-163.

392. Lingwood D, Simons K. Lipid rafts as a membrane-organizing principle. Science. 2010;327:46-50.

393. Lindner R, Naim HY. Domains in biological membranes. Exp Cell Res. 2009;315:2871-2878.

394. Foster LJ. Lessons learned from lipid raft proteomics. Expert Rev Proteomics. 2008;5:541-543.

395. Epand RM. Proteins and cholesterol-rich domains. Biochim Biophys Acta. 2008;1778:1576-1582.

396. Sun T, Fu M, Bookout AL, Kliewer SA, Mangelsdorf DJ. MicroRNA let-7 regulates 3T3-L1 adipogenesis. Mol Endocrinol. 2009;23: 925-931.

397. Li G, Li Y, Li X, Ning X, Li M, Yang G. MicroRNA identity and abundance in developing swine adipose tissue as determined by Solexa sequencing. J Cell Biochem. 2011;112:1318-1328.

398. Wang Q, Li YC, Wang J, Kong J, Qi Y, Quigg RJ, Li X. miR-17-92 cluster accelerates adipocyte differentiation by negatively regulating tumor-suppressor Rb2/p130. Proc Natl Acad Sci U S A. 2008;105: 2889-2894.

399. Kim YJ, Hwang SJ, Bae YC, Jung JS. MiR-21 regulates adipogenic differentiation through the modulation of TGF- $\beta$ signaling in mesenchymal stem cells derived from human adipose tissue. Stem Cells. 2009;27:3093-3102.

400. Lin Q, Gao Z, Alarcon RM, Ye J, Yun Z. A role of miR-27 in the regulation of adipogenesis. FEBS J. 2009;276:2348-2358.

401. Lee EK, Lee MJ, Abdelmohsen K, et al. miR-130 suppresses adipogenesis by inhibiting PPAR $\gamma$ expression. Mol Cell Biol. 2010;31: 626-638. 
402. Kloting N, Berthold S, Kovacs P, et al. MicroRNA expression in human omental and subcutaneous adipose tissue. PLoS One. 2009;4: 4699.

403. Estep M, Armistead D, Hossain N, et al. Differential expression of miRNAs in the visceral adipose tissue of patients with nonalcoholic fatty liver disease. Aliment Pharmacol Ther. 2010;32: 487-497.

404. Chang CL, Au LC, Huang SW, Kwok CF, Ho LT, Juan CC. Insulin up-regulates heme oxygenase-1 expression in 3T3-L1 adipocytes via PI3-kinase- and PKC-dependent pathways and heme oxygenase-1associated microRNA downregulation. Endocrinology. 2010;152: 384-393.

405. Parra P, Serra F, Palou A. Expression of adipose microRNAs is sensitive to dietary conjugated linoleic acid treatment in mice. PLoS One. 2010;5:e13005.

406. Jayachandran M, Miller VM, Heit JA, Owen WG. Methodology for isolation and characterization of microvesicles in peripheral blood. J Immunol Meth. 2012;375:207-214.

407. Mrvar-Brecko A, Sustar V, Jansa V, et al. Isolated microvesicles from peripheral blood and body fluids as observed by scanning electron microscope. Blood Cells Mol Dis. 2010;44:307-312.
408. Chen C, Skog J, Hsu C-H, et al. Microfluidic isolation and transcriptome analysis of serum microvesicles. Lab Chip. 2010;10:505-511.

409. Soo CY, Song Y, Zheng Y, et al. Nanoparticle tracking analysis monitors microvesicle and exosome secretion from immune cells. Immunology. 2012;136:192-197.

410. Simak J, Gelderman MP. Cell membrane microparticles in blood and blood products: potentially pathogenic agents and diagnostic markers. Transfus Med Rev. 2006;20:1-26.

411. Holme PA, Solum NO, Brosstad F, Roger M, Abdelnoor M. Demonstration of platelet-derived microvesicles in blood from patients with activated coagulation and fibrinolysis using a filtration technique and western blotting. Thromb Haemost. 1994;72:666-671.

412. Grant R, Ansa-Addo E, Stratton D, et al. A filtration-based protocol to isolate human plasma membrane-derived vesicles and exosomes from plasma. J Immunol Meth. 2011;371:143-151.

413. Wang K, Zhang S, Weber J, Baxter D, Galas DJ. Export of microRNAs and microRNA-protective protein by mammalian cells. Nucleic Acids Res. 2010;38:7248-7259.

414. Kosaka N, Iguchi H, Yoshioka Y, Takeshita F, Matsuki Y, Ochiya T. Secretory mechanisms and intercellular transfer of microRNAs in living cells. J Biol Chem. 2010;285:17442-17452.

\section{Publish your work in this journal}

Diabetes, Metabolic Syndrome and Obesity: Targets and Therapy is an international, peer-reviewed open-access journal committed to the rapid publication of the latest laboratory and clinical findings in the fields of diabetes, metabolic syndrome and obesity research. Original research, review, case reports, hypothesis formation, expert opinion and commentaries are all considered for publication. The manuscript management system is completely online and includes a very quick and fair peer-review system, which is all easy to use. Visit http://www.dovepress.com/testimonials.php to read real quotes from published authors. 